\title{
Cycles and weight effects on emissions and development of predictive emissions models for heavy duty trucks
}

Kuntal A. Vora

West Virginia University

Follow this and additional works at: https://researchrepository.wvu.edu/etd

\section{Recommended Citation}

Vora, Kuntal A., "Cycles and weight effects on emissions and development of predictive emissions models for heavy duty trucks" (2006). Graduate Theses, Dissertations, and Problem Reports. 1758.

https://researchrepository.wvu.edu/etd/1758

This Thesis is protected by copyright and/or related rights. It has been brought to you by the The Research Repository @ WVU with permission from the rights-holder(s). You are free to use this Thesis in any way that is permitted by the copyright and related rights legislation that applies to your use. For other uses you must obtain permission from the rights-holder(s) directly, unless additional rights are indicated by a Creative Commons license in the record and/ or on the work itself. This Thesis has been accepted for inclusion in WVU Graduate Theses, Dissertations, and Problem Reports collection by an authorized administrator of The Research Repository @ WVU. For more information, please contact researchrepository@mail.wvu.edu. 


\title{
Cycles and Weight Effects on Emissions and Development of Predictive Emissions Models for Heavy Duty Trucks
}

\author{
Kuntal A. Vora \\ Thesis submitted to the \\ College of Engineering and Mineral Resources \\ at West Virginia University \\ in partial fulfillment of the requirements \\ for the degree of \\ Master of Science \\ in \\ Aerospace Engineering \\ Nigel N. Clark, Ph.D., Chair \\ Mridul Gautam, Ph.D. \\ W. Scott Wayne, Ph.D. \\ Ralph D. Nine
}

Department of Mechanical and Aerospace Engineering

Morgantown, West Virginia

2006

Keywords: Emissions, Weight Effects, Emissions Modeling, Heavy Duty Trucks, Emissions

Correlations, $\mathrm{NO}_{\mathrm{X}}, \mathrm{PM}, \mathrm{CO}_{2}$ 


\section{Abstract \\ Cycles and Weight Effects on Emissions and Development of Predictive Emissions Models for Heavy Duty Trucks \\ Kuntal A. Vora}

When heavy-duty truck emissions are expressed in distance-specific units (such as g/mile), the values may depend strongly on the nature of the test cycle. Prior studies have compared emissions gained using different cycles and have proposed techniques for translating emissions factor rates between cycles. First, emissions data from the 5-mode CARB HHDDT Schedule, UDDS, and AC5080 were reviewed, with reference to each other. $\mathrm{NO}_{\mathrm{X}}$ and $\mathrm{PM}$ emissions were the two components of emissions reviewed. A heavy-duty chassis dynamometer was used for emissions characterization along with a full scale dilution tunnel. The vehicle test weights were simulated at 30,000 lbs, 56,000 lbs, and 66,000 lbs. For each vehicle, average data from one cycle have been compared with average data for a different cycle. When the Cruise mode and Transient mode of the HHDDT schedule were compared, it was evident that injection timing strategies affected the average Cruise mode emissions of $\mathrm{NO}_{\mathrm{X}}$. As a result, there was substantial data scatter when mode-averaged Cruise emissions were plotted against mode-averaged Transient emissions. Moreover, the relationship between Cruise and Transient $\mathrm{NO}_{\mathrm{X}}$ was not the same for the various test weights. Correlations for PM varied widely in goodness of fit to the data. This is because PM may increase substantially due to elemental carbon "puff" which occurs when the turbocharger has not reached full boost pressure at the onset of an increase in engine load. The AC5080, originally developed for inspection and maintenance applications, showed reasonable correlation with the UDDS, although a best fit line still caused the AC5080 to mis-predict 16 out of 25 UDDS $\mathrm{NO}_{\mathrm{X}}$ values by over $20 \%$. It was concluded that information is needed on both the transient and steady high speed emissions characteristics of a vehicle before an emissions factor can be estimated for a road link.

Next, two-dimensional correlations were used to predict the emissions rate on one cycle from the rates of two other cycles. The vehicle test weights were simulated at 56,000 lbs. The multidimensional analysis using two cycles yielded better predictive correlations for the emissions than single cycle correlations. The UDDS yielded the highest distance-specific emissions and it showed similar emissions as the combination of the Cruise mode and Transient mode of the HHDDT.

Weight, like transients, significantly effects the emissions of a vehicle. Its effect is different for different species. The emission of $\mathrm{NO}_{\mathrm{X}}, \mathrm{CO}, \mathrm{CO}_{2}, \mathrm{HC}$ and $\mathrm{PM}$ were analyzed with respect to weight. There were three types of vehicles analyzed: HHDDT, MHDDT and MHDGT. These 
vehicles were analyzed over eight drives cycles: Creep mode, Cruise mode, HHDDT_s mode, MHDTCR cycle, MHDTHI cycle, MHDTLO cycle, Transient mode and UDDS.

Vehicles did not follow linear $\mathrm{NO}_{\mathrm{X}}$ emissions trends over large test weight ranges. When considering the Road Load equation, it was observed that idle and wind drag cause non-linear emissions trends. This was noted in cycles with low average speed and inherently high idle. Emissions in cycles with high average speeds have greater variability from the wind drag term due to the effect of velocity cubed $\left(\mathrm{V}^{3}\right)$. Though accurate prediction of $\mathrm{NO}_{\mathrm{X}}$ was difficult over various drive cycles and test weights, accuracy increased within small ranges of test weights, as long as the data were interpolated for cycles with medium average velocities. Distance specific emissions fail to provide usable trends to predict single vehicle emissions. Fuel specific emissions for $\mathrm{NO}_{\mathrm{X}}$ can be predicted if the fueling rate is known. Fleet wide emissions for HHDDT could be predicted for test weights between $30,000 \mathrm{lbs}$ to $66,000 \mathrm{lbs}$ using the relationship: $\mathrm{X} \%$ increase in vehicle weight increases $\mathrm{NO}_{\mathrm{X}}$ emissions by $\frac{47}{100} \mathrm{X} \%$. It was also evident that emissions predictability is relatively plausible between smaller differences in test weight, but highly variable between larger test weights differences.

Modeling $\mathrm{CO}_{2}, \mathrm{NO}_{\mathrm{X}}$ and $\mathrm{PM}$ emissions to create viable emissions inventories is complex. Predicting emissions over a cycle requires an extensive database developed using existing vehicle data. A method was proposed to predict emissions based on the vehicle's emissions history from other cycles and on the properties of those cycles. Using a linear equation derived from the road load equation, emissions predictions were made. This technique was tested using emissions data from three existing cycles: Idle mode, Cruise mode and Transient mode of the 5mode HHDDT schedule, and cycle parameters of velocity, acceleration and impulse power. Two linear equations were considered to perform the prediction. One used a constant, velocity and acceleration as predictive parameters. The other used a constant, velocity and impulse power as the three predictive parameters.

The prediction of emissions was performed on six other cycles and the results were compared to experimental data for those vehicles. $\mathrm{CO}_{2}$ and $\mathrm{NO}_{\mathrm{X}}$ were better predicted than PM, with PM having a maximum average error of $60.80 \%$ and $\mathrm{CO}_{2}$ and $\mathrm{NO}_{\mathrm{X}}$ at $31.78 \%$ and $32.78 \%$ respectively. While $\mathrm{CO}_{2}$ was the best predicted emission, the equation best predicting it was also 
the equation of choice to calculate $\mathrm{NO}_{\mathrm{X}}$. This linear method can be used to evaluate emissions for any unknown cycle which represents actual driving for that vehicle. 


\section{Acknowledgments}

The author would like to thank Nigel N. Clark, Ralph D. Nine, Mridul Gautam, W. Scott Wayne, Gregory J. Thompson and Donald W. Lyons from West Virginia University (WVU) for their support and guidance. The author would also like to acknowledge the efforts of the WVU research staff and the staff of the Center for Alternative Fuels, Engines and Emissions (CAFEE).

The researcher is grateful to the National Renewable Energy Laboratory and the US Department of Energy for funding the Gasoline-Diesel PM split study. The researcher thanks Dr. Douglas Lawson of NREL for his guidance on this study.

The researcher gratefully acknowledges the sponsors of the CRC program E-55/59 namely: Coordinating Research Council, Inc., California Air Resources Board, U.S. Environmental Protection Agency, U.S. Department of Energy Office of FreedomCAR \& Vehicle Technologies through the National Renewable Energy Laboratory, South Coast Air Quality Management District and the Engine Manufacturers Association. The researchers express their gratitude to Tom Anderson and Greg Peterson of Ralphs Grocery, for their support.

The researcher is grateful to Ralphs Grocery for providing several of the test vehicles for the Gasoline-Diesel PM Split Study and a test site for both, the Gasoline-Diesel PM Split Study and the $\mathrm{E}-55 / 59$ program. 


\section{TABLE OF CONTENTS}

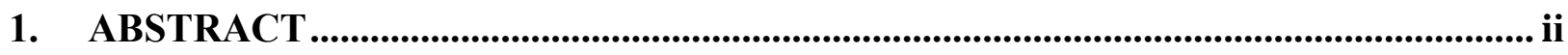

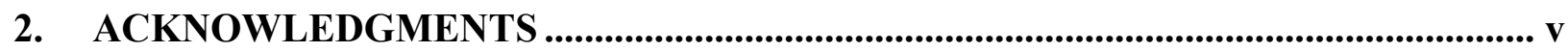

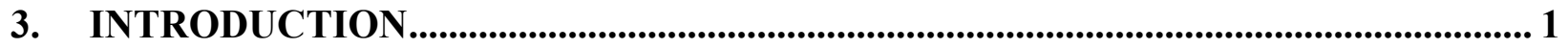

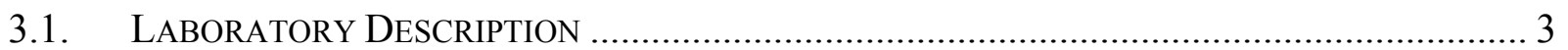

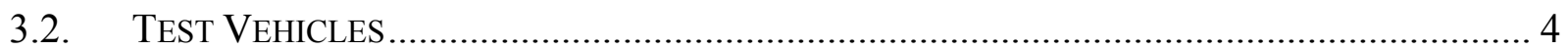

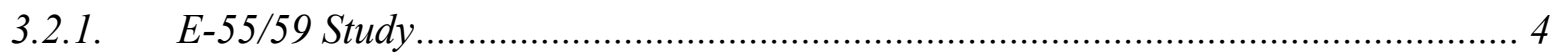

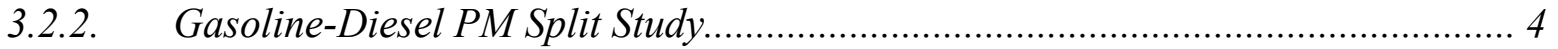

3.2.3. Medium Heavy-Duty Trucks (MHDT) ......................................................... 4

3.2.4. Heavy Heavy-Duty Diesel Trucks (HHDDT) ................................................... 4

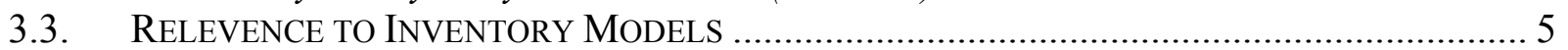

4. CORRELATION OF PM AND NO $\mathrm{X}_{\mathrm{X}}$ FOR HEAVY-DUTY VEHICLES ACROSS MULTIPLE DRIVE SCHEDULES ................................................................................. 8

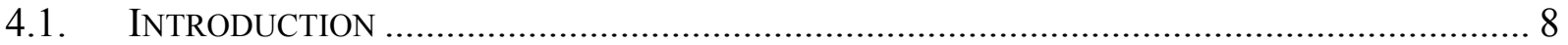

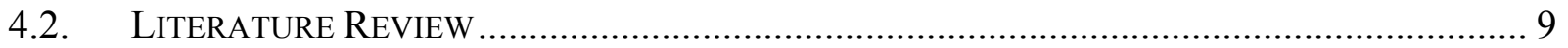

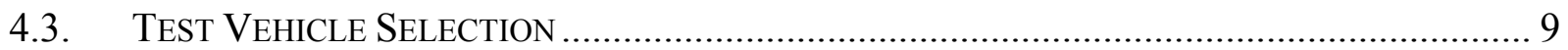

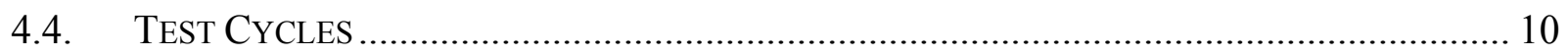

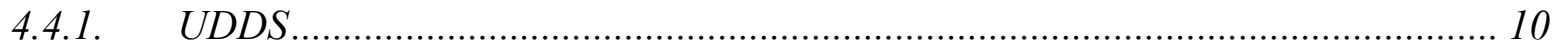

4.4.2. HHDDT Transient mode and Cruise mode ....................................................... 11

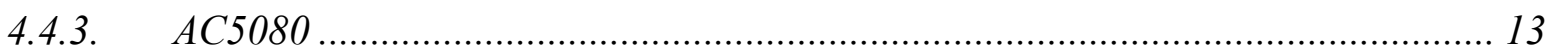

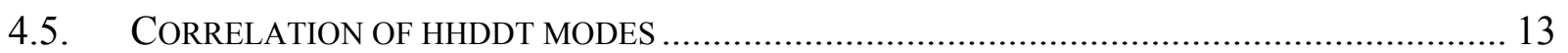

4.5.1. Correlation of UDDS versus Cruise mode ……............................................. 14

4.5.2. Correlation of Cruise mode versus Transient mode ............................................ 16

4.5.3. Correlation of Transient mode versus UDDS............................................... 18

4.5.4. Correlation of average of Transient mode and Cruise mode versus UDDS ........ 20

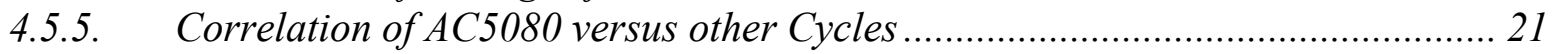

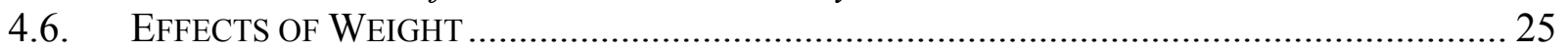

4.6.1. Correlation of Cruise mode versus Transient mode at 30,000 lbs ..................... 25

4.6.2. Correlation of Cruise mode versus Transient mode for 66,000 lbs Vehicles ....... 27

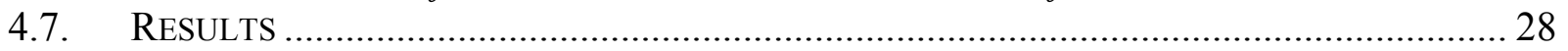

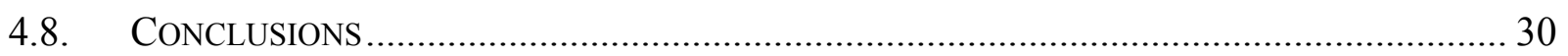

5. TWO-DIMENSIONAL CORRELATION USING LINEAR REGRESSION OF PM AND NO F $_{X}$ FOR HEAVY-DUTY DIESEL VEHICLES ...................................................... 31

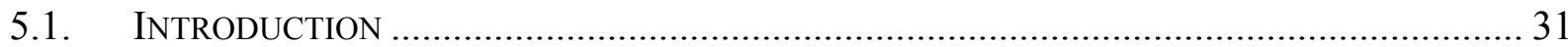

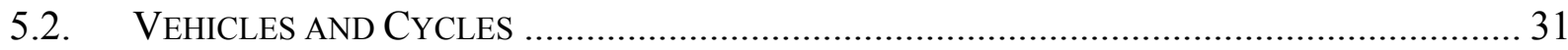

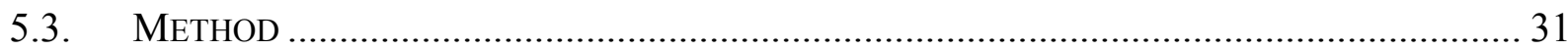

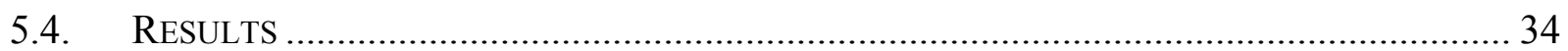

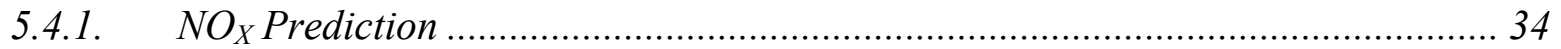

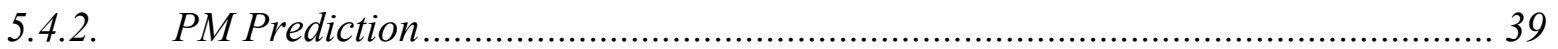

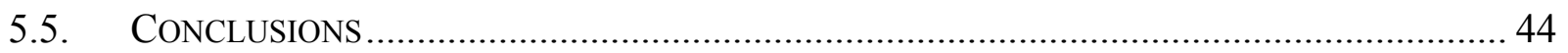

6. EMISSION TRENDS FOR MEDIUM DUTY TRUCKS AND HEAVY HEAVYDUTY TRUCKS AT MULTIPLE OPERATING WEIGHTS ......................................... 45

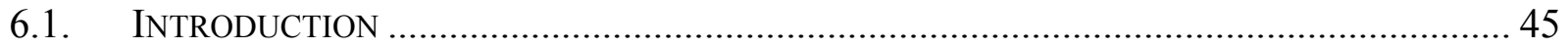

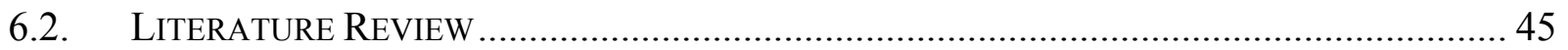




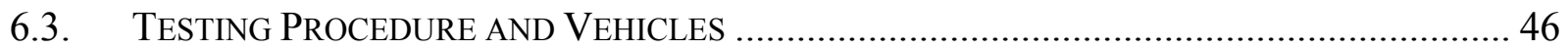

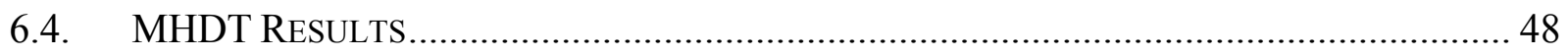

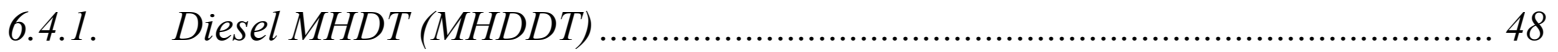

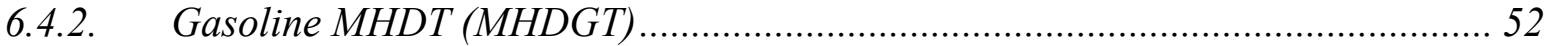

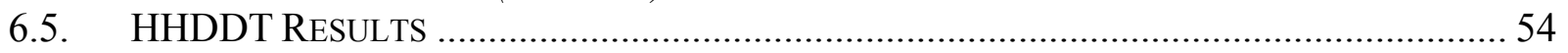

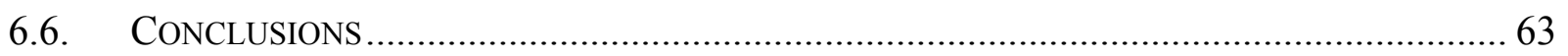

7. CYCLE BASED EMISSIONS FACTORS FOR PREDICTING $\mathrm{CO}_{2}, \mathrm{NO}_{\mathrm{X}}$ AND PM 65

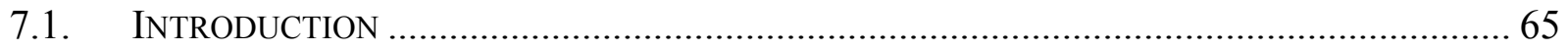

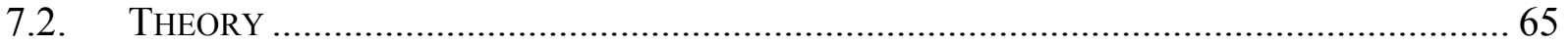

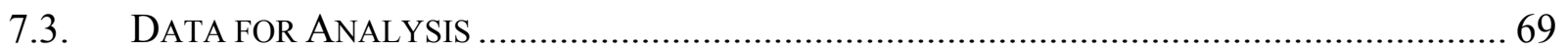

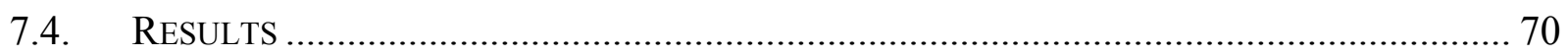

7.4.1. The Linear Form using the Acceleration Term........................................... 70

7.4.2. $\quad$ The Linear Form using the Inertial Power Term.......................................... 76

7.5. COMPARISON OF PREDICTABILITY BY THE Two LINEAR EQUATIONS .......................... 77

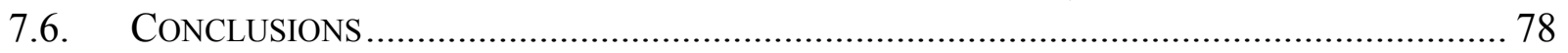

8. CONCLUSIONS AND RECOMMENDATIONS........................................................ 79

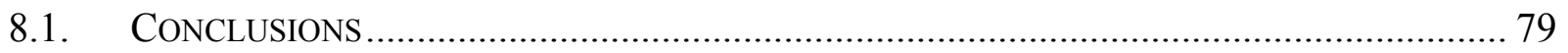

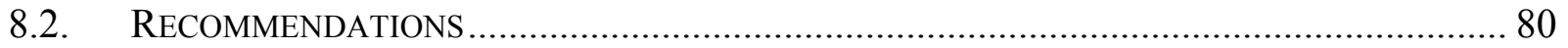

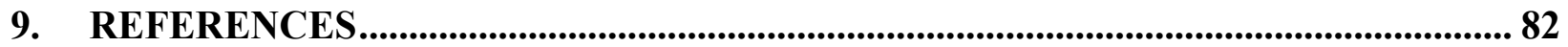




\section{LIST OF TABLES}

Table 1: Intensive properties of Cruise mode, Transient mode and UDDS ............................... 6

Table 2: Equation summary for linear regression lines for data on four cycles, three test weights

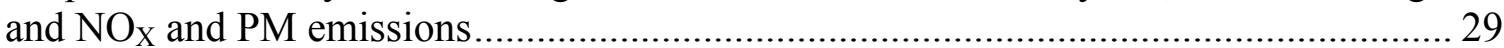

Table 3: Average 56,000 lbs vehicle data without engine model years 1995-1999 .................. 30

Table 4: Overall summary for two-dimensional regression and errors for data on four cycles and

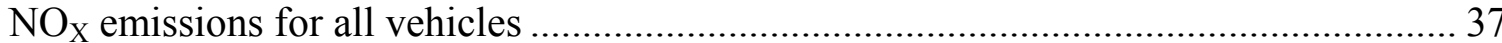

Table 5: Overall summary for two-dimensional regression and errors for data on four cycles and $\mathrm{NO}_{\mathrm{X}}$ emissions excluding vehicles of model years $1995-1999$...................................... 38

Table 6: Overall summary for two-dimensional regression and errors for data on four cycles and

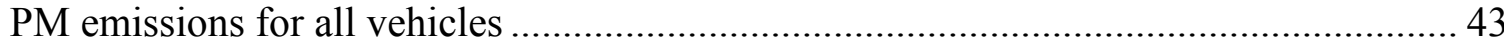

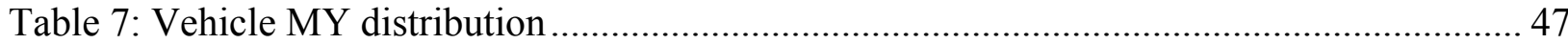

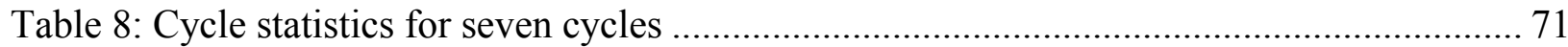

Table 9: Calculated $\mathrm{K}_{0}, \mathrm{~K}_{1}$ and $\mathrm{K}_{2}$ and predicted $\mathrm{NO}_{\mathrm{X}}$ for three HHDDT at 46,000 lbs using

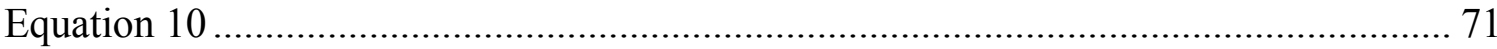

Table 10: Statistics of the measured and predicted values for the $30 \mathrm{HHDDT}$ at 56,000 lbs on the

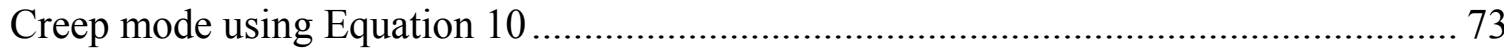

Table 11: Statistics of the measured and predicted values for the $30 \mathrm{HHDDT}$ at 56,000 lbs on the UDDS using Equation 10........................................................................... 75

Table 12: Statistics of the measured and predicted values for the $30 \mathrm{HHDDT}$ at 56,000 lbs on the

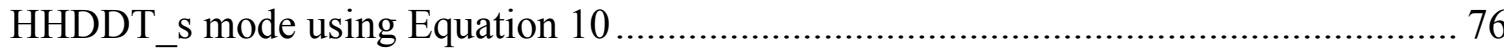




\section{LIST OF FIGURES}

Figure 1: Intensive properties of Cruise mode, Transient mode and UDDS, all referenced to the Transient mode

Figure 2: $\mathrm{NO}_{\mathrm{X}}$ emissions for average speeds of Cruise mode, Transient mode and UDDS and a

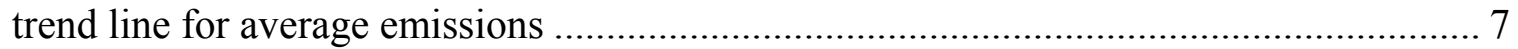

Figure 3: Test vehicle distribution with reference to engine model year ................................ 10

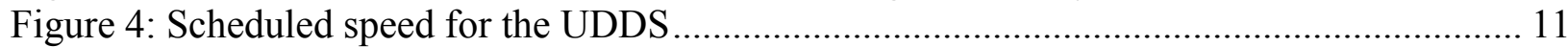

Figure 5: Scheduled speed for the Transient mode of the HHDDT 5-Mode schedule................ 12

Figure 6: Scheduled speed for the Cruise mode of the HHDDT 5-Mode schedule .................... 12

Figure 7: Scheduled speed for the AC5080 short test............................................................. 13

Figure 8: Average $\mathrm{NO}_{\mathrm{X}}$ on UDDS versus Cruise mode ......................................................... 15

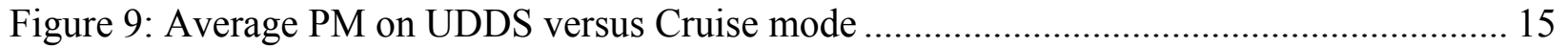

Figure 10: Average $\mathrm{NO}_{\mathrm{X}}$ on Transient mode versus Cruise mode .......................................... 17

Figure 11: Average $\mathrm{CO}_{2}$ on Cruise mode versus Transient mode........................................... 17

Figure 12: Average PM on Transient mode versus Cruise mode .............................................. 18

Figure 13: Average $\mathrm{NO}_{\mathrm{X}}$ on Transient mode versus UDDS .................................................... 19

Figure 14: Average PM on Transient mode versus UDDS .................................................... 19

Figure 15: Average $\mathrm{NO}_{\mathrm{X}}$ on Transient mode and Cruise mode combined and averaged versus

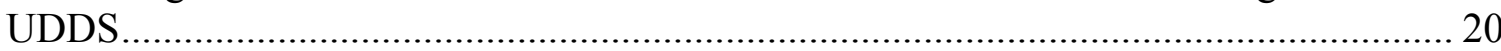

Figure 16: Average PM on Transient mode and Cruise mode combined and averaged versus

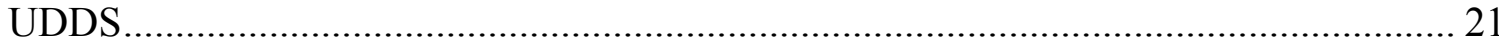

Figure 17: Average $\mathrm{NO}_{\mathrm{X}}$ on AC5080 versus Cruise mode....................................................... 22

Figure 18: Average PM on AC5080 versus Cruise mode.......................................................... 22

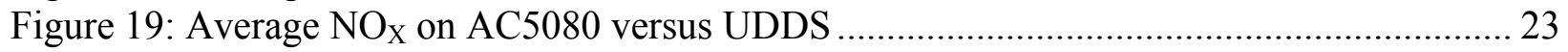

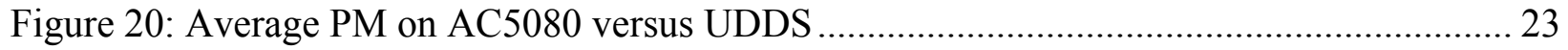

Figure 21: Average $\mathrm{NO}_{\mathrm{X}}$ on AC5080 versus Transient mode ................................................ 24

Figure 22: Average PM on AC5080 versus Transient mode ................................................... 24

Figure 23: Average $\mathrm{NO}_{\mathrm{X}}$ on Transient mode versus Cruise mode for 30,000 lbs vehicles......... 25

Figure 24: Cruise mode to Transient mode $\mathrm{NO}_{\mathrm{X}}$ ratio as a function of engine model year ......... 26

Figure 25: Cruise mode $\mathrm{NO}_{\mathrm{X}} / \mathrm{CO}_{2}$ ratio as a function of engine model year ............................ 26

Figure 26: Average PM on Transient mode versus Cruise mode for 30,000 lbs vehicle ............ 27

Figure 27: Average $\mathrm{NO}_{\mathrm{X}}$ on Cruise mode versus Transient mode for $66,000 \mathrm{lbs}$ vehicles.......... 28

Figure 28: Average PM on Cruise mode versus Transient mode for 66,000 lbs vehicles........... 28

Figure 29: Parity plot of measured versus predicted $\mathrm{NO}_{\mathrm{X}}$ in $\mathrm{g} /$ mile on UDDS as a function of $\mathrm{NO}_{X}$ in $\mathrm{g} /$ mile on Cruise mode and $\mathrm{NO}_{X}$ in $\mathrm{g} /$ mile on Transient mode for all vehicles... 33

Figure 30: Parity plot of measured versus predicted $\mathrm{NO}_{\mathrm{X}}$ in $\mathrm{g} / \mathrm{mile}$ on Transient mode as a function of $\mathrm{NO}_{\mathrm{X}}$ in $\mathrm{g} / \mathrm{mile}$ on Cruise mode and $\mathrm{NO}_{\mathrm{X}}$ in $\mathrm{g} / \mathrm{mile}$ on $\mathrm{AC} 5080$ for all vehicles

31: Parity plot of measured versus predicted $\mathrm{NO}_{X}$ in $\mathrm{g} /$ mile on UDDS as a function of $\mathrm{NO}_{\mathrm{X}}$ in $\mathrm{g} /$ mile on Cruise mode and $\mathrm{NO}_{\mathrm{X}}$ in $\mathrm{g} /$ mile on AC5080 for all vehicles ............. 35

Figure 32: Parity plot of measured versus predicted $\mathrm{NO}_{\mathrm{X}}$ in $\mathrm{g} / \mathrm{mile}$ on UDDS as a function of $\mathrm{NO}_{\mathrm{X}}$ in $\mathrm{g} / \mathrm{mile}$ on Cruise mode and $\mathrm{NO}_{\mathrm{X}}$ in $\mathrm{g} / \mathrm{mile}$ on Transient mode excluding vehicles of model year 1995-1999 ......................................................................................... 36

Figure 33: Parity plot of measured versus predicted PM in $\mathrm{g} / \mathrm{mile}$ on Transient mode as a function of PM in $\mathrm{g} / \mathrm{mile}$ on Cruise mode and PM in $\mathrm{g} / \mathrm{mile}$ on AC5080 for all vehicles 40

Figure 34: Magnified parity plot of measured versus predicted PM in $\mathrm{g} / \mathrm{mile}$ on Transient mode as a function of PM in $\mathrm{g} /$ mile on Cruise mode and PM in $\mathrm{g} / \mathrm{mile}$ on AC5080 ................ 40 
Figure 35: Parity plot of measured versus predicted PM in g/mile on UDDS as a function of PM in $\mathrm{g} /$ mile on Cruise mode and PM in $\mathrm{g} /$ mile on AC5080 for all vehicles........................ 41

Figure 36: Magnified parity plot of measured versus predicted PM in g/mile on UDDS as a function of PM in $\mathrm{g} /$ mile on Cruise mode and PM in $\mathrm{g} /$ mile on AC5080 ...................... 42

Figure 37: Parity plot of measured versus predicted PM in $\mathrm{g} / \mathrm{mile}$ on UDDS as a function of PM in $\mathrm{g} /$ mile on Cruise mode and PM in $\mathrm{g} /$ mile on Transient mode for all vehicles ............ 42

Figure 38: Magnified parity plot of measured versus predicted PM in $\mathrm{g} / \mathrm{mile}$ on UDDS as a function of PM in $\mathrm{g} / \mathrm{mile}$ on Cruise mode and PM in $\mathrm{g} / \mathrm{mile}$ on Transient mode for all vehicles

Figure 39: $\mathrm{NO}_{\mathrm{X}}$ emission trends for different vehicles at various operating weights on the HHDDT_s mode ............................................................................................. 48

Figure 40: $\mathrm{NO}_{\mathrm{X}}$ emission trends for different vehicles at various operating weights on the

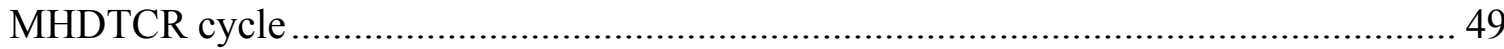

Figure 41: Increase in distance specific emissions relative to increase in operating weight on the

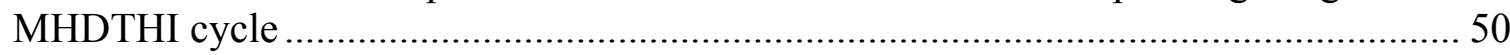

Figure 42: $\mathrm{NO}_{\mathrm{X}}$ emission trends for different vehicles at various operating weights on the

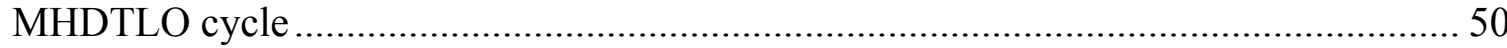

Figure 43: $\mathrm{NO}_{\mathrm{X}}$ emission trends for different vehicles at various operating weights on the UDDS

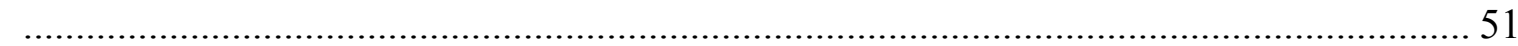

Figure 44: Average percent increase of the weight and various emissions for the different cycles

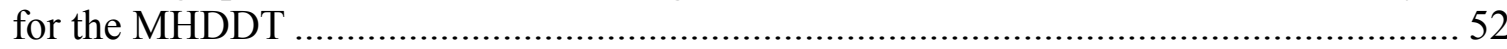

Figure 45: Average percent increase of the weight and various emissions for the different cycles

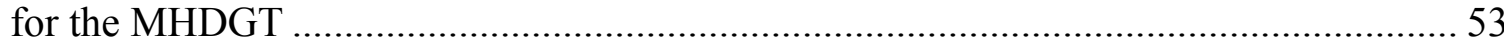

Figure 46: Increase in fuel specific emissions in terms of \% change of emissions to \% change of

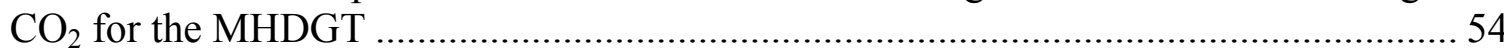

Figure 47: $\mathrm{NO}_{\mathrm{X}}$ emission trends for different vehicles at multiple operating weights on the Creep

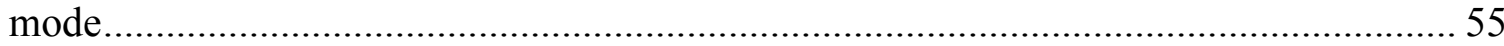

Figure 48: $\mathrm{NO}_{\mathrm{X}}$ emission trends for different vehicles at various operating weights on the Cruise

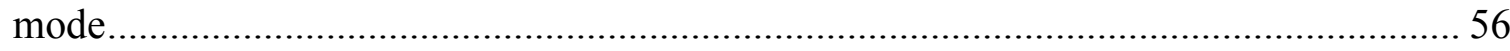

Figure 49: $\mathrm{NO}_{\mathrm{X}}$ emission trends for different vehicles at various operating weights on the

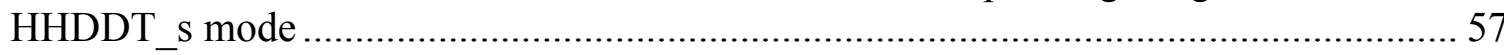

Figure 50: $\mathrm{NO}_{\mathrm{X}}$ emission trends for different vehicles at various operating weights on the

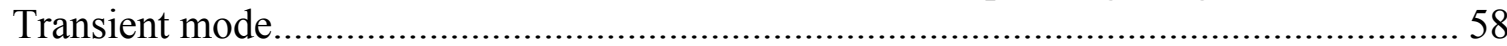

Figure 51: Transient mode $\mathrm{CO}_{2}$ averages ............................................................................. 59

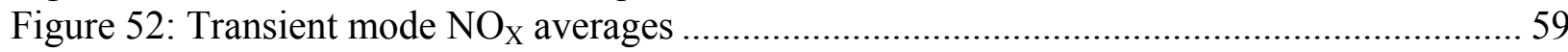

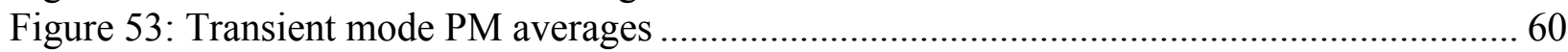

Figure 54: Ratios of the fleet wide averages for the vehicles at $56,000 \mathrm{lbs}$ to $30,000 \mathrm{lbs}$.......... 61

Figure 55: Ratios of the fleet wide averages for the vehicles at 66,000 lbs to 30,000 lbs.......... 61

Figure 56: Ratio of Transient mode $\mathrm{NO}_{\mathrm{X}}$ emissions on vehicles tested at 30,000 lbs and 56,000

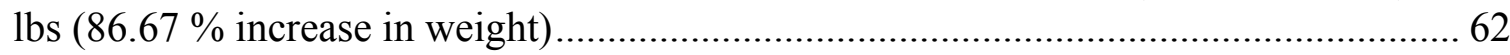

Figure 57: Ratio of Transient mode $\mathrm{NO}_{\mathrm{X}}$ emissions on vehicles tested at 30,000 lbs and 66,000

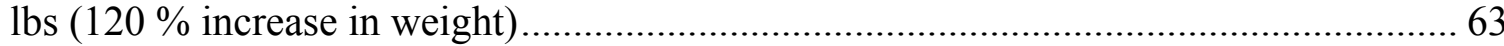

Figure 58: Predicted versus measured $\mathrm{CO}_{2}$ values of $56 \mathrm{HHDDT}$ at 56,000 lbs on the Creep

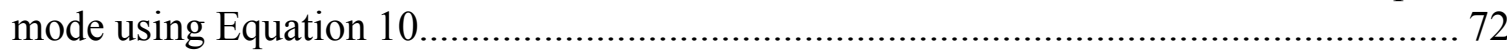

Figure 59: Predicted versus measured $\mathrm{NO}_{\mathrm{X}}$ and PM values of $56 \mathrm{HHDDT}$ at 56,000 lbs on the

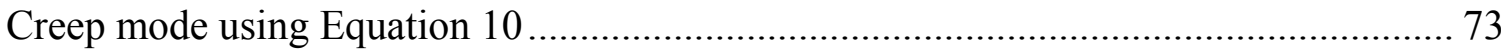

Figure 60: Predicted versus measured $\mathrm{CO}_{2}$ values of $56 \mathrm{HHDDT}$ at 56,000 lbs on the UDDS using Equation 10 
Figure 61: Predicted versus measured $\mathrm{NO}_{\mathrm{X}}$ and PM values of $56 \mathrm{HHDDT}$ at 56,000 lbs on the UDDS using Equation 10................................................................................. 74

Figure 62: Predicted versus measured $\mathrm{CO}_{2}$ values of $27 \mathrm{HHDDT}$ at 56,000 lbs on the HHDDT_s

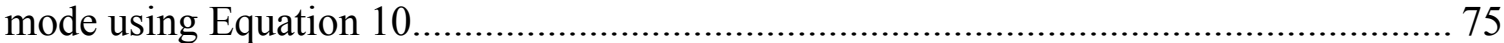

Figure 63: Predicted versus measured $\mathrm{NO}_{\mathrm{X}}$ and PM values of $27 \mathrm{HHDDT}$ at 56,000 lbs on the HHDDT_s mode using Equation 10 .................................................................. 76

Figure 64: Statistical comparison of the percentage errors of predictions for the two methods for the three cycles: UDDS, HHDDT_s mode and Creep mode ...................................... 78

Figure 65: Magnified view of the emission species of $\mathrm{CO}_{2}$ on UDDS predicted using the Transient mode, Cruise mode and Idle mode ........................................................ 81

Figure 66: Emissions species of $\mathrm{NO}_{\mathrm{X}}$ and $\mathrm{PM}$ on UDDS predicted using the Transient mode, Cruise mode and Idle mode 


\section{LIST OF ABBREVIATIONS, ACRONYMS, NOMENCLATURES OR SYMBOLS}

$\frac{\partial \mathbf{v}}{\partial \mathbf{t}}$ : Acceleration component from cycle

Abs: Mathematical absolute value

AC5080: A test derived by Parsons Australia for CARB

AF: Frontal cross sectional area $\left(\mathrm{m}^{2}\right)$

Ahp-hr/mile: Axle horse power hour per mile

CARB: California Air Resource Board

$\mathbf{C}_{\mathbf{D}}$ : Aerodynamic drag coefficient

CFR: Code of Federal Regulations

CO: Carbon monoxide

$\mathbf{C O}_{2}$ : Carbon dioxide

$\mathbf{C}_{\mathbf{R}}$ : Rolling resistance

CRC: Coordinating Research Council

CSHVR: City-Suburban Heavy Vehicle Route

CTA: California Trucking Association

CVS: Critical flow Venturi System

ECU: Electronic Control Unit

EGR: Exhaust Gas Recirculation

$\mathbf{E}_{\mathbf{M}}$ : Emissions (g/min)

EPA: Environmental Protection Agency

$\mathbf{g}_{\mathbf{a}}$ : Acceleration due to gravity

GVWR: Gross Vehicle Weight Rating

HC: Hydrocarbon

HDT: Heavy Duty Trucks

HEPA: High Efficiency Particulate Air

HHDDT: Heavy Heavy-Duty Diesel Truck

HHDDT_s: High speed cruise part of the 5-mode HHDDT schedule

IM: Inspection and Maintenance

$\mathbf{K}_{\mathbf{b}}$ : Vehicular constant (watts)

$\mathbf{K}_{\mathbf{c}}$ : Vehicular constant $(\mathrm{kg})$

$\mathbf{K}_{\mathbf{d}}$ : Vehicular constant $\left(\mathrm{kg}-\mathrm{m} / \mathrm{s}^{2}\right)$ 
$\mathbf{K}_{\mathbf{e}}$ : Vehicular constant $(\mathrm{kg} / \mathrm{m})$

m: Vehicle mass $(\mathrm{kg})$

Max: Maximum value

MHDDT: Medium Heavy Duty Diesel Trucks

MHDGT: Medium Heavy Duty Gasoline Trucks

MHDT: Medium Heavy Duty Trucks

MHDTCR: Medium Heavy Duty Truck Cruise mode

MHDTHI: Medium Heavy Duty Truck High-Speed Transient mode

MHDTLO: Medium Heavy Duty Truck Low-Speed Transient mode

min: Minutes

MOVES: Motor Vehicle and Equipment Emission System

mpg: Miles per gallon

mph: Miles per hour

MY: Model Year

NDIR: Non-Dispersive Infrared

NO$_{\mathbf{x}}$ : Oxides of nitrogen

$\mathbf{P}_{\text {aux }}$ : Power needed for accessories such as lights, compressors, A/C (watts)

$\mathbf{P}_{\mathbf{D}}$ : Total power demand of vehicle (watts)

PM: Particulate Matter

$\mathbf{R}^{2}$ : Residuals for linear regression

T\&M: Tampering and Malmaintenance

TPM: Total Particulate Matter

Translab: Transportable Heavy-Duty Vehicle Emissions Testing Laboratory

UDDS: Urban Dynamometer Driving Schedule

V: Velocity

WVU: West Virginia University

$\eta$ : Drivetrain efficiency

$\rho:$ Density of air $\left(\mathrm{kg} / \mathrm{m}^{3}\right)$ 


\section{Introduction}

The objectives if this analysis were to first establish trends for emissions between cycles using one-dimensional correlation analysis. Then, verify if these trends show better correlations if two cycles are used to predict the emissions on a third cycle using two-dimensional correlation analysis. The effect of weight on the emissions and the ability to predict these emissions was also evaluated. And finally, develop a linear model to predict emissions based on the properties of cycles and the emissions history of that vehicle.

Concerns over diesel emissions' environmental and health effects have been expressed widely in literature [1] and necessitate the estimation of emissions contribution from mobile sources. Accurate prediction of heavy-duty vehicle emissions is needed to create meaningful vehicle emissions inventories and must take into account the performance of the real-world fleet. Without an accurate inventory, source apportionment is flawed, and policy to improve air quality may be ill-informed.

Particulate matter $(\mathrm{PM})$ and oxides of nitrogen $\left(\mathrm{NO}_{\mathrm{X}}\right)$ are recognized to be the species of greatest concern for heavy-duty vehicle operation [1]. The average speed and the degree of transient behavior can affect the distance-specific vehicle emissions [2,3,4]. It is important to characterize the emissions for the most appropriate activity in terms of speed-time behavior. However, researchers and regulators usually do not have the luxury of measuring the emissions for a large number of different activity patterns, and data are usually available only for limited test fleets on a limited number of test cycles.

Emissions modeling have taken a central role in fleet configurations designed to accommodate current and future environmental standards. There are models like Greenhouse Gases, Regulated Emissions, and Energy Use in Transportation (GREET) designed by Argonne National Laboratories Transportation Technology R\&D Center and MOBILE (version 6.2 being the EPA standard). These models are evolving to achieve reliable emissions predictions. In-cylinder $\mathrm{NO}_{\mathrm{X}}$ emission is proving to be a complex variable to model, further influenced by advancement in engine control strategies and after treatment systems.

Some electronically-managed engines were known to advance timing of injection for purposes of improving fuel economy under cruise conditions. The variability of the engine control 
algorithms used to determine cruise operation and the variability of the degrees of advance make prediction of these "off-cycle" emissions difficult. After vehicle model year 1995 (where engines may have a 1994 or 1995 date of manufacture), off-cycle operation was pervasive, and continued until 1999, when it was substantially curtailed. Hence by excluding data from vehicles in the 1995 to 1999 model year range, much of the off-cycle operation would be excluded, and superior ability to predict $\mathrm{NO}_{\mathrm{X}}$ emissions could be expected. Both, the complete data set and the data set without 1995 to 1999 vehicles, were examined for the one and two dimensional correlation analysis, from the vehicles tested at the time of that analysis.

The first step in predicting emissions was to see if the cycles, modes or schedules (The term "cycle" will be used generically to cover all three terms) were dependent on each other. A one dimensional correlation analysis was conducted to see if one cycle's emissions could predict another cycle's emissions. This kind of analysis did not provide the variables responsible for such a prediction, but indicated the ability of using cycle based parameters to predict the emissions. This analysis is presented in Section 4.

Upon further investigation, a multi-dimensional correlation model was created. This was used to check if more than one cycle was used to predict the emissions on another cycle, would the error of prediction be reduced compared to a one-dimensional model. This model is presented in Section 5 .

The effect of load / weight on emissions was investigated in Section 6. This analysis compared the results of previous studies, but used a larger data base of vehicles (47 vehicles). Here, HHDDT, MHDT and MHDGT vehicles were analyzed for $\mathrm{NO}_{\mathrm{X}}, \mathrm{PM}, \mathrm{CO}_{2}$ and $\mathrm{HC}$.

The ability to predict emissions based on cycles and the effect of load on the emissions was then used to develop an emissions factors based technique to predict emissions on a vehicle. This technique used the road load equation and allowed the translation of emissions between cycles. This technique is presented in Section 7.

Each section has its own introduction, literature reviews and conclusions. Sections 4 and 5 have been presented at the SAE Fall 2004 Powertrain \& Fluid Systems Conference and the 2005 SAE World Congress respectively $[5,6]$. 


\subsection{LABORATORY DESCRIPTION}

The West Virginia University (WVU) Transportable Heavy-Duty Vehicle Emissions Testing Laboratories (Translab) were constructed to gather emissions data from in-use heavy-duty vehicles. Detailed information pertaining to the design and operation of the laboratories can be found in technical papers $[5,7,8,9]$.

The Laboratory consisted of two trailers. One trailer incorporated rollers, flywheels and power absorbers for the dynamometer function, and a second trailer housed the controls and emissions measurement equipment. The vehicle to be tested was driven onto the chassis dynamometer and positioned on two sets of rollers. The outer wheel of the dual wheel set on each side of the vehicle was removed and replaced with hub adapters that couple the drive axle directly to the dynamometer units on each side of the vehicle. Vehicle inertia was mimicked using a flywheel set. Various flywheels could be engaged to mimic a desired vehicle inertia weight up to 70,000 lbs in $250 \mathrm{lb}$ increments. Road-load drag on the vehicle was mimicked partially by the irreversible (frictional) losses on the laboratory, and was adjusted to the correct value at each speed using the eddy current power absorber with closed-loop torque control. A human driver operated the vehicle through the driving cycles.

The full exhaust from the tail pipe of the test vehicle was ducted to a full-flow exhaust dilution tunnel where it was mixed with HEPA filtered dilution air. The quantity of diluted exhaust was metered precisely by a critical flow venturi system (CVS). Samples of the diluted exhaust were analyzed using NDIR for carbon monoxide (CO) and carbon dioxide $\left(\mathrm{CO}_{2}\right)$, and chemiluminescent detection for $\mathrm{NO}_{\mathrm{X}}$. Hydrocarbons $(\mathrm{HC})$ were analyzed using a heated flame ionization detector (HFID). Total particulate matter (TPM) was collected using $70 \mathrm{~mm}$ fluorocarbon coated glass fiber filter media and PM emissions are determined gravimetrically.

For each run, background bags were gathered, analyzed and used to correct gaseous emissions. Dilute gas bags were also collected during a run, but continuous data, integrated over the run, were used for reporting purposes. Separate runs were used to gather background PM levels for PM filter weight correction. Even though the tunnel had HEPA filtered air, PM backgrounds were essential because the tunnel itself may shed PM particles or outgas heavy hydrocarbons that condense onto the PM. 
Vehicle road-load loss was simulated by performing a "coast-down" on the chassis dynamometer. The vehicle was accelerated to a speed of $55 \mathrm{mph}$, the transmission was put into neutral, and the vehicle was then allowed to coast to a stop.

\subsection{TEST VEHICLES}

\subsubsection{E-55/59 STUDY}

Data were acquired as part of the E-55/59 program [10,11], the sponsors of which are presented in the acknowledgements section. A program objective was to procure and test 75 Heavy Duty Trucks (HDT) for emissions inventory and chemical analyses. This program had four phases: 1, 1.5, 2 and 3 [12-15]. Vehicles were recruited by the California Trucking Association (CTA) and WVU researchers. These vehicles complied with a model year distribution determined by the California Air Resources Board (CARB) and Coordinating Research Council (CRC). One tandem-axle "straight" truck was tested at 45,000 lbs, but not included in this analysis as it was the only vehicle at that weight. The vehicles from this study were referenced as E55CRC-XX, with XX designating a number in the order in which the vehicle was recruited.

\subsubsection{GASOLINE-DIESEL PM SPLIT STUDY}

This study aimed to determine the contribution of diesel versus gasoline-powered exhaust to the PM inventory from heavy-duty and light-duty vehicles in southern California. Other species measured were $\mathrm{NO}_{\mathrm{X}}, \mathrm{CO}$ and $\mathrm{HC}$. 34 Heavy-duty diesel vehicles and 59 light-duty vehicles were tested based on the program requirements. The detailed testing procedure, vehicle inventory, and analysis have been presented as part of a report and paper $[16,17]$.

\subsubsection{MEDIUM HEAVY-DUTY TRUCKS (MHDT)}

MHDT were only tested on two test weights as part of the E-55/59 Study. MHDT were vehicles with a gross vehicle weight rating (GVWR) between 19,500 lbs and 33,000 lbs. All MHDT were tested at $50 \%$ and $75 \%$ of their gross vehicle weight (GVW), except for a 1974 Ford (E55CRC-73), which was tested at $56 \%$ and $75 \%$ of GVW.

\subsubsection{HEAVY HEAVY-DUTY DIESEL TRUCKS (HHDDT)}

The vehicles used from the E-55/59 Study had emissions data at test weights of 30,000 lbs and $56,000 \mathrm{lbs}$. Some vehicles were also tested at 66,000 lbs. The three vehicles used from the Gasoline-Diesel PM Split Study were tested at 46,000 lbs. These included tandem-axle road- 
tractors as well as any "full size" single-axle road tractors, since these typically have a gross combination weight of $52,000 \mathrm{lbs}$ to $80,000 \mathrm{lbs}$.

\subsection{RELEVENCE TO INVENTORY MODELS}

It is of interest to determine whether emissions determined on one cycle can be translated reliably to predict emissions during a different type of vehicle operation. For example, the California emissions code EMFAC [18] has based its heavy-duty emissions factors at present on data from a single cycle, the Urban Dynamometer Driving Schedule (UDDS) [5]. The reliability of this when projected to different truck behaviors has not been studied comprehensively. The federal EPA code MOBILE [19] has used speed correction factors [20], which have existed since MOBILE 1, which rely on this very issue of translating emissions from one cycle to another, using the single variable of average speed.

WVU has conducted prior modeling, using artificial neural networks [21], where a network is trained on one or more test cycles and is then used to predict emissions on another. However, this is an involved process which would restrict its use by any local authority trying to predict emissions from a link, and would not be used by a vehicle operator seeking to compare two vehicles that were tested for emissions on different cycles. The intent was to see whether there is hope of estimating emissions over one behavior or link (imitated here by a cycle) from other cycles, particularly when the two cycles are different, just by using linear combinations from those cycles.

Prior studies have looked at cycle properties as a translation medium [10] rather than direct correlation. In Taylor et al. [10], properties were average speed, stops per mile, percent idle and average kinetic energy and a direct solution to predict activity on a different cycle was attempted. It was evident that average speed was insufficient as a single variable for translation and supported the need for a more complete examination of cycle effects. Although a complete methodology for predicting emissions on a previously unseen cycle was not provided, it did examine relationships between existing data on one inspection and maintenance cycle and three cycles derived from real-world operation. The data presented offered a justification for developing cycle translation techniques that are superior to speed correction factors.

The transient nature of cycles is perhaps the most relevant factor after average speed. Speed versus time traces of the UDDS, Cruise mode [5] and Transient mode [5] have been used to 
compute various intensive properties to see the effect of transient behavior. Results are shown in Table 1 and Figure 1. The average of the absolute value of acceleration (Equation 1) and the average of the square of acceleration (Equation 2) indicate transient dominance. Though Cruise mode has highest average speed, UDDS is comparable to Cruise mode for standard deviation of speed and is most significant in acceleration and deceleration.

Equation 1

$\sum_{1}^{i}\left|V_{i+1}-V_{i}\right|$

Length of Cycle

Equation 2

$$
\sum_{1}^{i}\left[\left(V_{i+1}-V_{i}\right)^{2}\right]
$$

Length of Cycle

Since MOBILE6 [19] uses speed correction factors for emissions prediction, Figure 2 was developed to show the results of the E-55/59 inventory for $\mathrm{NO}_{\mathrm{X}}$ emissions at three different average speeds (average speed for Cruise mode, average speed for Transient mode and average speed for UDDS). There is considerable data scatter for emissions of different vehicles at similar average speeds, as expected, but the resulting curve has the concave upward shape expected of a speed correction factor curve. The minimum average $\mathrm{NO}_{\mathrm{X}}$ shown in this figure arises due to the concave fit of the curve and may not represent average emissions at that average speed.

Table 1: Intensive properties of Cruise mode, Transient mode and UDDS

\begin{tabular}{|l|l|l|l|}
\hline & Cruise mode & Transient mode & UDDS \\
\hline Average Speed (mph) & 39.876 & 14.918 & 18.829 \\
\hline Standard Deviation $(\mathrm{mph})$ & 22.004 & 13.437 & 19.819 \\
\hline Average of Change in speed / Change in time (mph/s) & 0.023 & 0.058 & 0.063 \\
\hline $\begin{array}{l}\text { Average of Square of Change in Speed / Change in } \\
\text { time }\left(\mathrm{mph}^{2} / \mathrm{s}\right)\end{array}$ & 0.003 & 0.009 & 0.013 \\
\hline
\end{tabular}




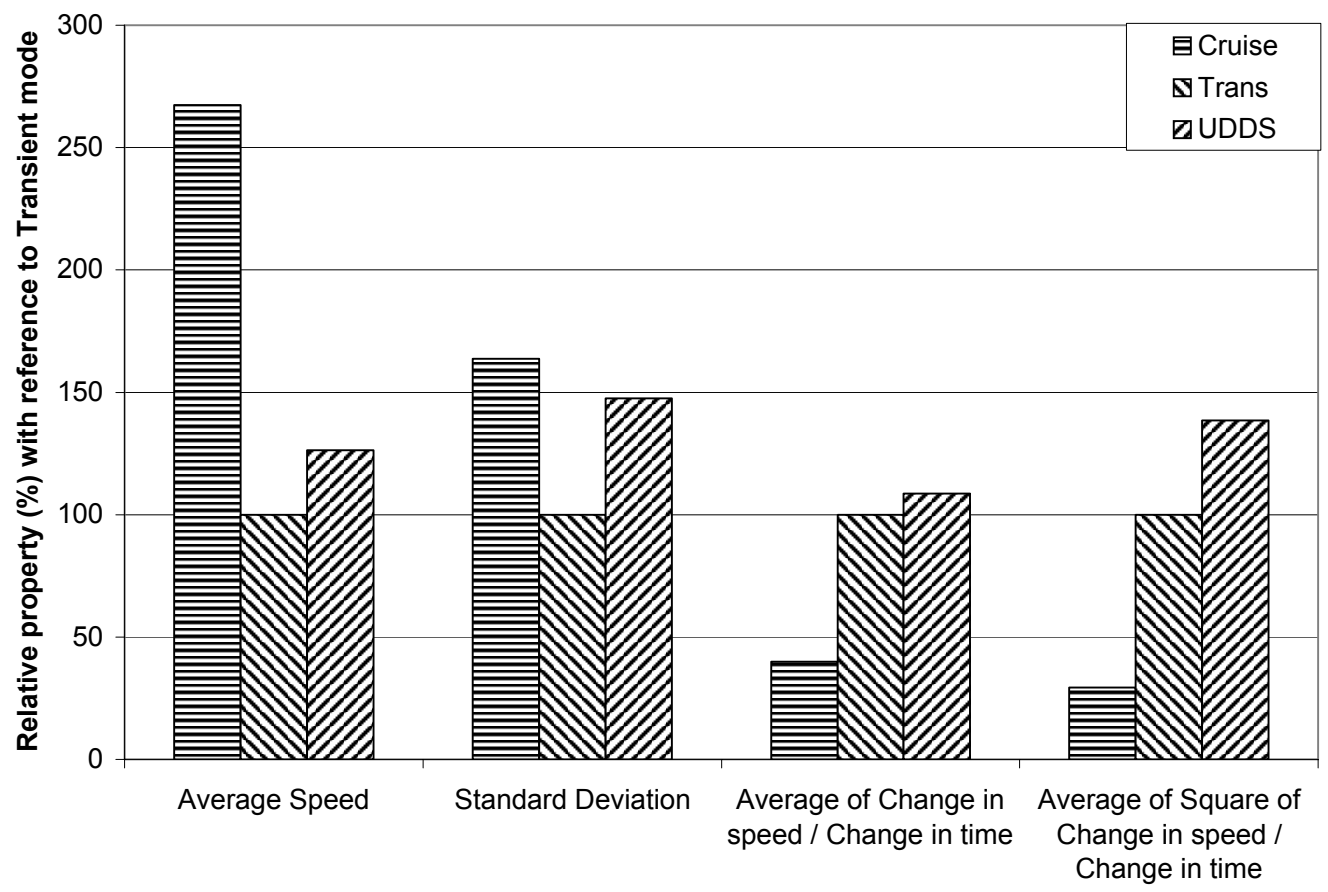

Figure 1: Intensive properties of Cruise mode, Transient mode and UDDS, all referenced to the Transient mode

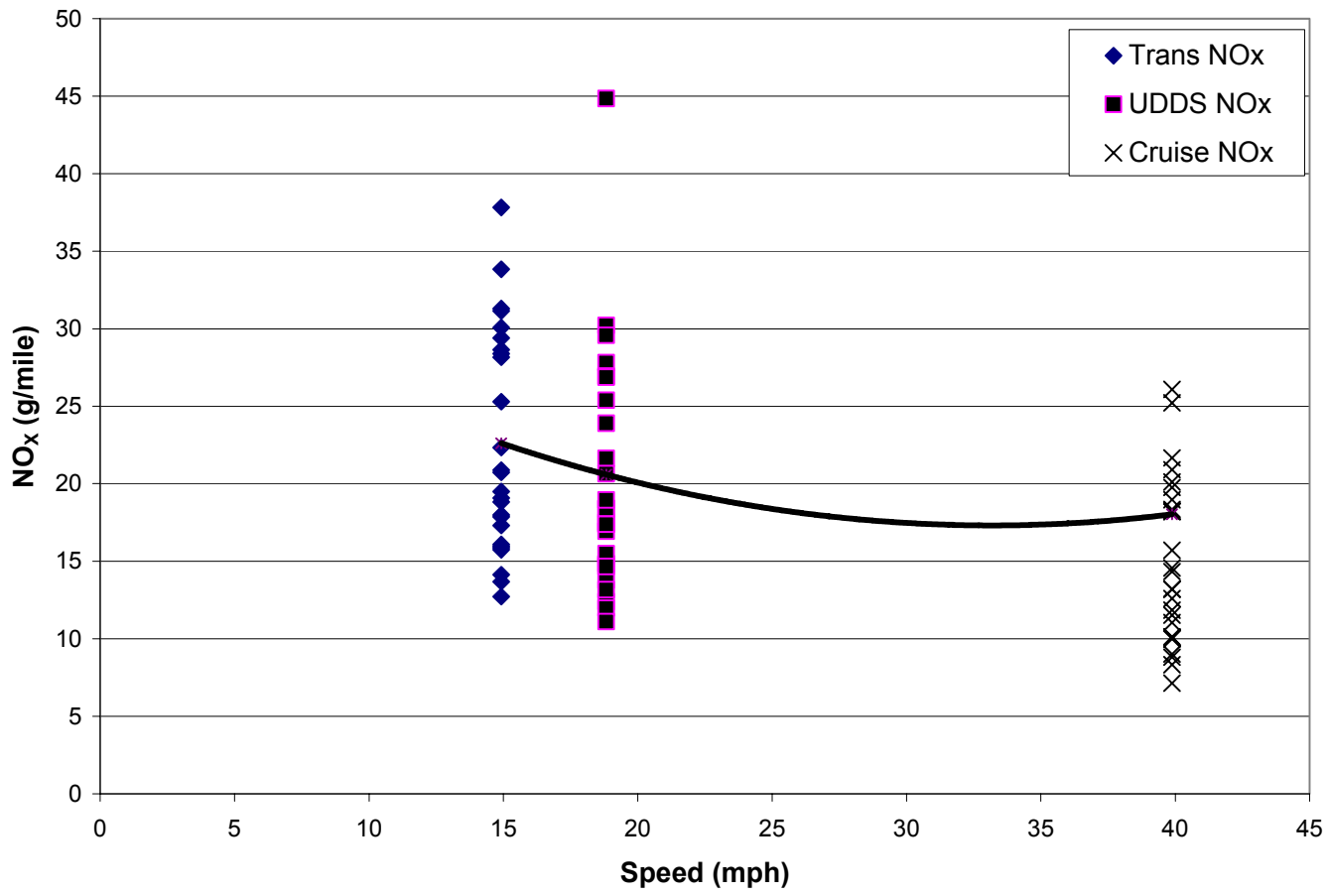

Figure 2: $\mathrm{NO}_{\mathrm{X}}$ emissions for average speeds of Cruise mode, Transient mode and UDDS and a trend line for average emissions 


\section{Correlation of PM and $\mathrm{NO}_{x}$ for Heavy-Duty Vehicles Across Multiple Drive Schedules}

\subsection{INTRODUCTION}

Distance specific emissions factors (in units such as $\mathrm{g} / \mathrm{mile}$ ) are widely used in combination with distance traveled (vehicle miles traveled) to formulate mobile source emissions inventories. When heavy-duty truck emissions are expressed in distance-specific units, the values may depend strongly on the nature of the test cycle. This fact is tacitly acknowledged in speed correction factors that may be used to "correct" emissions predictions based on average vehicle speed. Speed correction factors usually account in their formulation not only for average speed of operation, but also for the vehicle behavior implied by that average speed. For example, consideration of truck behavior suggests that an average speed of 60 or $70 \mathrm{mph}$ implies steady high speed operation, whereas an average speed of 15 or $20 \mathrm{mph}$ implies transient behavior, rather than a steady slow speed. Speed correction factor curves are usually plotted as distancespecific emissions rates versus average speed, and are concave upward, because higher distancespecific emissions occur at very low speeds and at very high speeds. Weinblatt et al. [22] showed that for diesel powered vehicles this upturn in $\mathrm{NO}_{\mathrm{X}}$ emissions may occur at speeds higher than those normally associated with truck highway travel. PM emissions have usually been regarded as difficult to correct because the PM production may be influenced strongly by the engine transient behavior $[2,23]$.

Speed correction factors were clearly approximate, because the same average speed may describe two truck activities that were still different in their transient nature. The influence of test schedule on the emissions has been the topic of prior studies. Vehicle test weight can also influence emissions [24] although few data existed before the year 2000 to quantify the effect. The influence of test weight on emissions will be discussed in more detail in Section 6 .

In this section, data from Phase 1 and Phase 1.5 of the E-55/59 study [10,11] have been used to compare average emissions from a variety of cycles. Very high distance-specific emissions were found for the Creep mode [25], because it includes long idle periods, and covers a short distance and therefore this mode was excluded from the analysis for this section. The comparison was performed using one-dimensional linear regression. 


\subsection{LITERATURE REVIEW}

Graboski et al. [26] plotted Central Business District cycle emissions versus emissions from other cycles, and showed that parity did not exist on the plot. Taylor et al. [10] showed that it was possible to predict the emissions on one test cycle if one were given the emissions measured using four different modes of behavior, one of which was a steady Idle mode. The data used by Taylor et al. [10] represented part of the data set presented in this section. In the Gasoline-Diesel PM Split Study [16], data showed conclusively that emissions from the City-Suburban Heavy Vehicle Route (CSHVR) [27] differed from emissions gained using a Highway cycle [27]. Clark et al. [28] used neural network predictive techniques to predict emissions when the network was trained on other data from the same vehicle. Models such as MOVES [29] may be used to reconstruct emissions on one cycle using a database of emissions gained from other cycles, and Clark et al. [30] have developed speed-acceleration emissions factors that can be used to reconstruct the emissions on a different cycle.

\subsection{TEST VEHICLE SELECTION}

The most important variable that influences emissions within a weight class, is believed to be the engine certification standard. This is reflected in the engine model year, and hence vehicle model year. The vehicle model year may not reflect the appropriate standard in the unusual case of a vehicle re-power when an engine of a newer standard may be installed. Rebuilds normally return the engine to its original condition, whereas a re-power usually employs a newer technology engine. The engine model year influences the level of emissions for certification. In

some cases, the engine model year preceded the vehicle model year due to vehicle integration by multiple manufacturers. In this study, the vehicle model year was used to determine the recruitment of the vehicle.

The first 46 vehicles recruited as part of the E-55/59 Study and used in this section had an engine model year distribution as illustrated in Figure 3. The model year groupings reflect California certifications. 


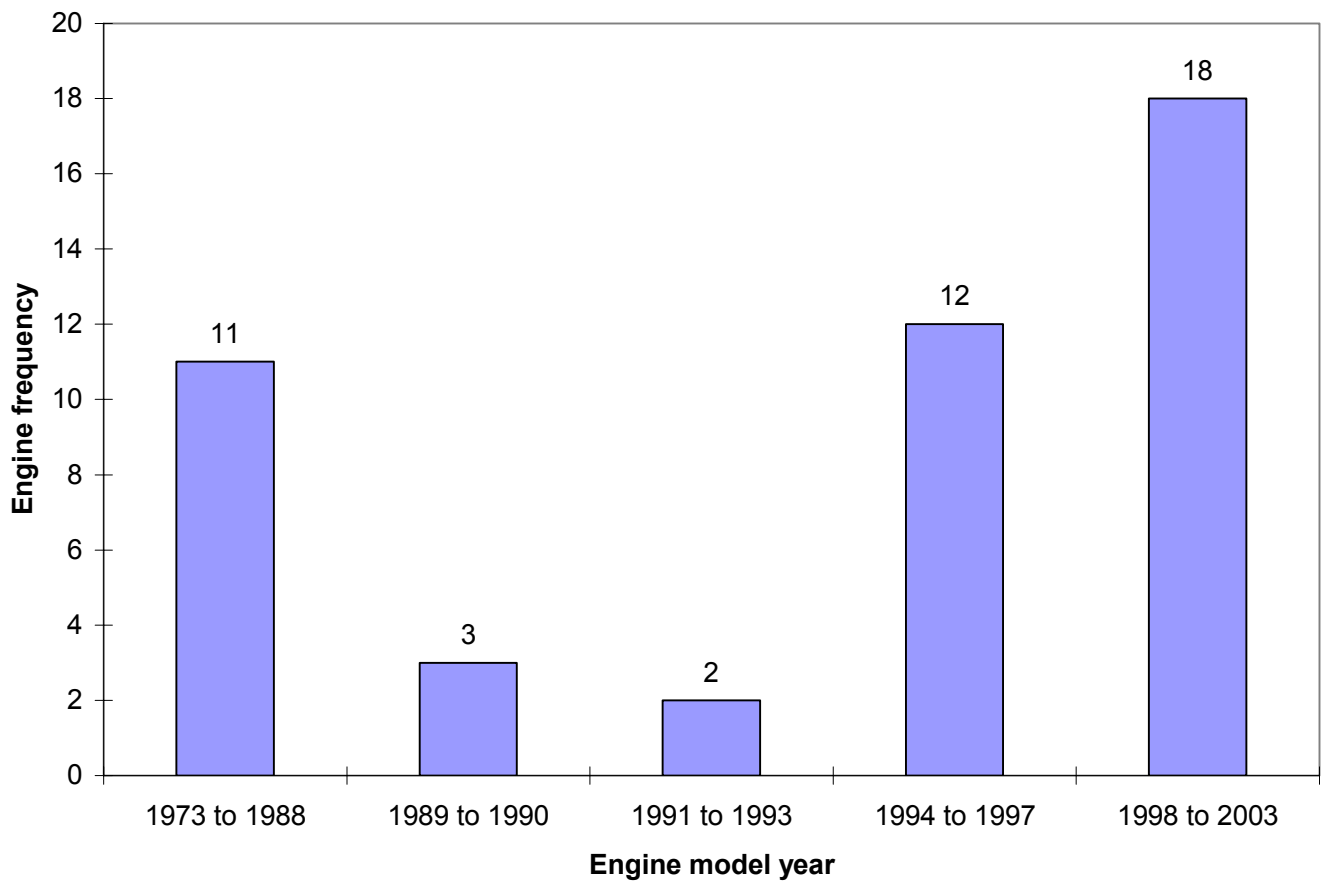

Figure 3: Test vehicle distribution with reference to engine model year

\subsection{TEST CYCLES}

Four dynamometer driving cycles were used for this study, namely the UDDS, the Transient mode and Cruise mode of the 5-Mode CARB HHDDT cycle, and AC5080 as a short test.

\subsubsection{UDDS}

The UDDS is taken from the Code of Federal Regulations (CFR) [27]. Figure 4 shows the target speed versus time schedule for the UDDS. This schedule has a target distance of $5.54 \mathrm{mi}$. This test schedule is widely recognized and has been used in many previous studies $[2,10,16]$. 


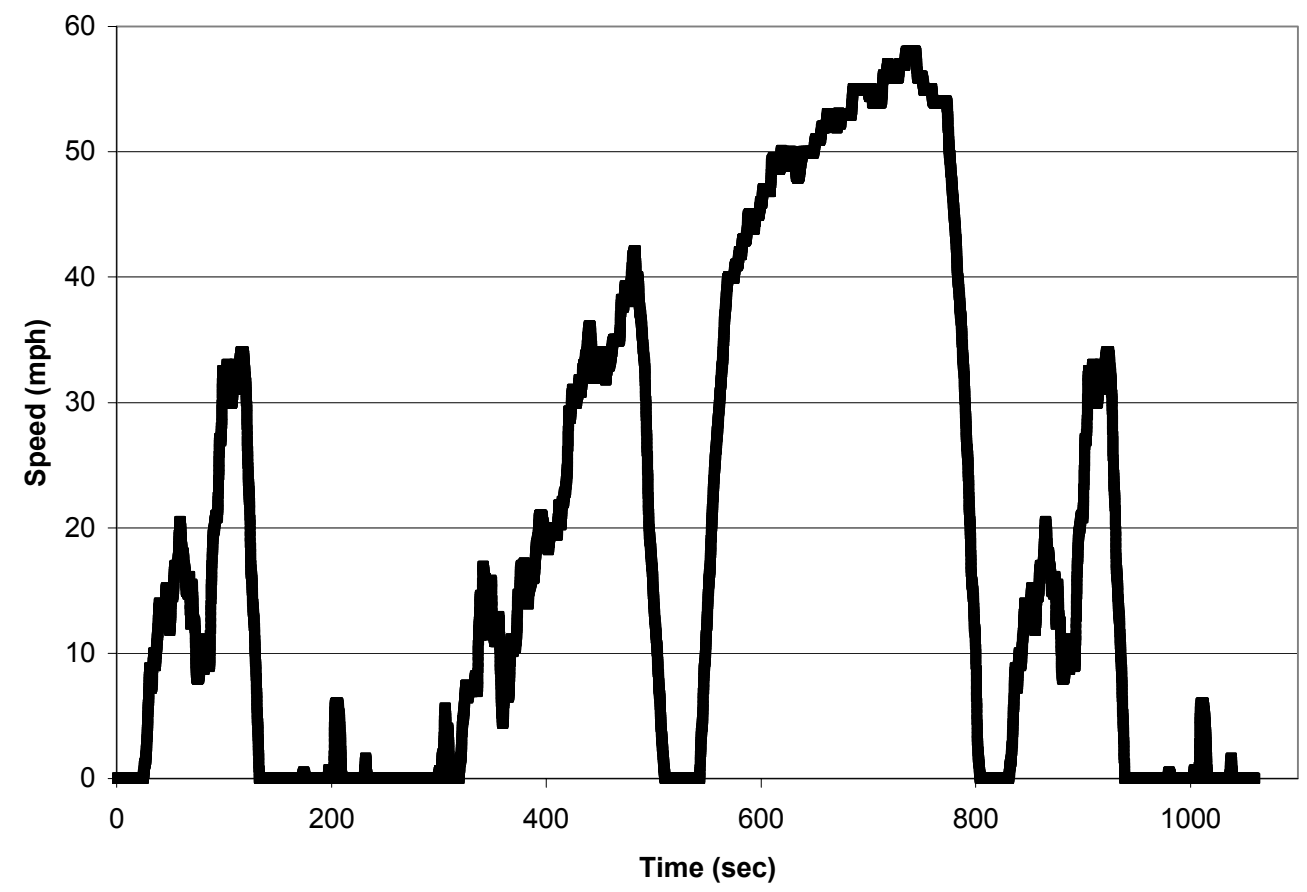

Figure 4: Scheduled speed for the UDDS

\subsubsection{HHDDT TRANSIENT MODE AND CRUISE MODE}

The HHDDT schedule [25] is a 5-Mode test schedule made up of varying modes of operation: Idle, Creep, Transient, Cruise, and a high speed cruise referred to as HHDDT_s [13]. This section only utilizes the Cruise mode and Transient mode for analysis. Figure 5 and Figure 6 show the Cruise mode and Transient mode vehicle speed versus time. 


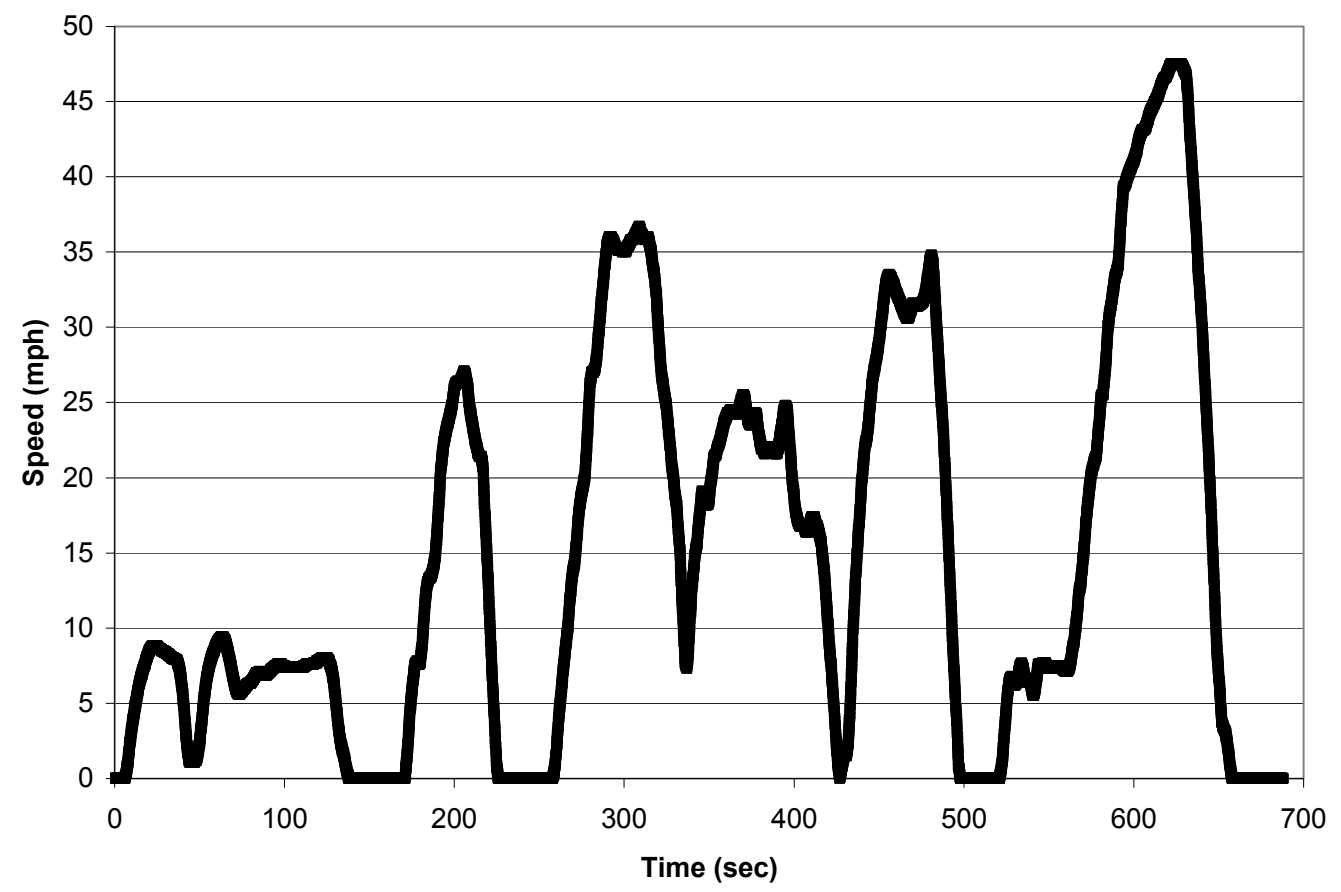

Figure 5: Scheduled speed for the Transient mode of the HHDDT 5-Mode schedule

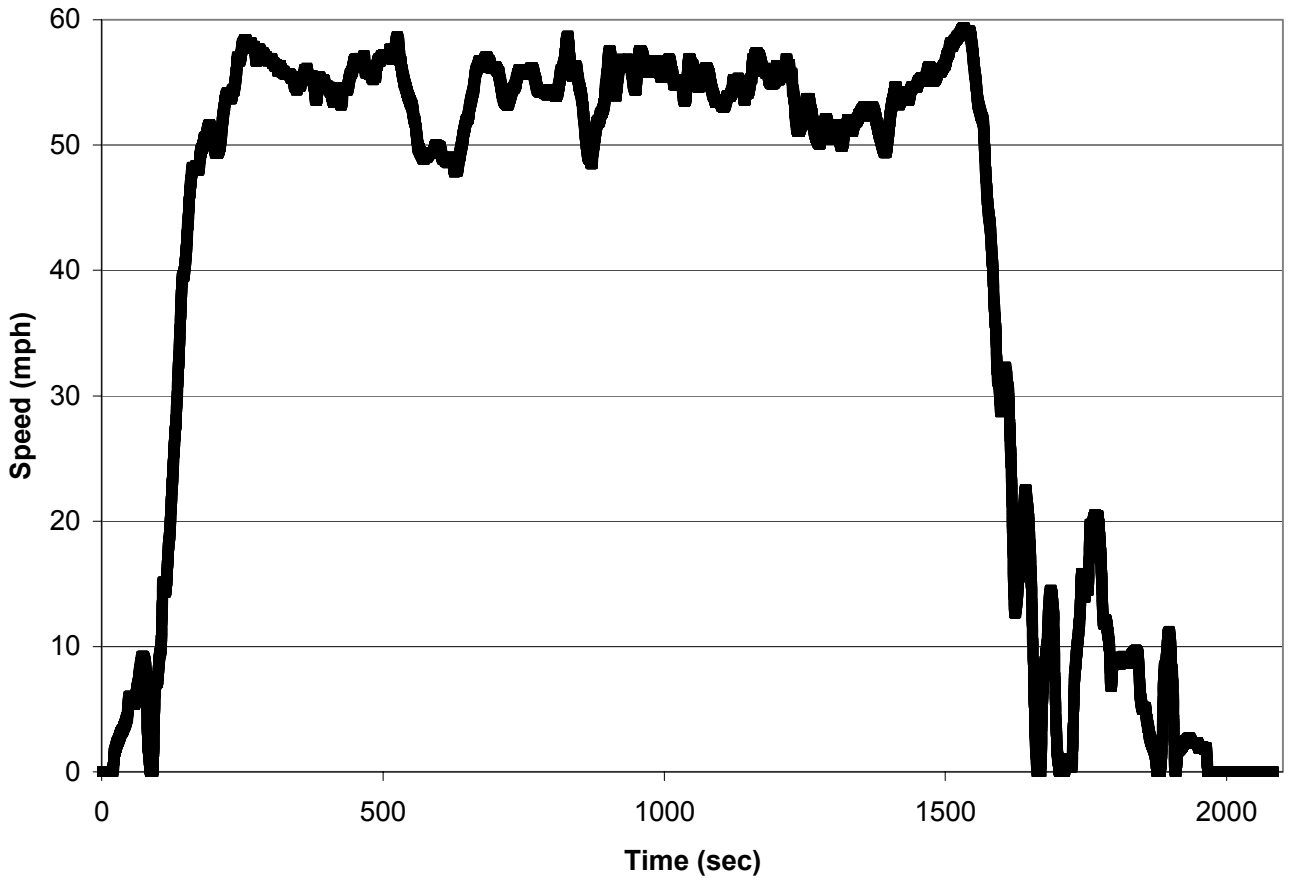

Figure 6: Scheduled speed for the Cruise mode of the HHDDT 5-Mode schedule 


\subsubsection{AC5080}

The AC5080, shown in Figure 7, is a short test derived by Parsons Australia for the CARB. It consists of two steady speeds of $50 \mathrm{~km} / \mathrm{hr}$ and $80 \mathrm{~km} / \mathrm{hr}$. While accelerating to the target speeds, the vehicle is not required to meet any speed-time trace requirements. Emissions are integrated over the entire duration of the test.

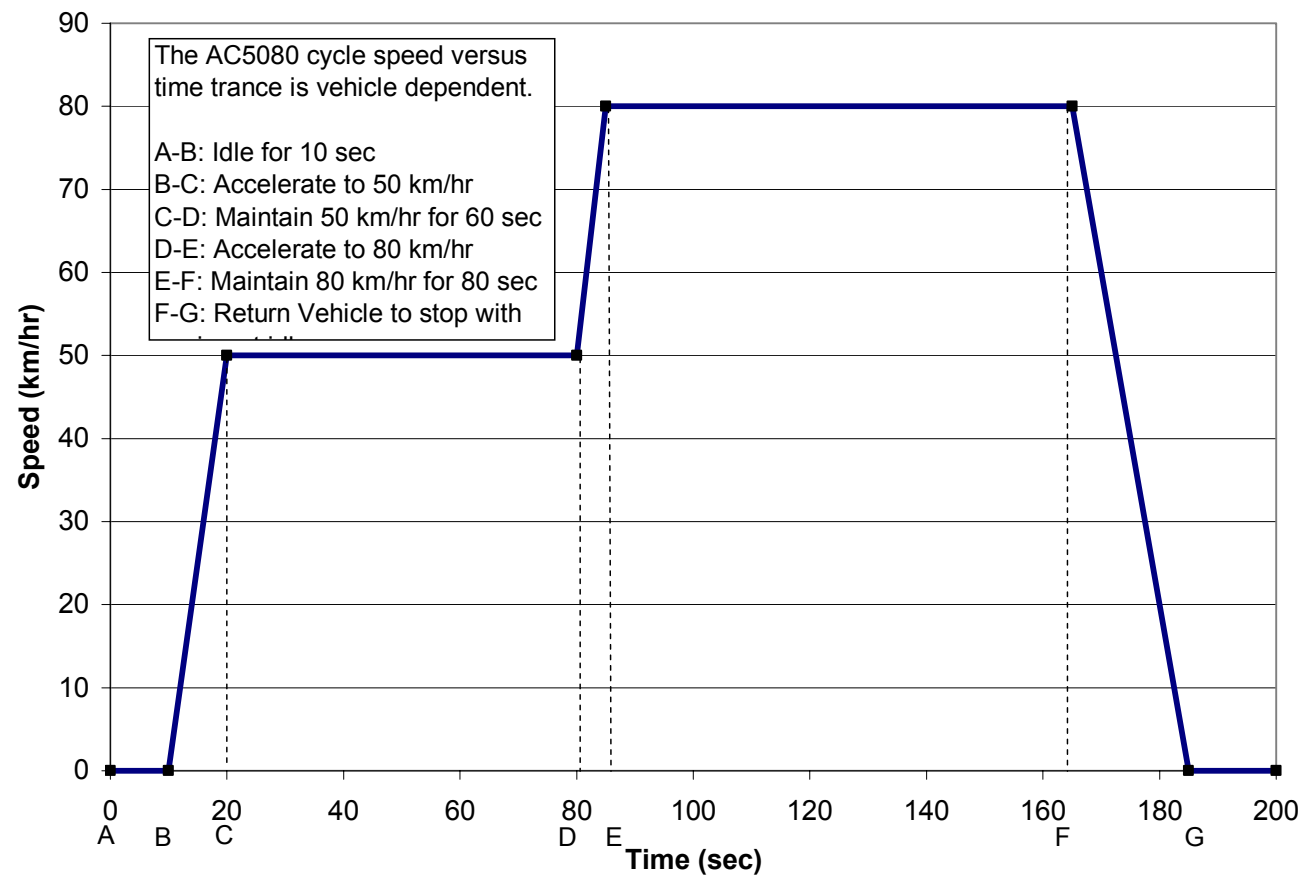

Figure 7: Scheduled speed for the AC5080 short test

\subsection{CORRELATION OF HHDDT MODES}

One vehicle was identified as an outlier in relation to all other vehicles in the program. PM emissions for this vehicle were excessive and indicated an extreme engine malfunction. This vehicle was identified as a 1979 Caterpillar with E-55/59 designation E55CRC-16 and was excluded from the PM emissions analysis.

The method used to compare emissions from two cycles was linear regression. Though this technique did not indicate the properties directly responsible for the correlation, it did show whether there was a possibility of predicting the emissions of one cycle given data from another cycle. While evaluating relationships based on linear regression, it is important to note that a single high point or outlier can have significant effect on the $\mathrm{R}^{2}$. However, values of other statistical quantifiers, like percentage error, would be less prone to mathematical influences 
arising from outliers. Low $\mathrm{R}^{2}$ value would be the result of clustering of data points which could be a result of vehicles with similar fuel economy.

While conducting analysis using linear regression, two cases for each correlation were studied. One relationship used the entire data set provided to get the linear regression equations and is denoted in all graphs with a dashed line and the equation as the second linear equation. The second relation excluded vehicles with engine model years from 1995-1999 and is represented with a solid line on all graphs and the resulting equations are summarized in Table 2 in the results section. Vehicles in the model year range 1995-1999 may have "off-cycle" injection timing strategies, and it was desirable to consider vehicles without this strategy separately.

The "off-cycle" vehicles refer to the vehicles covered under the U.S. EPA's 1998 Consent Decree. These vehicles were identified as excessive producers of $\mathrm{NO}_{\mathrm{X}}$ emissions during highway driving that did not occur during engine certification testing. This allowed the vehicles to be more fuel efficient.

\subsubsection{CORRELATION OF UDDS VERSUS CRUISE MODE}

Figure 8 compares the distance-specific emissions from the Cruise mode with the UDDS $\mathrm{NO}_{\mathrm{X}}$ emissions at 56,000 lbs. A strong visual trend is evident, but the points that lie furthest from the best fit line would be predicted with an error that is nearly a factor of two. While trying to predict the $\mathrm{NO}_{\mathrm{X}}$ on the Cruise mode using UUDS, there was an average error of $18.71 \%$. This may be attributed in part to off-cycle injection timing strategies, which are discussed in more detail when the Transient and Cruise modes are compared below. For PM, at 56,000 lbs, there is also a trend between the Cruise mode and UDDS, as shown in Figure 9, but scatter is considerable, and two trucks have PM levels differing by a factor of six on the Cruise mode, while their levels are almost identical on the UDDS. The UDDS is more transient in nature than the Cruise mode, and it is likely that the truck with low Cruise mode emissions but high UDDS emissions was producing PM primarily during transient accelerations, as elemental carbon "puff." 


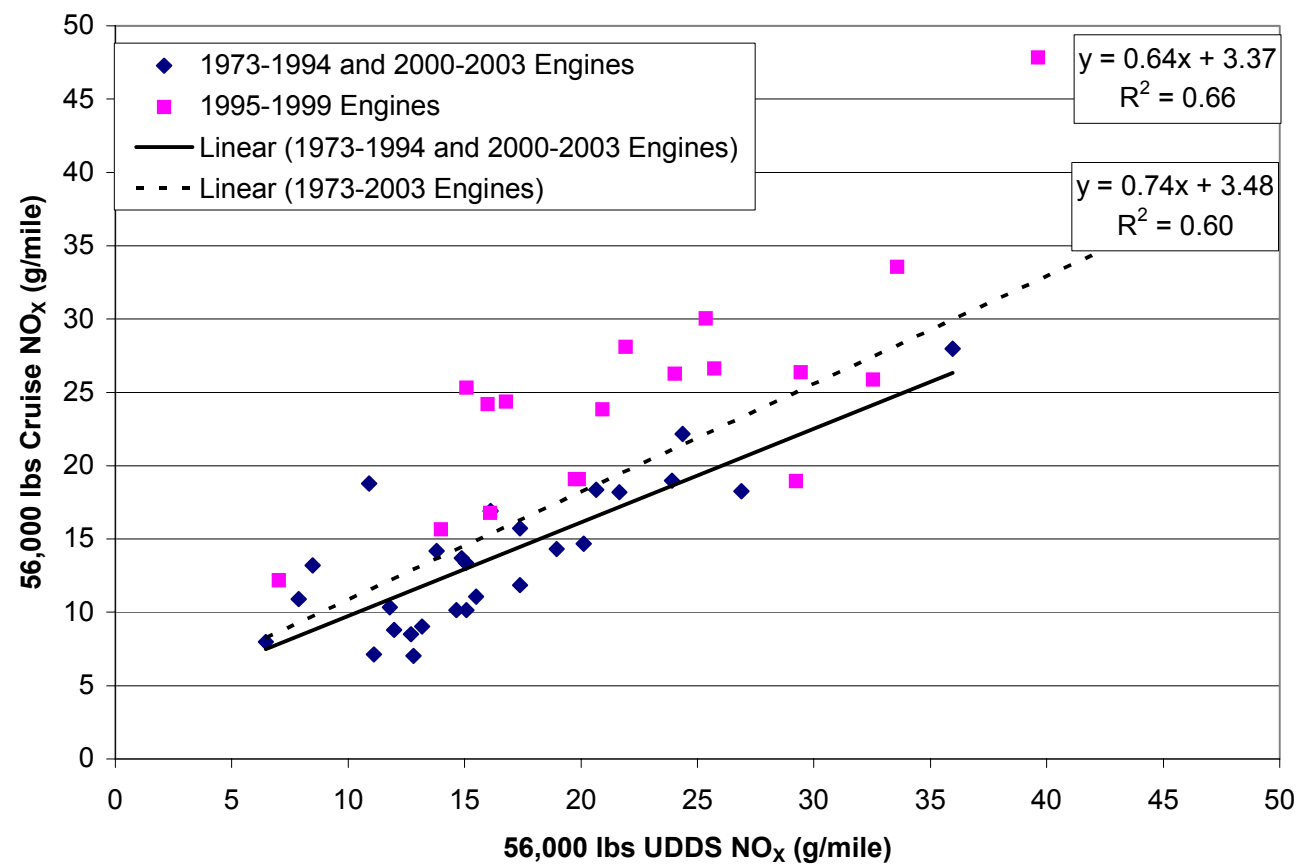

Figure 8: Average $\mathrm{NO}_{\mathrm{X}}$ on UDDS versus Cruise mode

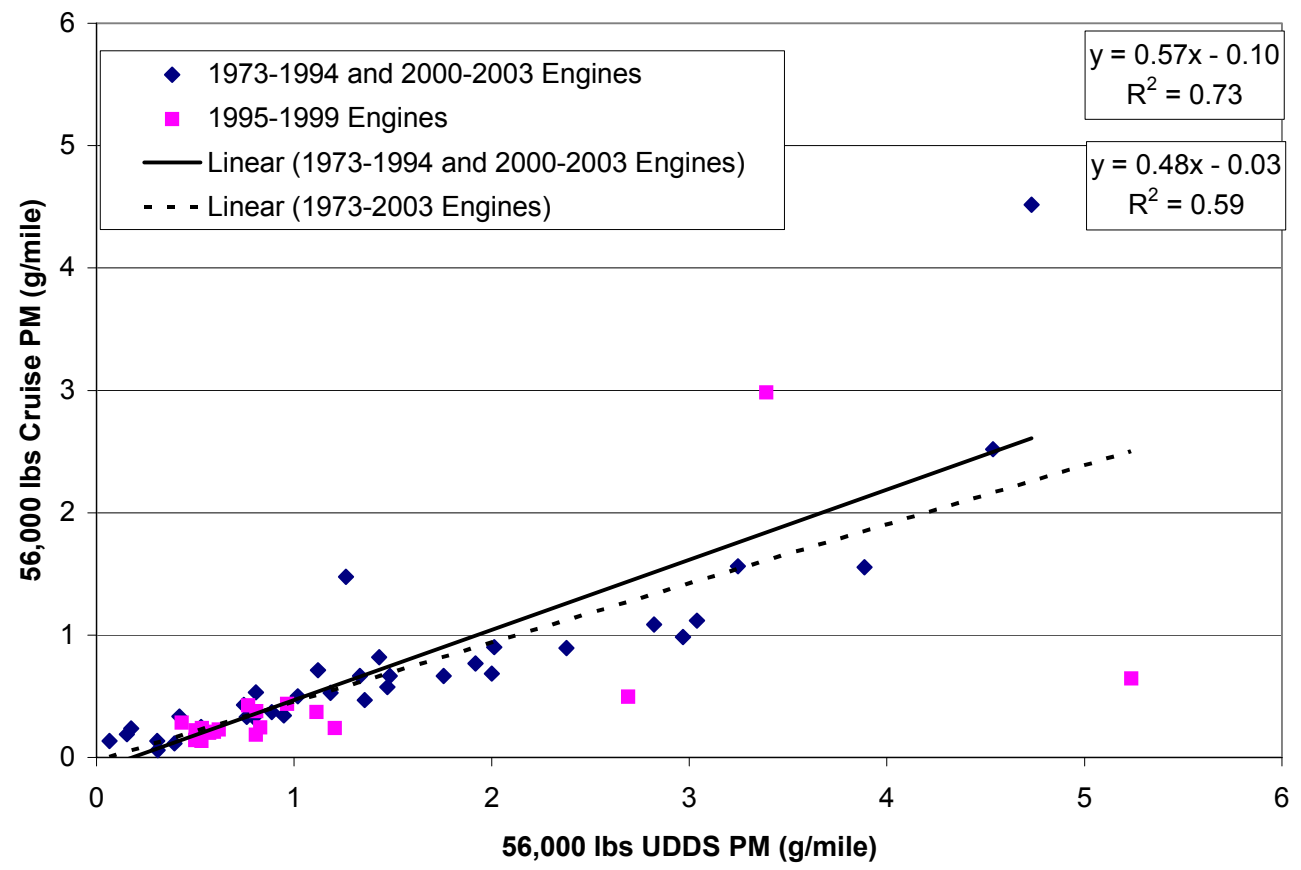

Figure 9: Average PM on UDDS versus Cruise mode 


\subsubsection{CORRELATION OF CRUISE MODE VERSUS TRANSIENT MODE}

Figure 10 compares the $\mathrm{NO}_{\mathrm{X}}$ emissions at a test weight of 56,000 lbs. The Cruise mode versus Transient mode, scatter is greater than for the Cruise mode versus UDDS comparison. Points that lie far above the best fit line in Figure 10 correspond to vehicles with electronically managed engines, primarily in the 1995-1999 model year range. For these vehicles, it was common practice to advance the timing of injection at steady cruise in order to improve fuel economy by a few percent. However, the result of the advanced timing was a substantial rise in $\mathrm{NO}_{\mathrm{X}}$ emissions. Earlier model year vehicles, being mechanically injected, did not have the facility to advance the timing in this way, and the practice of advancing the timing has been carefully controlled through regulation for late model year vehicles. When advanced timing was employed, the onset of the timing change and the degree of advance varied between manufacturers and even engine models, so that the additional $\mathrm{NO}_{\mathrm{X}}$ generated is difficult to quantify a priori. The data in Figure 10 therefore suggest that it is impractical to attempt to predict Cruise mode emissions from Transient mode data, and vice versa, for the case of $\mathrm{NO}_{\mathrm{X}}$. To confirm this timing effect, the authors plotted the distance specific $\mathrm{CO}_{2}$ emissions for the Cruise mode against those for the Transient mode in Figure 11. $\mathrm{CO}_{2}$ closely represents the quantity of fuel burned, and varies very little with timing change. In Figure 10, the average error in predicting the Cruise $\mathrm{NO}_{\mathrm{X}}$ was $14.58 \%$, while in Figure 11 the average error of prediction for $\mathrm{CO}_{2}$ was $11.07 \%$. The correlation is superior to that for $\mathrm{NO}_{\mathrm{X}}$ shown in Figure 10, which implies that the fuel specific $\mathrm{NO}_{\mathrm{X}}$ varied in Figure 10 due to timing. 


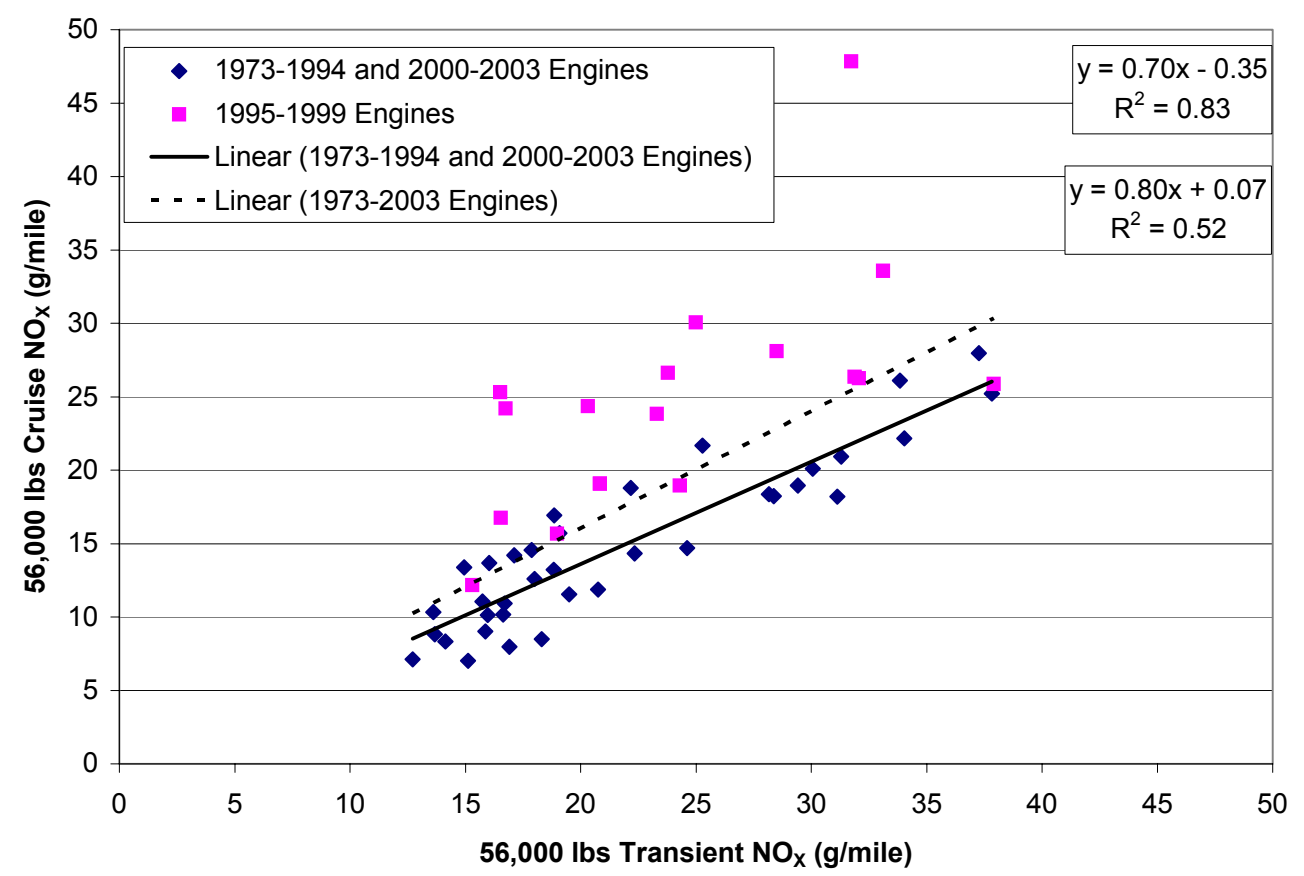

Figure 10: Average $\mathrm{NO}_{\mathrm{X}}$ on Transient mode versus Cruise mode

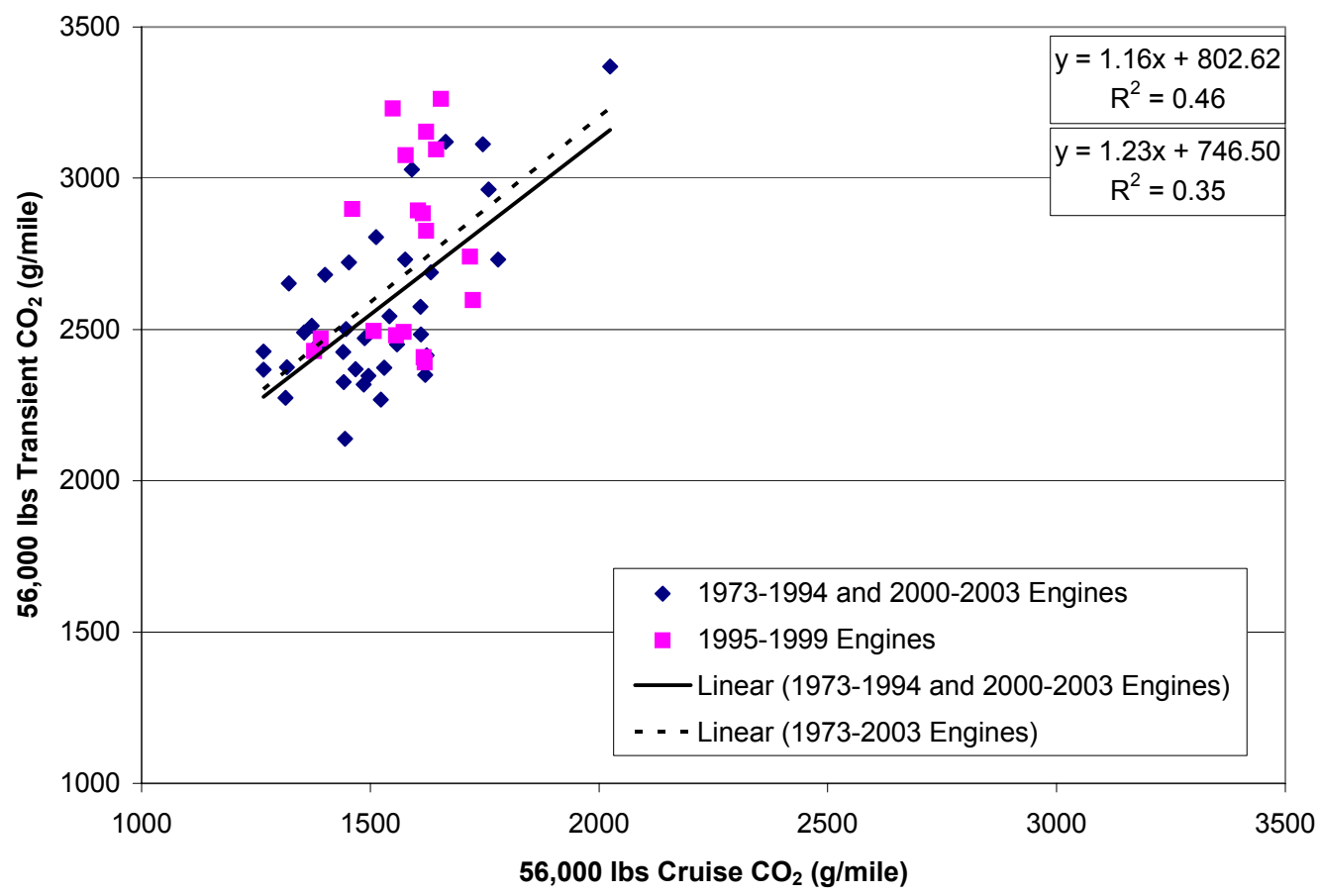

Figure 11: Average $\mathrm{CO}_{2}$ on Cruise mode versus Transient mode 
PM data at a test weight of 56,000 lbs for the Cruise mode are compared with data for the Transient mode in Figure 12. The Transient mode has a range of values up to $17 \mathrm{~g} /$ mile whereas the Cruise mode has no values higher than $5 \mathrm{~g} / \mathrm{mile}$. This can be attributed to two causes. First, the Transient mode is more energy intensive over a given distance, as shown by the $\mathrm{CO}_{2}$ data presented in Figure 11, and, all else being equal; one would expect PM to rise in sympathy with fuel consumed. Secondly, the Transient mode by definition is more transient than the Cruise mode, leading to the extra "puff" PM discussed above in the Cruise mode-UDDS comparison.

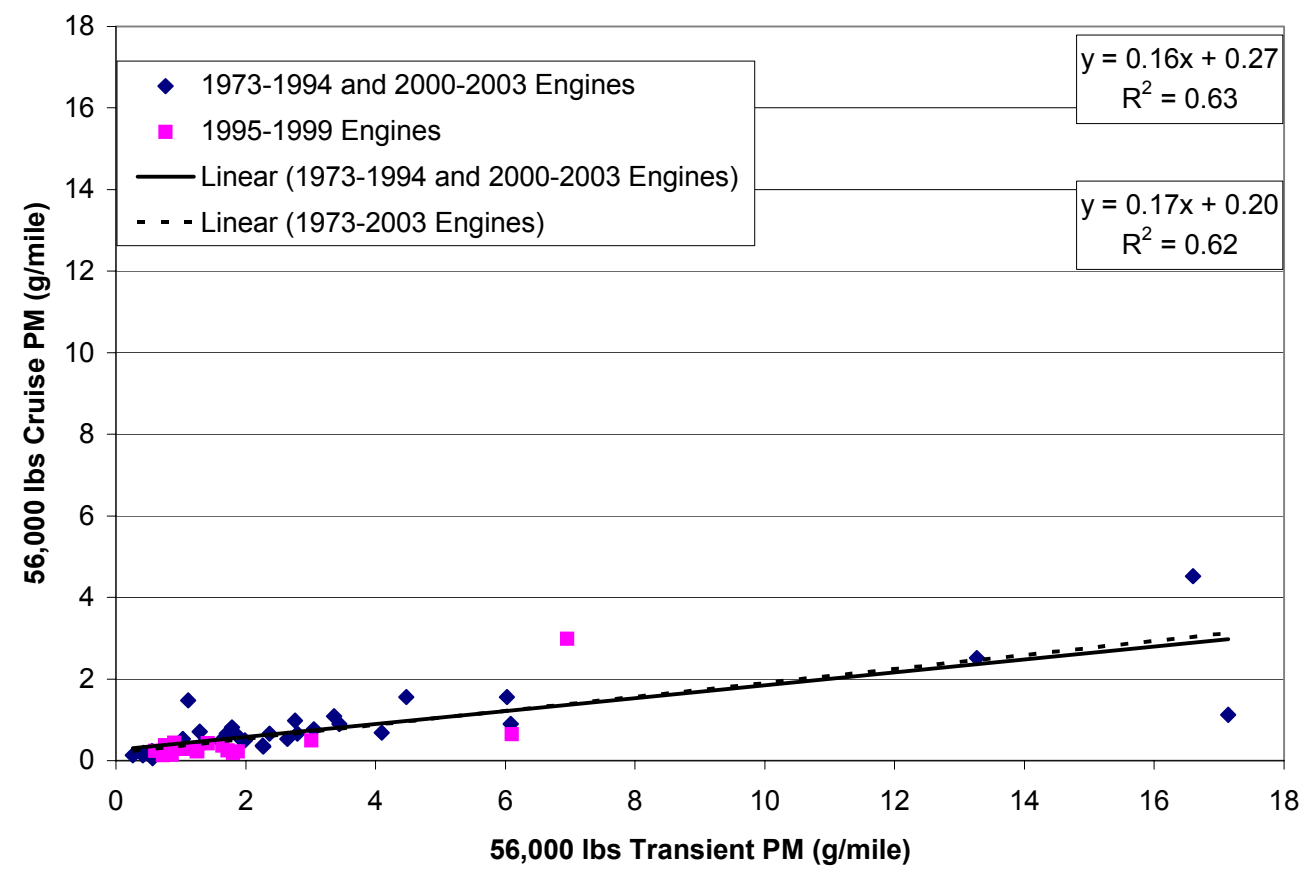

Figure 12: Average PM on Transient mode versus Cruise mode

\subsubsection{CORRELATION OF TRANSIENT MODE VERSUS UDDS}

In Figure 13, the UDDS and Transient Mode are compared for 56,000 lbs test weight. The correlation between the two is only slightly better than the UDDS versus Cruise mode comparison. The UDDS lies between the Cruise and Transient modes in vehicle behavior, and Figure 15 confirms this. 


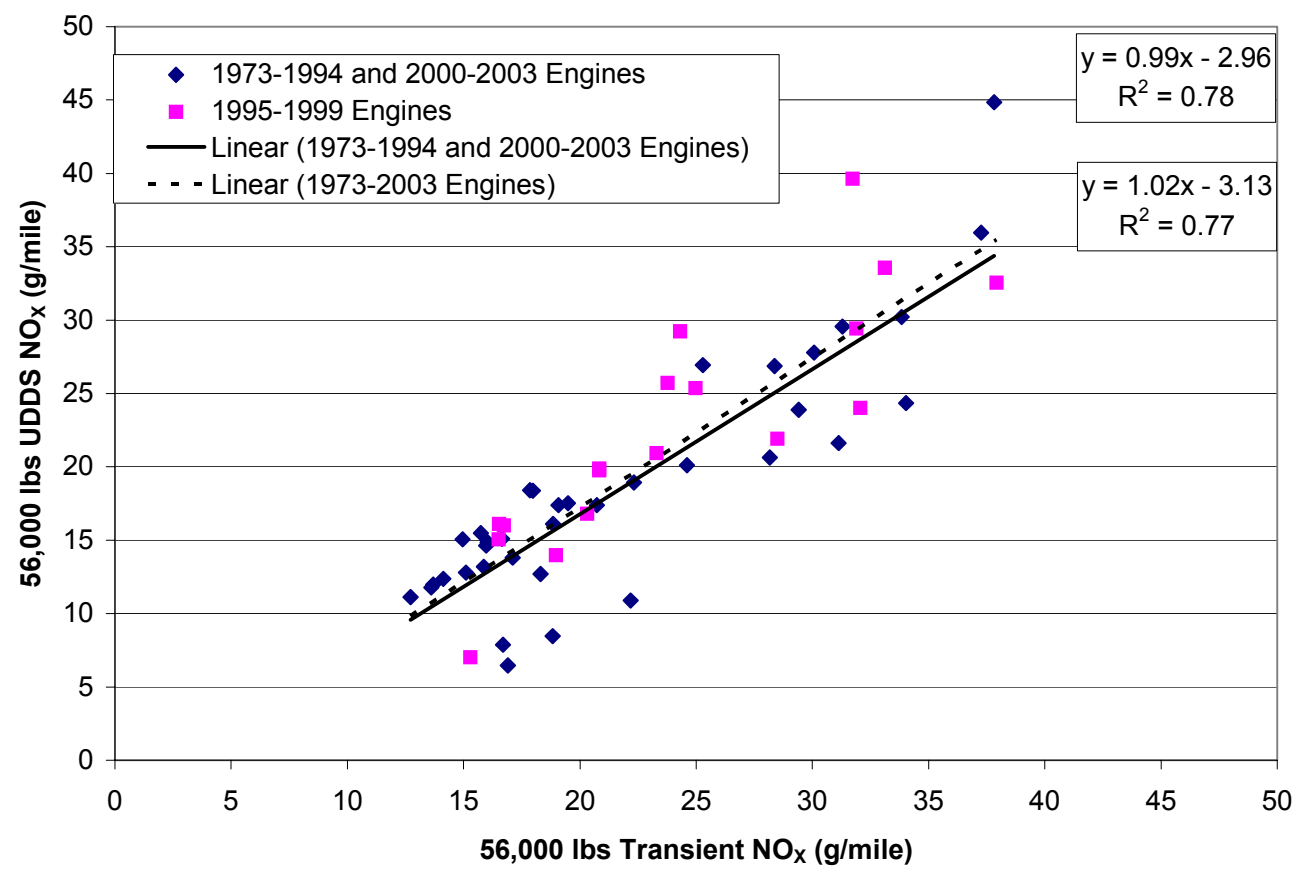

Figure 13: Average $\mathrm{NO}_{\mathrm{X}}$ on Transient mode versus UDDS

On the other hand, the PM relationship for Transient mode versus UDDS shows a similar quality of prediction as compared to the UDDS versus Cruise mode correlation. This can be seen by comparing Figure 14 and Figure 9.

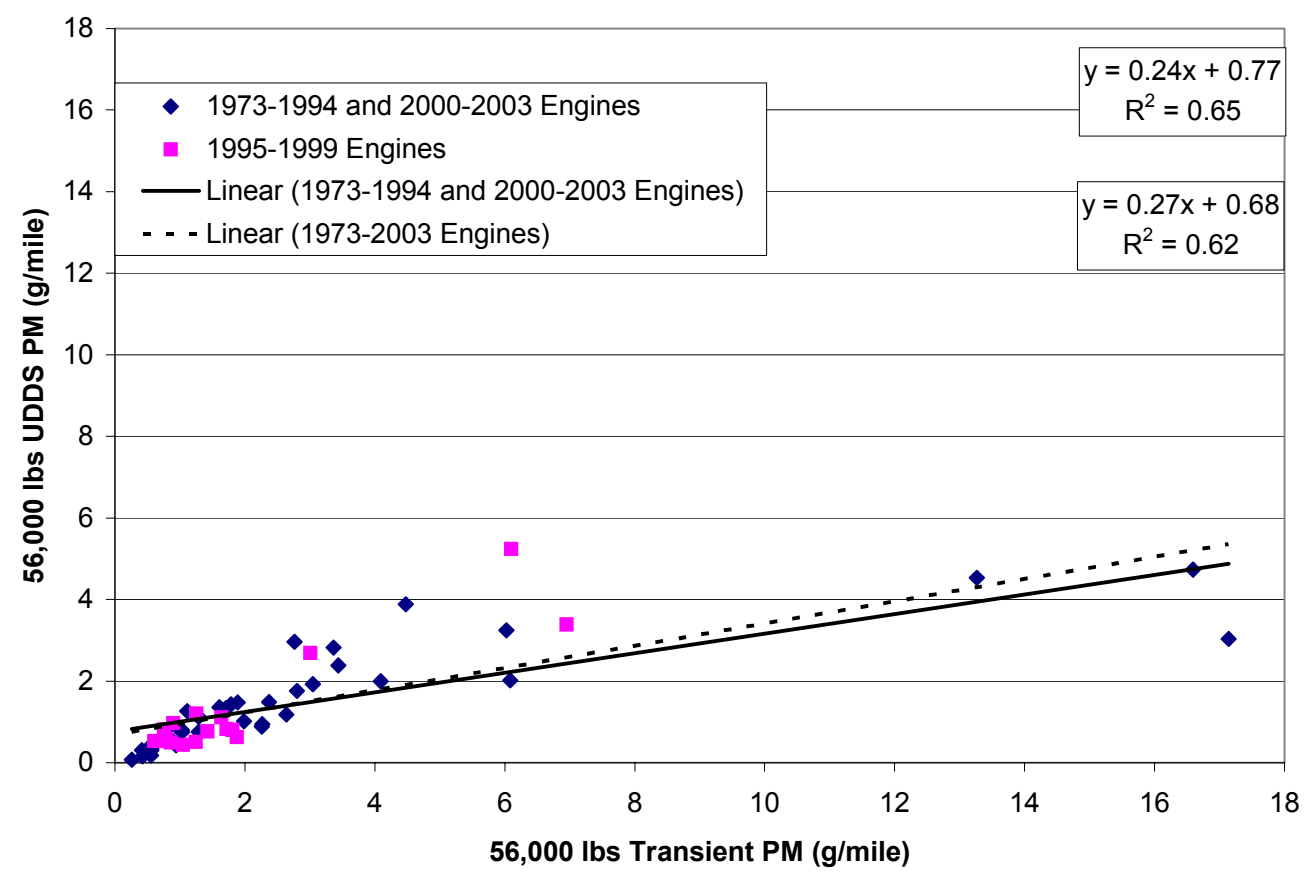

Figure 14: Average PM on Transient mode versus UDDS 


\subsubsection{CORRELATION OF AVERAGE OF TRANSIENT MODE AND CRUISE MODE VERSUS UDDS}

Figure 15 plots the $\mathrm{NO}_{\mathrm{X}}$ emissions on the UDDS against the simple average of the distancespecific emissions for the Transient and Cruise modes, and yields a useful correlation, although it is not substantially better than prediction using Transient mode alone. This figure provides hope that $\mathrm{NO}_{\mathrm{X}}$ emissions can be predicted for a cycle if data from a sufficiently transient and from a sufficiently steady-state cycle are available, and is a step toward the philosophy presented by Taylor et al. [10].

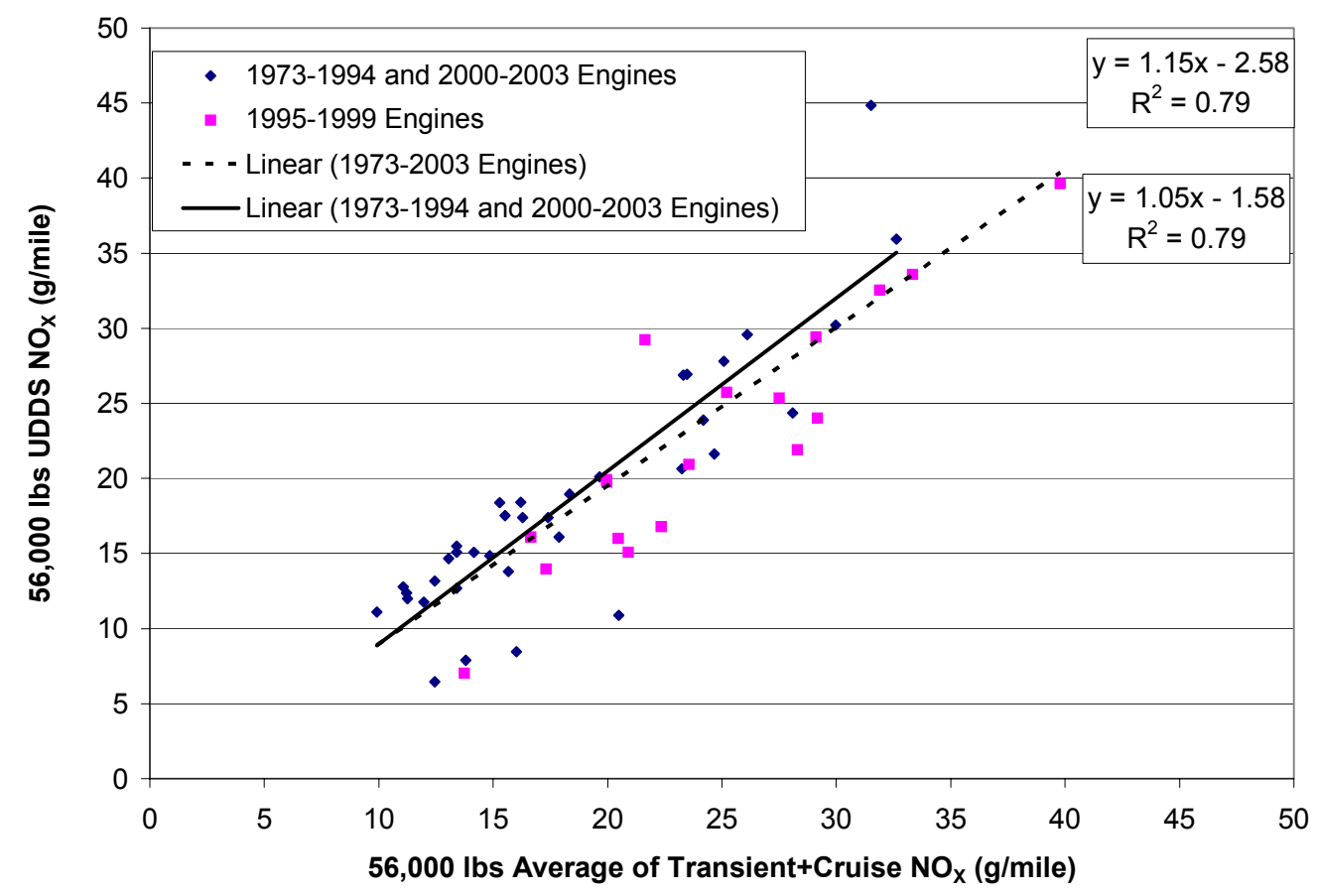

Figure 15: Average $\mathrm{NO}_{\mathrm{X}}$ on Transient mode and Cruise mode combined and averaged versus UDDS 


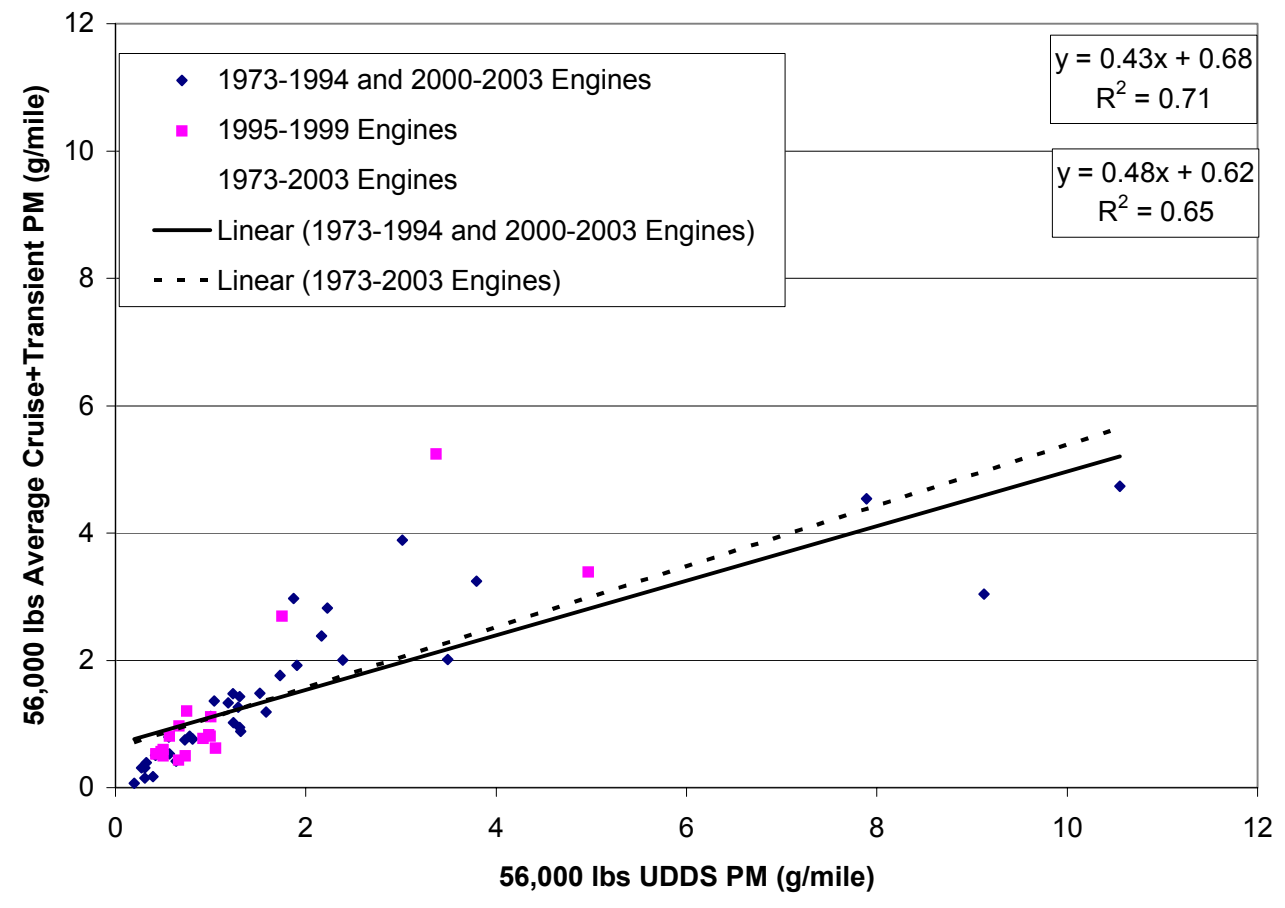

Figure 16: Average PM on Transient mode and Cruise mode combined and averaged versus UDDS

\subsubsection{CORRELATION OF AC5080 VERSUS OTHER CYCLES}

The AC5080 was used to predict emissions from the Cruise mode, Transient mode and UDDS, as shown in Figure 17 to Figure 22. Correlation coefficients were poor for prediction of Cruise mode $\mathrm{NO}_{X}$, UDDS $\mathrm{NO}_{\mathrm{X}}$ and Transient mode $\mathrm{NO}_{\mathrm{X}}$, although a visual relationship was evident. Although correlation coefficients were higher for the three PM cases, a single high PM point was a major contributor to the relationship, and substantial scatter was still evident at lower PM values. The AC5080 could be used to screen for high emitters, but did not prove to predict onroad emissions with high accuracy. 


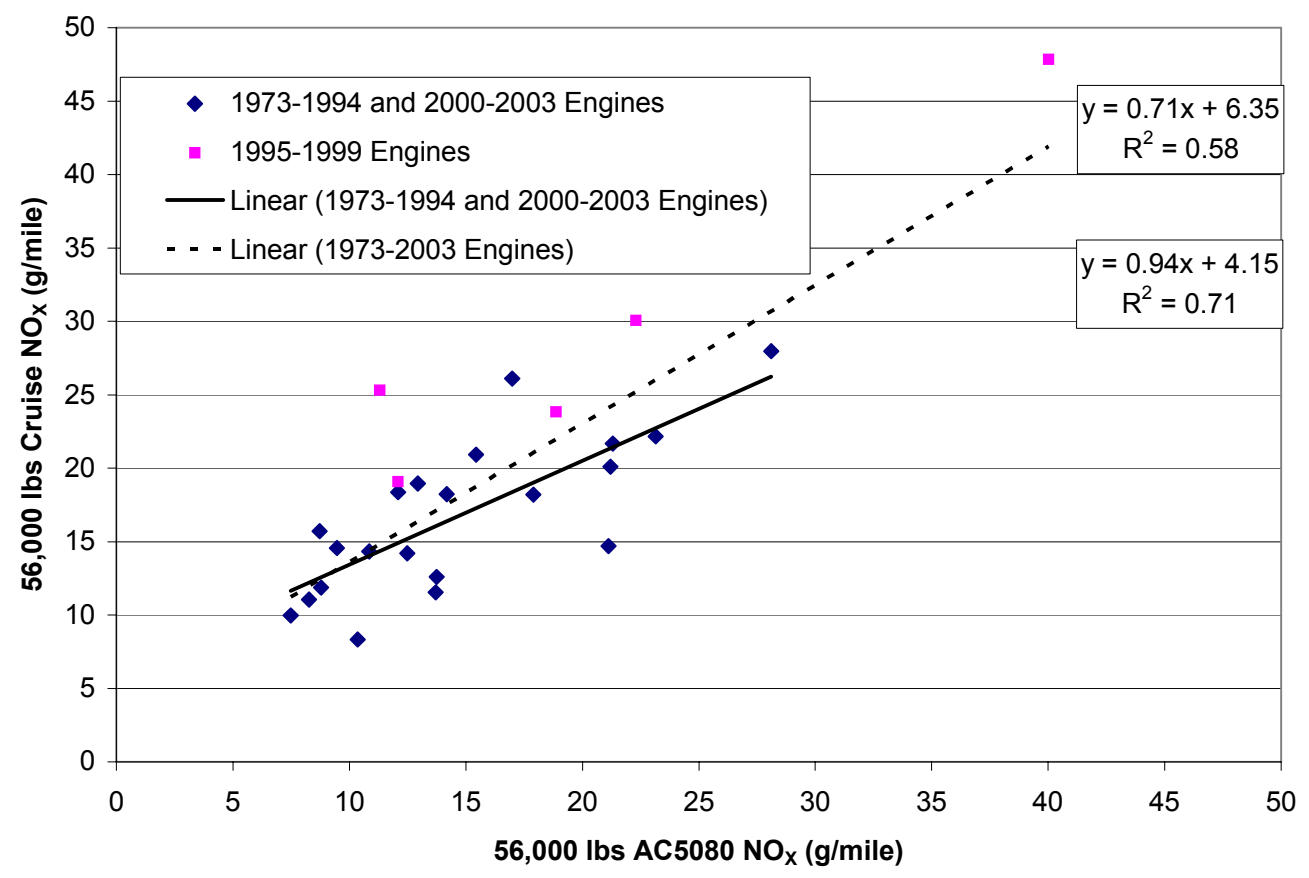

Figure 17: Average $\mathrm{NO}_{\mathrm{X}}$ on $\mathrm{AC} 5080$ versus Cruise mode

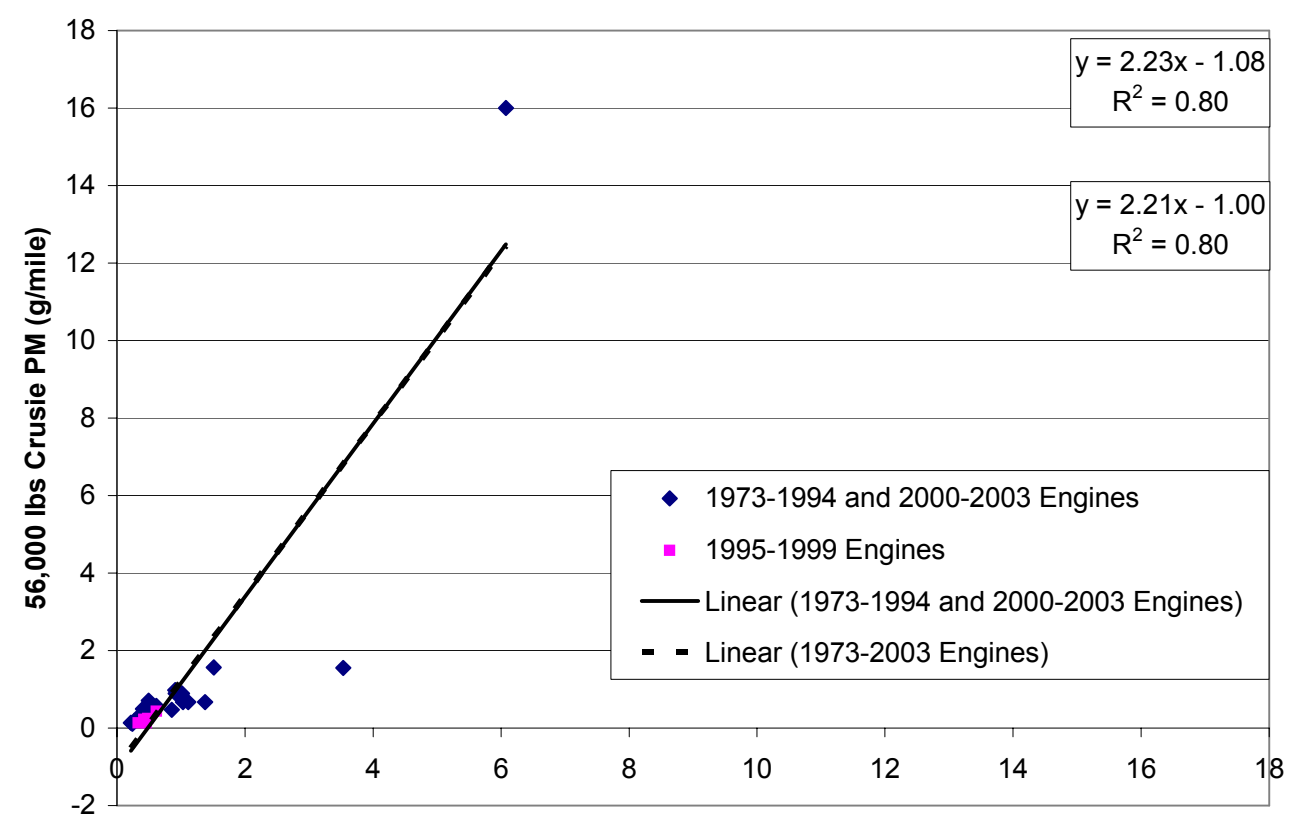

56,000 lbs AC5080 PM (g/mile)

Figure 18: Average PM on AC5080 versus Cruise mode 


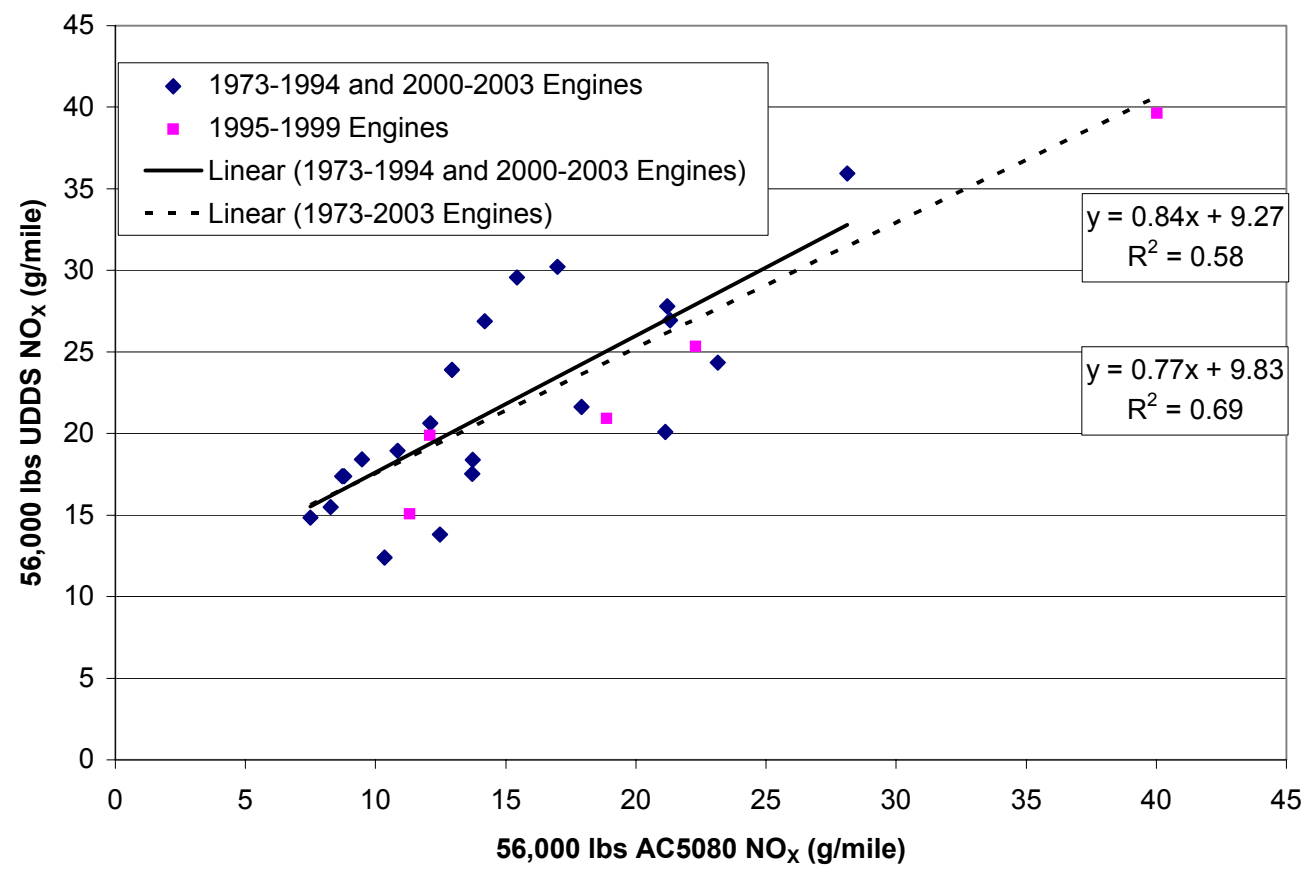

Figure 19: Average $\mathrm{NO}_{\mathrm{X}}$ on AC5080 versus UDDS

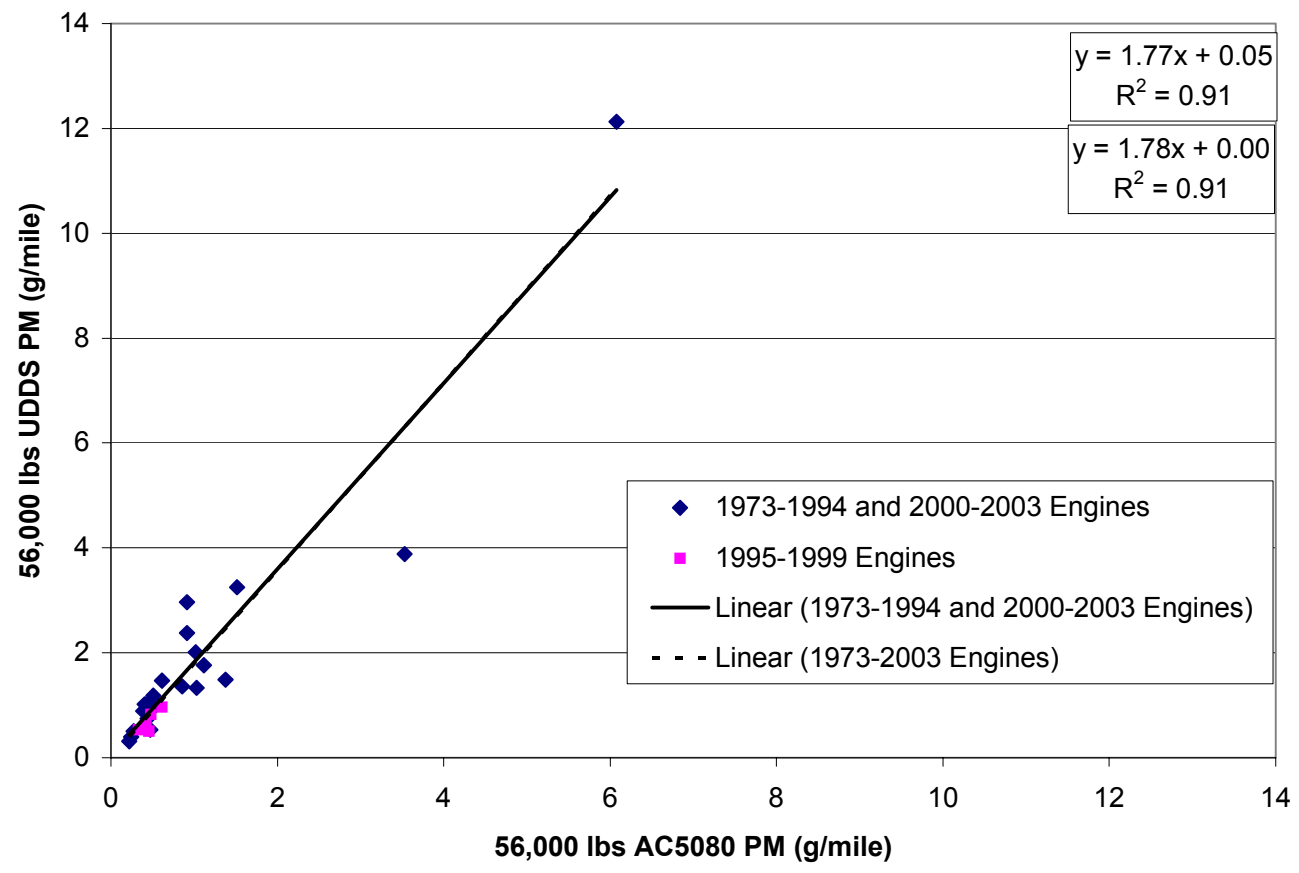

Figure 20: Average PM on AC5080 versus UDDS 


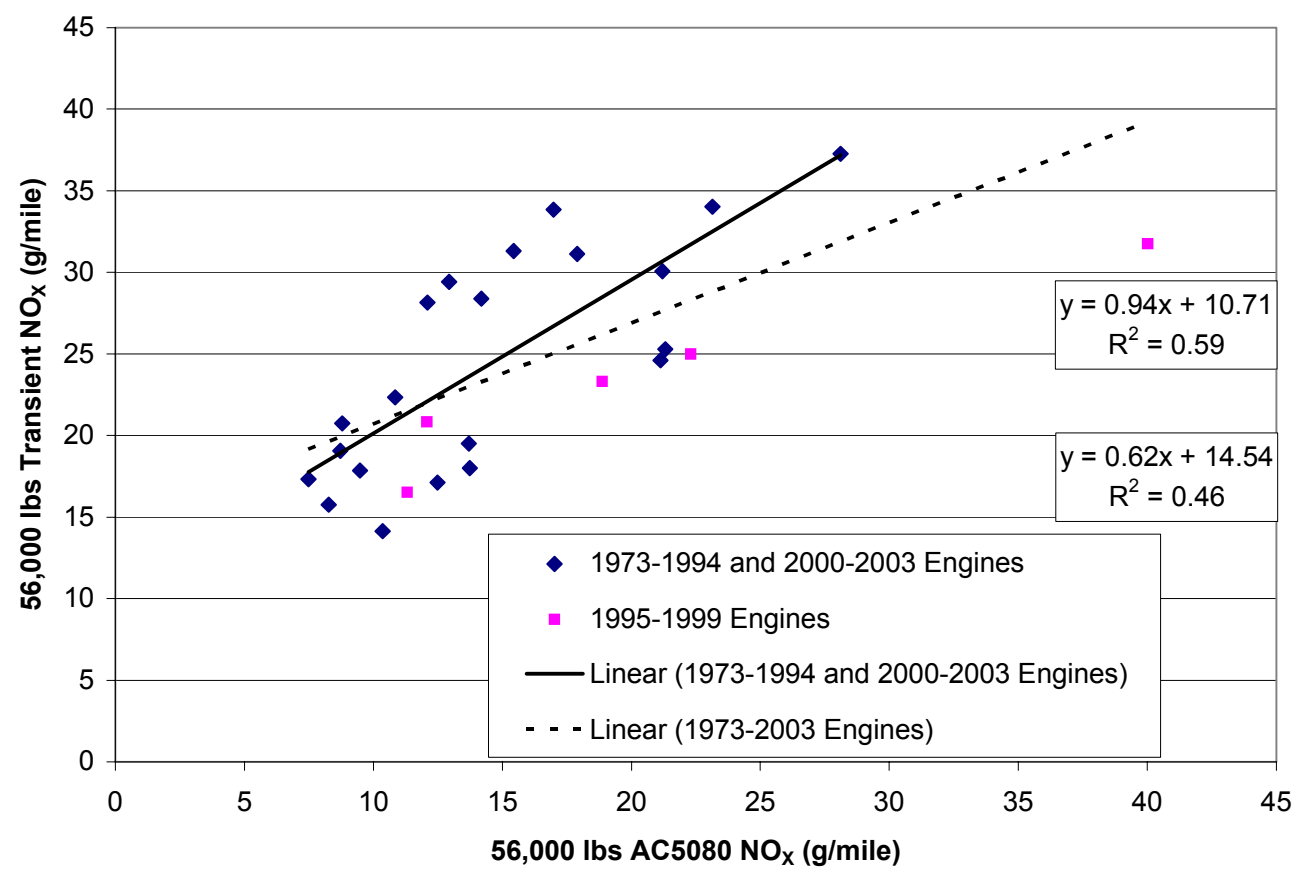

Figure 21: Average $\mathrm{NO}_{\mathrm{X}}$ on AC5080 versus Transient mode

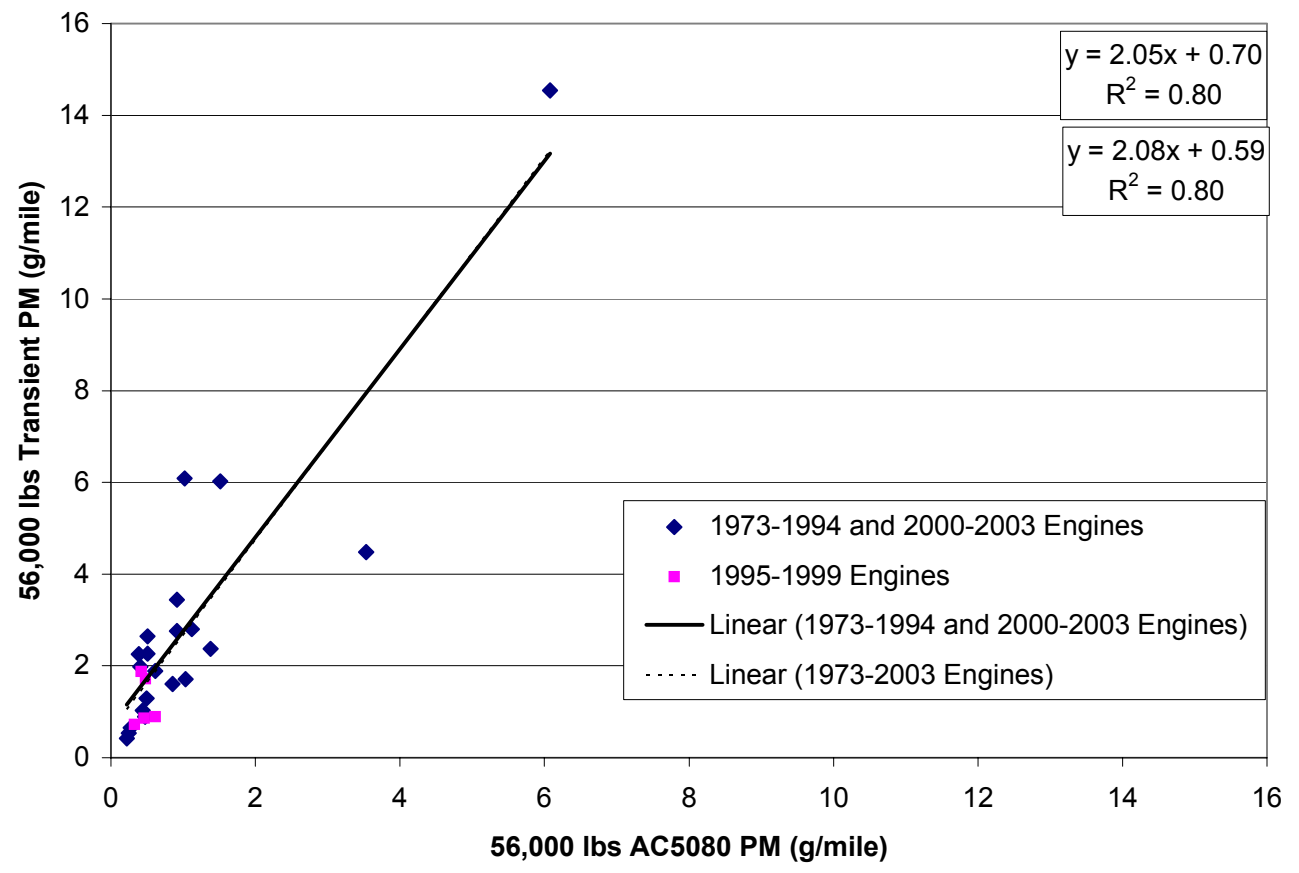

Figure 22: Average PM on AC5080 versus Transient mode 


\subsection{EFFECTS OF WEIGHT}

\subsubsection{CORRELATION OF CRUISE MODE VERSUS TRANSIENT MODE AT 30,000 LBS}

The Cruise mode and Transient mode were also compared at 30,000 lbs test weight. Figure 23 shows the resulting plot, with the model years 1995-1999 separated using a different symbol. The high $\mathrm{NO}_{\mathrm{X}}$ emissions for this group of vehicles are even more evident than for the 56,000 lbs test case, shown in Figure 10. To demonstrate further that the correlation of the cycles was thwarted by off-cycle injection timing, the ratio of $\mathrm{NO}_{\mathrm{X}}$ emissions on the Cruise mode to $\mathrm{NO}_{\mathrm{X}}$ emissions on the Transient mode has been plotted against vehicle model year in Figure 24. Also, the $\mathrm{NO}_{\mathrm{X}} / \mathrm{CO}_{2}$ ratio has been plotted in Figure 25. Figure 24 and Figure 25 show the high ratios arising in the span of model years associated most strongly with the off-cycle phenomenon. Outside of these years, correlation of the Cruise mode and Transient mode is superior.

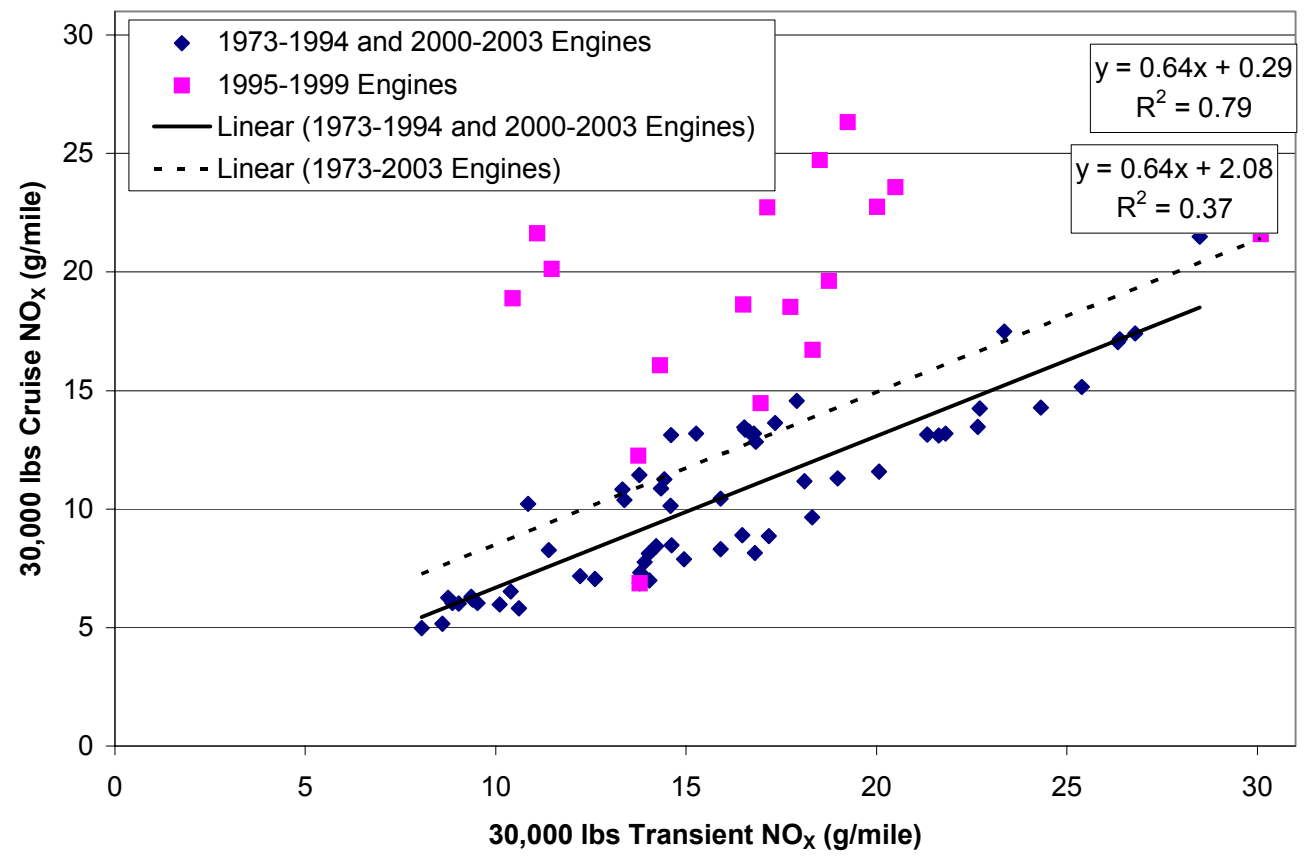

Figure 23: Average $\mathrm{NO}_{\mathrm{X}}$ on Transient mode versus Cruise mode for $30,000 \mathrm{lbs}$ vehicles 


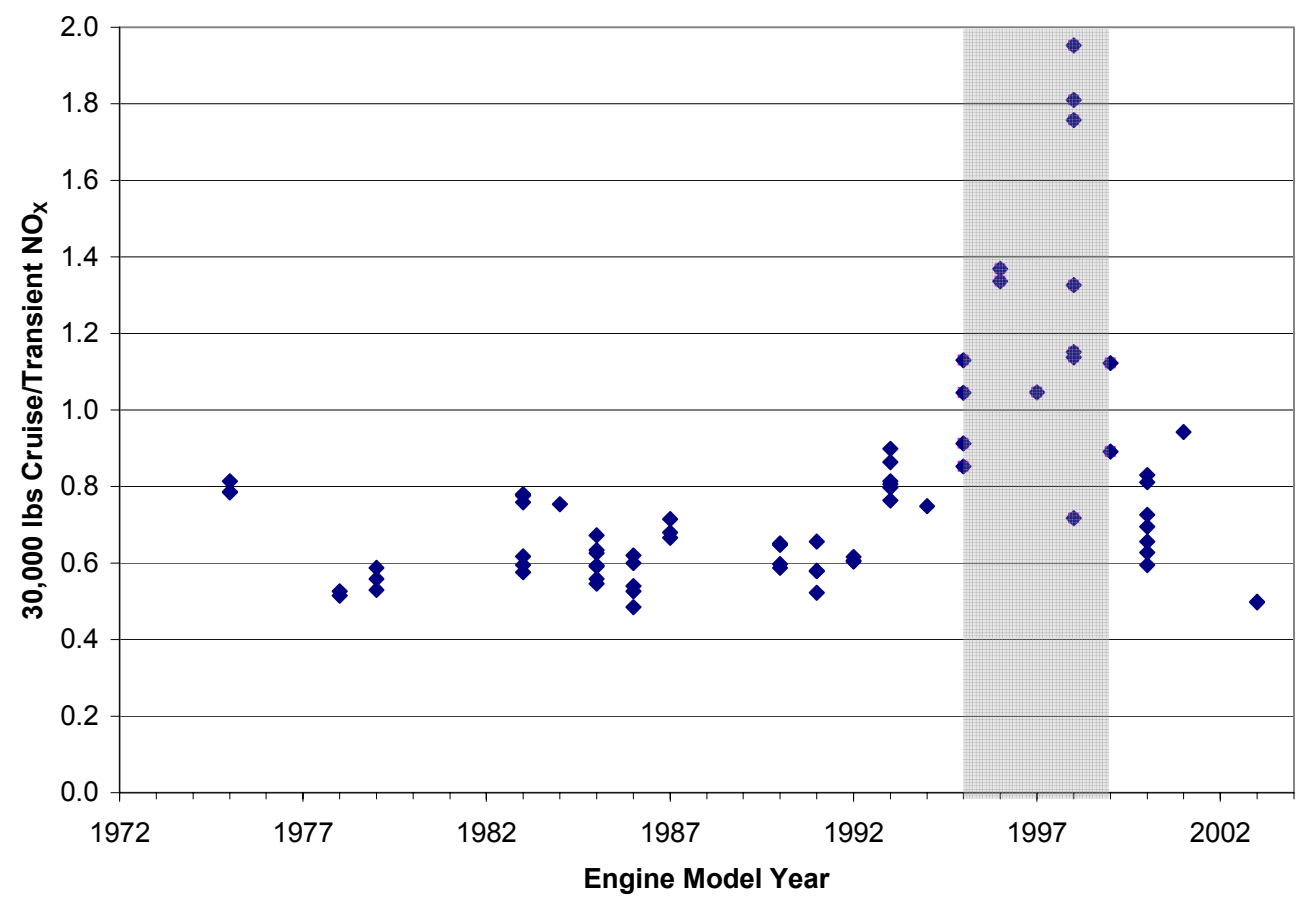

Figure 24: Cruise mode to Transient mode $\mathrm{NO}_{\mathrm{X}}$ ratio as a function of engine model year

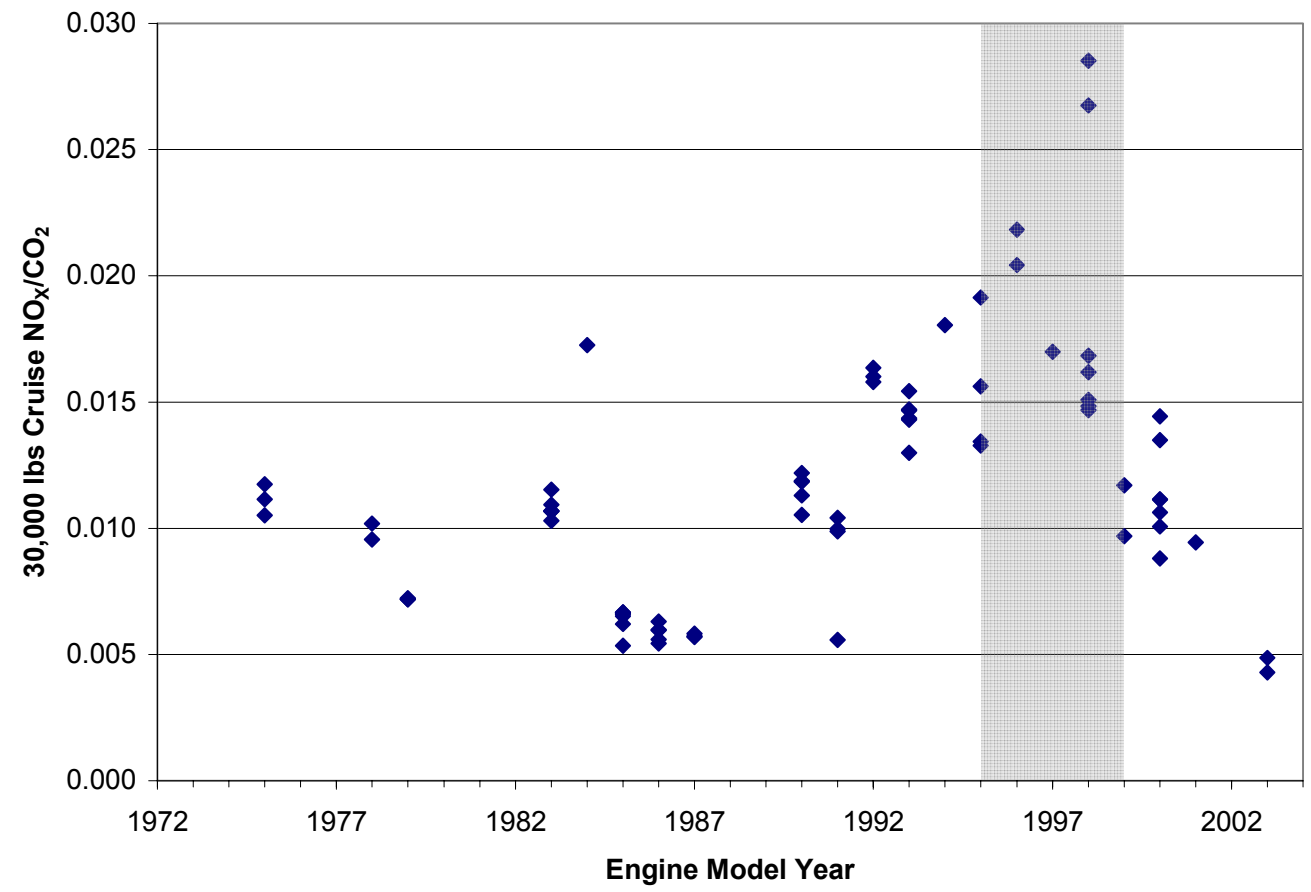

Figure 25: Cruise mode $\mathrm{NO}_{\mathrm{X}} / \mathrm{CO}_{2}$ ratio as a function of engine model year

The PM from the Cruise mode varied with the PM from the Transient mode in a similar fashion for 30,000 lbs test weight and 56,000 lbs test weight, as shown in Figure 26 and Figure 12, respectively. The comparison of PM emissions, and the extent to which they arise from transient 
behavior is also summarized in Table 3, which shows that for the 56,000 lbs case, the UDDS yields about twice the emissions on average as the Cruise mode. The Transient mode elicits about five times the Cruise mode emissions, on a distance specific basis. If the emissions are considered in fuel specific or energy specific units, the result is more indicative of the effect of transient control strategy, and the effects of braking and acceleration (in an energy sense) are excluded. Table 3 also reflects these data.

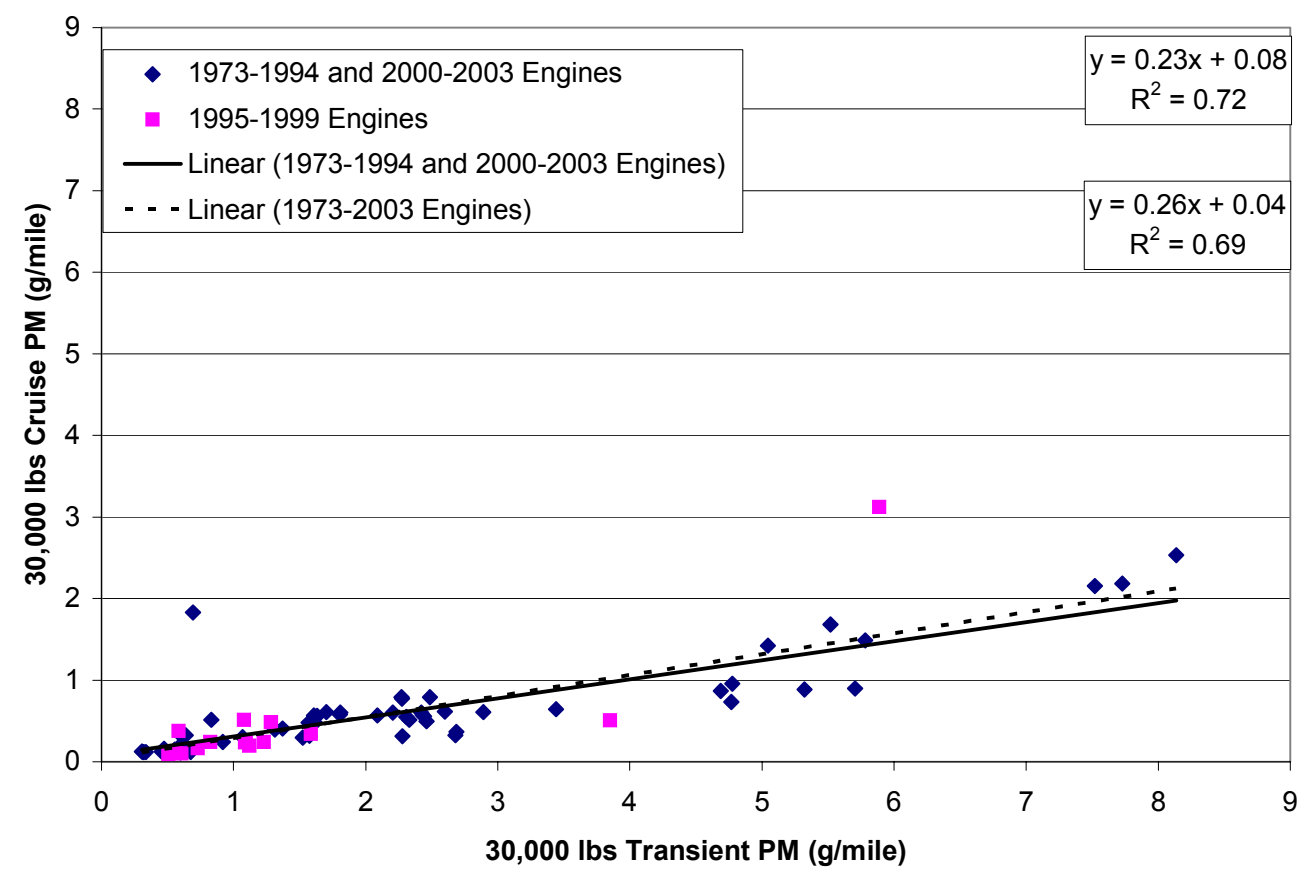

Figure 26: Average PM on Transient mode versus Cruise mode for 30,000 lbs vehicle

\subsubsection{CORRELATION OF CRUISE MODE VERSUS TRANSIENT MODE FOR 66,000 LBS VEHICLES}

Figure 27 and Figure 28 show the relation between the Cruise mode and Transient mode for 66,000 lbs vehicles for $\mathrm{NO}_{\mathrm{X}}$ and $\mathrm{PM}$ respectively. The $\mathrm{NO}_{\mathrm{X}}$ relation for the two modes shows a reasonable predictive correlation, but the PM data have much scatter and shows a very poor correlation to use for a predictive analysis for PM. A detailed analysis on the effects of weight on each cycle is presented in Section 6. 


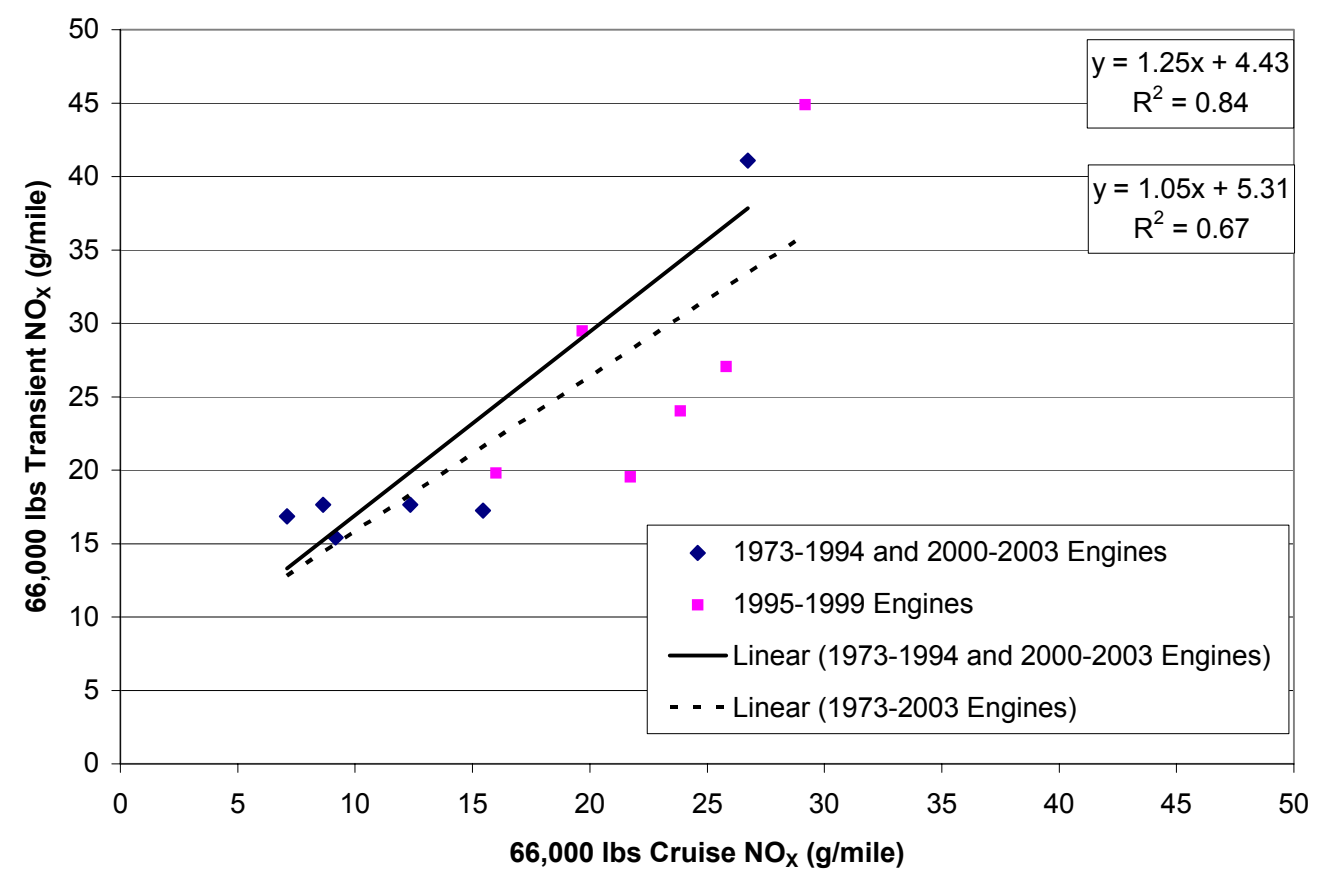

Figure 27: Average $\mathrm{NO}_{\mathrm{X}}$ on Cruise mode versus Transient mode for $66,000 \mathrm{lbs}$ vehicles

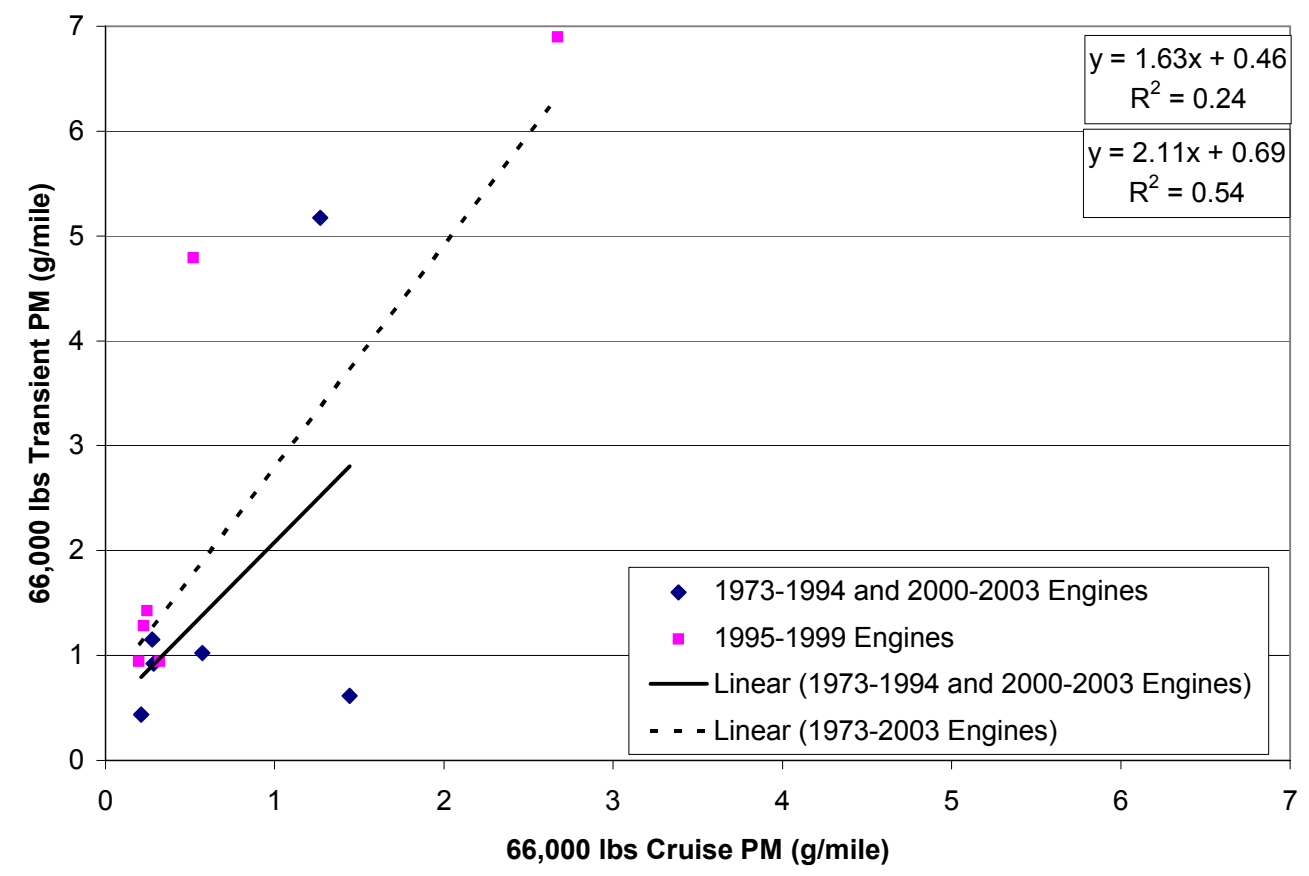

Figure 28: Average PM on Cruise mode versus Transient mode for 66,000 lbs vehicles

\subsection{RESULTS}

The equations resulting from linear regression of the comparative studies shown in Figure 8 to Figure 28 are summarized in Table 2. The equations highlighted in black are of results with fair 
correlation of $\mathrm{R}^{2}$ greater than 0.77 and the equation dotted and gray is of data with a very poor correlation. However, it has been acknowledged in this section that $\mathrm{R}^{2}$ is the sole measure of good fit, and that it may not represent the average error incurred in predicting emissions from one cycle from emissions on a different cycle. All the equations are derived from the emissions data for engine model years 1973-1994 and 2000-2003.

Table 3 gives the average fuel economy (mpg), ahp-hr/mile, and PM for the four modes in consideration. A coefficient is obtained by dividing these values. One such set of coefficients is the ratio of AC5080, Transient mode and UDDS in $\mathrm{g} / \mathrm{mile}$ to Cruise mode in $\mathrm{g} / \mathrm{mile}$. This table emphasizes the role of both schedule energy consumption and schedule transient content in producing PM emissions.

Table 2: Equation summary for linear regression lines for data on four cycles, three test weights and $\mathrm{NO}_{\mathrm{X}}$ and PM emissions

\begin{tabular}{|c|c|c|c|c|c|c|}
\hline \multirow[t]{12}{*}{$\mathrm{NO}_{\mathrm{X}}$} & \multicolumn{3}{|l|}{$56,000 \mathrm{lbs}$} & \multirow{2}{*}{$\begin{array}{l}\mathrm{y} \\
\text { Cruise }\end{array}$} & \multirow{2}{*}{$\begin{array}{l}\mathrm{x} \\
\text { UDDS }\end{array}$} & \multirow{2}{*}{$\begin{array}{l}\mathrm{R}^{2} \\
0.66\end{array}$} \\
\hline & $y=0.64$ & $\mathrm{x}$ & $\begin{array}{l}+3.37 \\
\end{array}$ & & & \\
\hline & $y=0.70$ & $x$ & - $\quad 0.35$ & Cruise & Trans & 0.83 \\
\hline & $\mathrm{y}=0.99$ & $\mathrm{x}$ & -2.96 & UDDS & Trans & 0.78 \\
\hline & $y=0.82$ & $\mathrm{X}$ & $\begin{array}{l}+\quad 0.91 \\
\end{array}$ & AC5080 & Cruise & 0.58 \\
\hline & $y=0.70$ & $\mathrm{x}$ & - $\quad 0.37$ & AC5080 & UDDS & 0.58 \\
\hline & $y=0.62$ & $\mathrm{x}$ & 0.56 & AC5080 & Trans & 0.59 \\
\hline & $y=0.69$ & $\mathrm{x}$ & $\begin{array}{l}+5.60 \\
\end{array}$ & $\mathrm{Tr}+\mathrm{Cr}$ & UDDS & 0.79 \\
\hline & $30,000 \mathrm{lbs}$ & & & & & \\
\hline & $y=0.64$ & $\mathrm{x}$ & $\begin{array}{r}+\quad 0.29 \\
\end{array}$ & Cruise & Trans & 0.79 \\
\hline & $66,000 \mathrm{lbs}$ & & & & & \\
\hline & $\mathrm{y}=0.80$ & $\mathrm{x}$ & 3.54 & Cruise & Trans & 0.84 \\
\hline
\end{tabular}

\begin{tabular}{|c|c|c|c|c|c|c|c|c|c|}
\hline \multirow[t]{12}{*}{$\mathrm{PM}$} & \multicolumn{6}{|c|}{$56,000 \mathrm{lbs}$} & \multirow{2}{*}{$\begin{array}{l}\mathrm{y} \\
\text { Cruise }\end{array}$} & \multirow{2}{*}{$\begin{array}{l}\mathrm{x} \\
\text { UDDS }\end{array}$} & \multirow{2}{*}{$\frac{\mathrm{R}^{2}}{0.73}$} \\
\hline & $y$ & $=$ & 0.57 & $\mathrm{x}$ & - & 0.10 & & & \\
\hline & $\mathrm{y}$ & $=$ & 0.16 & $\mathrm{X}$ & . & 0.27 & Cruise & Trans & 0.63 \\
\hline & $\mathrm{y}$ & $=$ & 0.24 & $X$ & - & 0.77 & UDDS & Trans & 0.65 \\
\hline & $\mathrm{y}$ & $=$ & 0.36 & $X$ & - & 0.61 & AC5080 & Cruise & 0.8 \\
\hline & $\mathrm{y}$ & $=$ & 0.51 & $\mathrm{x}$ & 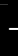 & 0.08 & AC5080 & UDDS & 0.91 \\
\hline & $\mathrm{y}$ & $=$ & 0.39 & $\mathrm{x}$ & - & 0.05 & AC5080 & Trans & 0.8 \\
\hline & & $=$ & 1.65 & $\mathrm{x}$ & - & 0.55 & $\mathrm{Tr}+\mathrm{Cr}$ & UDDS & 0.71 \\
\hline & \multicolumn{6}{|c|}{$30,000 \mathrm{lbs}$} & & & \\
\hline & & $=$ & 0.23 & $\mathrm{X}$ & 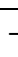 & 0.08 & Cruise & Trans & 0.72 \\
\hline & \multicolumn{6}{|c|}{$66,000 \mathrm{lbs}$} & & & \\
\hline & $\mathrm{y}$ & $=$ & 0.47 & $\mathrm{X}$ & - & 0.22 & Cruise & Trans & 0.24 \\
\hline
\end{tabular}


Table 3: Average 56,000 lbs vehicle data without engine model years 1995-1999

\begin{tabular}{|c|c|c|}
\hline & CruiseUDDS & Trans:AC5080 \\
\hline $\mathrm{mpg}$ & $6.62 \quad 4.52$ & $3.91 \quad 5.75$ \\
\hline ahp-hr / mile & $1.97 \quad 2.82$ & $3.08 \quad 2.29$ \\
\hline $\mathrm{PM}(\mathrm{g} / \mathrm{mile})$ & $1.45 \quad 2.51$ & $3.69: 1.41$ \\
\hline $\mathrm{PM}$ (g/gallon) & $8.81 \quad 11.20$ & 14.147 .89 \\
\hline $\mathrm{PM}$ (g/ahp-hr) & 0.730 .93 & $1.22 \quad 0.61$ \\
\hline PM / Cruise-PM (g/mile) & $1.00 \quad 1.73$ & 2.550 .97 \\
\hline $\mathrm{PM} /$ Cruise-PM (g/gallon) & $1.00 \quad 1.27$ & 1.610 .90 \\
\hline $\mathrm{PM} /$ Cruise-PM (g/ahp-hr) & $1.00 \quad 1.27$ & $1.68 \quad 0.84$ \\
\hline
\end{tabular}

\subsection{CONCLUSIONS}

Distance specific emissions of $\mathrm{NO}_{\mathrm{X}}$ and $\mathrm{PM}$ have been compared when the vehicle is exercised through different test modes or schedules. The axle energy required per mile traveled is greater for the Transient mode than the UDDS, which in turn is greater than for the Cruise mode. If brake-specific emissions were constant, one would expect the emissions from these two modes and the UDDS to fall in the same order. However, for $\mathrm{NO}_{\mathrm{X}}$, emissions are highest in the Cruise mode for certain model years (mainly 1995 to 1999) due to timing strategies. For PM, emissions are highest for the Transient mode, not only due to energy requirements, but also due to the production of PM "puff" due to transient behavior. For PM, the UDDS lay between the Transient mode and Cruise mode. In general, the transient production of PM and the presence of off-cycle timing made it difficult to predict emissions on one cycle from emissions on only one other cycle. However, UDDS $\mathrm{NO}_{\mathrm{X}}$ emissions were reasonably predicted when the average of Cruise mode and Transient mode $\mathrm{NO}_{\mathrm{X}}$ data were used. The AC5080 test proved able to screen for very high emitters, but did not predict the emissions from the UDDS, Transient mode and Cruise mode very closely. For $\mathrm{NO}_{\mathrm{X}}$, correlations with the 1995 to 1999 model year vehicles excluded from the database were superior in accuracy because the off-cycle $\mathrm{NO}_{\mathrm{X}}$ phenomenon was avoided. 


\section{Two-Dimensional Correlation Using Linear Regression of PM and NOx for Heavy-Duty Diesel Vehicles}

\subsection{INTRODUCTION}

Recently, the relationship between distance-specific emissions on different test schedules [5] was examined. In Section 4, relationships were calculated with only one dependent and one independent variable and only cycle-averaged emissions were examined. This was done using one-dimensional linear regression.

It was found during the one-dimensional study [Section 4] and during the study of diesel emissions prediction from dissimilar cycles [10] that superior correlation could be found by using more than one test cycle for purposes of prediction. The accuracy of predicting both PM and $\mathrm{NO}_{\mathrm{X}}$ emissions on one cycle using $\mathrm{PM}$ and $\mathrm{NO}_{\mathrm{X}}$ emissions values from two other cycles, for a wider variety of cases is examined in this section. In all cases the emissions are expressed in units of $\mathrm{g} / \mathrm{mile}$ below, and the analysis was not extended to fuel-specific correlations. This analysis will use two-dimensional linear regression.

Since PM is affected only slightly by these timing changes, only the whole data set was used for PM emissions rate prediction.

\subsection{VEHICLES AND CYCLES}

The data used in this section came from Phases 1 and 1.5 of the E-55/59 program [10,11]. The trucks considered for analysis in this section were E55CRC-01 - E55CRC-49, the same HHDDT and emissions data used for the analysis in Section 4. Vora et al. [5] have described the various cycles used for this analysis, viz. UDDS, Transient mode (of the 5-Mode HHDDT), Cruise mode (of the 5-Mode HHDDT) and the AC5080.

\subsection{METHOD}

The distance-specific data were processed using a multidimensional linearization algorithm in Matlab $^{\circledR}$. For each calculation, the predictive variable was held constant and the measured variables were linearized to find a best-fit plane of predictability. This linearization used the "least square" norms to develop a best fit. The error was minimized for the predicted variable. 
If the equation was rearranged and the errors were minimized for a different variable, then a different equation would be found. In other words, the best correlation for predicting the UDDS emissions from the Transient and Cruise modes emissions, if rearranged, would differ from the best correlation for predicting the Cruise mode emissions from the UDDS and Transient mode emissions.

Errors may be calculated for a variety of formats. Different error calculations stress outliers differently to provide varying sensitivity to points that are very poorly predicted. These equations are explained below.

\section{Equation 3}

Error $=\mid$ Predicted - Measured $\mid$

\section{Equation 4}

Max Error $=\max ($ Errors in Prediction Matrix $)$

Equation 5

Sqrt Sum of Square Error $=\sqrt{\frac{\sum(\text { Error })^{2}}{\text { Number of Vehicles }}}$

\section{Equation 6}

Average Error $=\frac{\sum \text { Error }}{\text { Number of Vehicles }}$

An example of an equation resulting from the linearization is shown in Equation 7 and a detailed chart is provided in Table 4 for all vehicles in the study and in Table 5 for all vehicles excluding model years 1995-1999 for $\mathrm{NO}_{\mathrm{X}}$. Table 6 is for all vehicles for PM. The constant represents the intercept of the equations.

While performing the analysis, vehicles were considered differently if any kind of maintenance or repair procedure was performed during the E-55/59 study. Although only 49 vehicles were tested, some were found to have failures that influenced emissions, and these were repaired and retested. These vehicles provided one data set prior to repair, and another data set after repair. When repaired vehicles were also counted, the total was 59. Since not all vehicles were tested on AC5080, any calculation which involved AC5080 as a variable, measured or predicted, used only 26 vehicles in total (and 21 vehicles when the 1995 to 1999 model years were excluded). 
For all other calculations, 59 vehicles were used for the full data set and 40 vehicles were used when 1995-1999 model year vehicles excluded. Outlier vehicles were identified using residuals after linearization with less than a $95 \%$ confidence interval. The off-cycle vehicles were a subset of the outlier vehicles and thus removed from the $\mathrm{NO}_{\mathrm{X}}$ model and the equations and errors were recomputed. These results are presented in Table 5.

Equation 7 shows the best fit found to predict the UDDS $\mathrm{NO}_{\mathrm{X}}$ level from the Cruise mode and Transient mode, in units of $\mathrm{g} / \mathrm{mile}$.

Equation 7

$\mathrm{E}_{\text {UDDS }}=-1.102+(0.281) \mathrm{E}_{\text {Cruise }}+(0.735) \mathrm{E}_{\text {Transient }}$

The data are shown in Figure 29. Although there is an intercept for this best fit, it is small in comparison to both the average and the minimum values for the $\mathrm{NO}_{\mathrm{X}}$ emissions on the UDDS. Equation 7 implies that the UDDS has more transient content than cruise content, and this is borne out by the fact that only $40 \%$ of the non-idle time in the UDDS has vehicle speeds that hold steady within $8 \mathrm{mph}$.

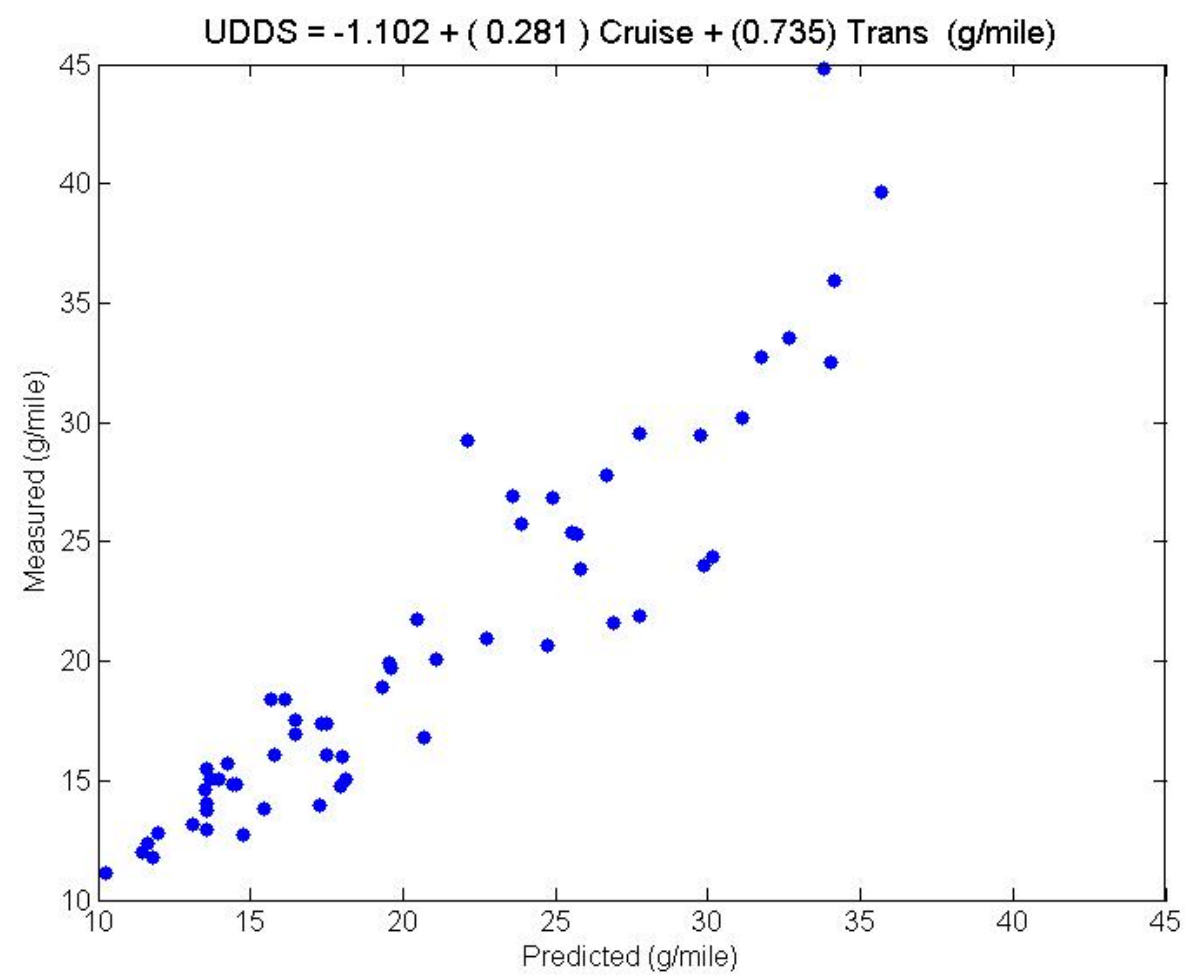

Figure 29: Parity plot of measured versus predicted $\mathrm{NO}_{\mathrm{X}}$ in $\mathrm{g} / \mathrm{mile}$ on UDDS as a function of $\mathrm{NO}_{\mathrm{X}}$ in $\mathrm{g} /$ mile on Cruise mode and $\mathrm{NO}_{\mathrm{X}}$ in $\mathrm{g} /$ mile on Transient mode for all vehicles 


\subsection{RESULTS}

\subsection{1. $\mathrm{NO}_{X}$ PREDICTION}

The results were plotted as predicted emissions versus measured emissions to yield parity plots. These plots, as shown in Figure 30 and Figure 31, for the specific predictive cases for the Transient mode and UDDS, help visualize the goodness of fit $\left(\mathrm{R}^{2}\right)$. Table 4 presents a summary of all the coefficients for prediction of $\mathrm{NO}_{\mathrm{X}}$ on one cycle using a constant and the values from two different cycles. Table 4 also shows the goodness of fit $\left(\mathrm{as} \mathrm{R}^{2}\right)$ and the error for the worst fit (in actual units of $\mathrm{g} / \mathrm{mile}$ ).

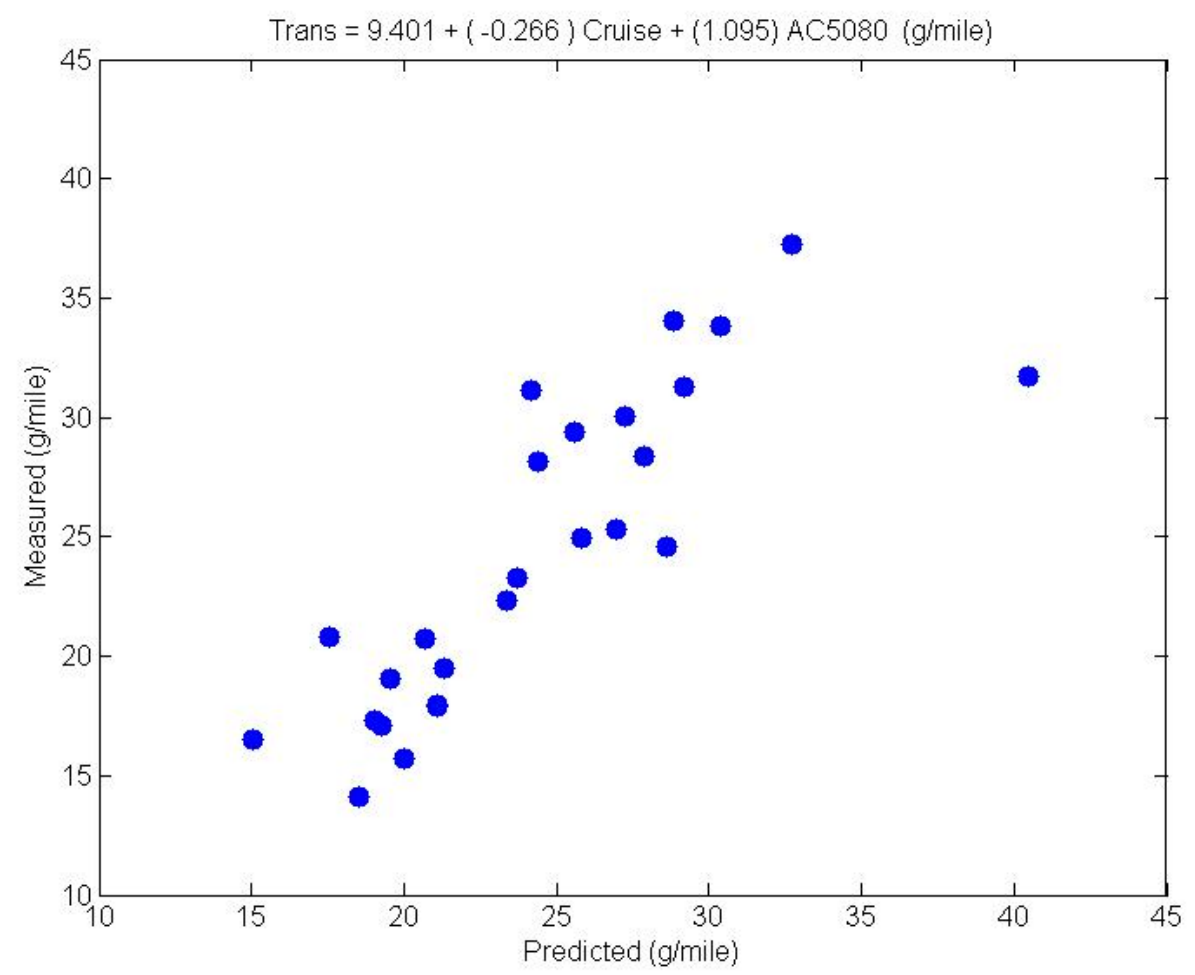

Figure 30: Parity plot of measured versus predicted $\mathrm{NO}_{\mathrm{X}}$ in $\mathrm{g} /$ mile on Transient mode as a function of $\mathrm{NO}_{\mathrm{X}}$ in $\mathrm{g} /$ mile on Cruise mode and $\mathrm{NO}_{\mathrm{X}}$ in $\mathrm{g} /$ mile on AC5080 for all vehicles 


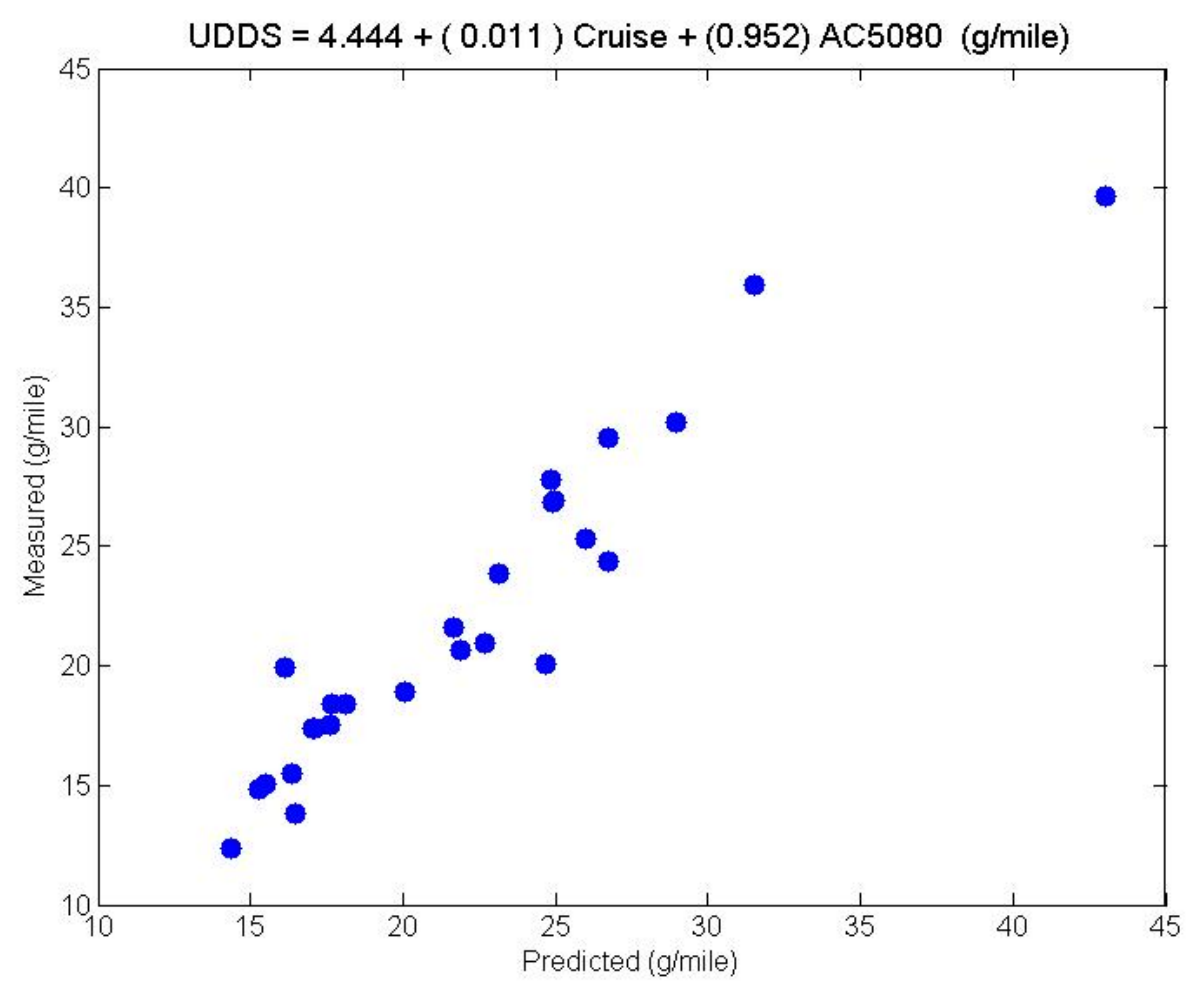

Figure 31: Parity plot of measured versus predicted $\mathrm{NO}_{\mathrm{X}}$ in $\mathrm{g} /$ mile on UDDS as a function of $\mathrm{NO}_{\mathrm{X}}$ in $\mathrm{g} /$ mile on Cruise mode and $\mathrm{NO}_{\mathrm{X}}$ in $\mathrm{g} /$ mile on AC5080 for all vehicles

Table 4 shows that accuracy of predictions varies widely. For the case of predicting the UDDS emissions from the Transient mode and the Cruise mode, the fit was good with $\mathrm{R}^{2}=0.873$. This may be attributed to the fact that the UDDS contains two behaviors that may be considered urban (transient, at low speed) and freeway (more steady, at higher speed). In this way, the UDDS may be regarded as containing aspects of behavior that appear in both the Transient mode and Cruise mode. Similarly, the good fit for the UDDS predicted by the AC5080 and the Transient mode arises because the AC5080 contains both steady state and transient behavior. When AC5080 emissions were predicted using the Transient mode and the Cruise mode, those two modes were evenly weighted in the predictions.

Some of the data scatter in Figure 29, Figure 30 and Figure 31, as well as some poor predictions shown in Table 4, can be attributed to the fact that some vehicles may emit $\mathrm{NO}_{\mathrm{X}}$ at two different levels at the same power output and engine speed, as a result of variable timing strategies. Also, in some cases, the truck may be in a different gear for the same instantaneous load and speed on two different cycles and this means torque could vary, with modest $\mathrm{NO}_{\mathrm{X}}$ variation implications. These timing strategies existed for engine model years from about 1993 up to 1998 and the authors have chosen vehicle model years 1995-1999 to represent this behavior, as described 
above. Although these model years do not delineate trucks with variable timing unambiguously, it is of interest to consider a dataset with vehicles of these model years excluded. Table 5 shows that predictions are better in several cases for the reduced data set. This is because the $\mathrm{NO}_{\mathrm{X}}$ emissions are almost monotonically related to power when the timing variations are excluded. Figure 32, which shows the data only for the trucks outside of the 1995 to 1999 model years, may be compared with the whole data set presented in Figure 29.

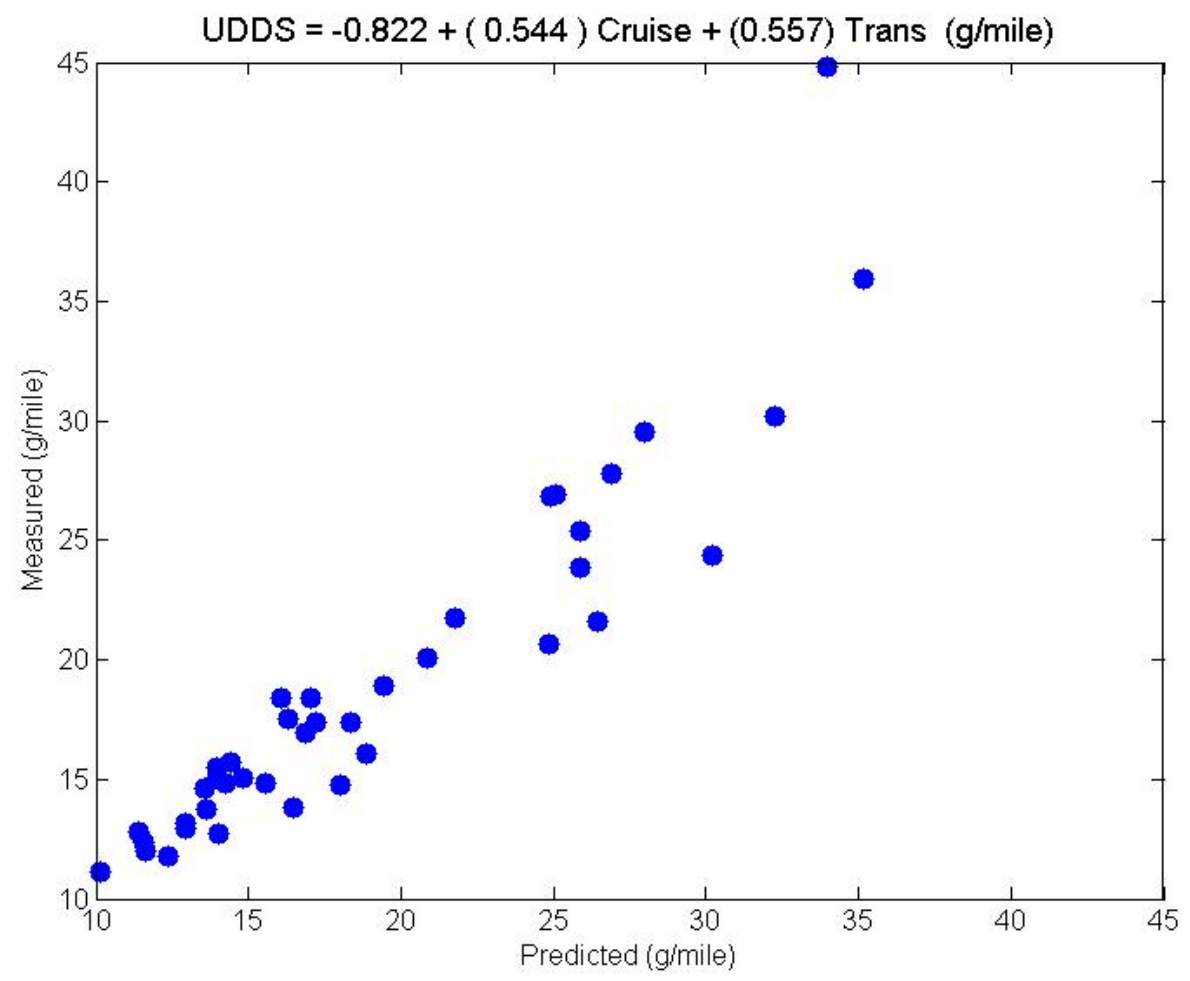

Figure 32: Parity plot of measured versus predicted $\mathrm{NO}_{\mathrm{X}}$ in $\mathrm{g} /$ mile on UDDS as a function of $\mathrm{NO}_{\mathrm{X}}$ in $\mathrm{g} /$ mile on Cruise mode and $\mathrm{NO}_{\mathrm{X}}$ in $\mathrm{g} /$ mile on Transient mode excluding vehicles of model year 19951999

Table 4, Table 5 and Table 6 show the results of the two-dimensional correlation analysis. The cycle being predicted was in the top row. Depending on the cycles used for the correlation, either column 2, 3 or 4 could be used. Based upon the data, various error statistics for each of the cycle combinations used for the correlation were presented below for each column. For example, to predict the $\mathrm{NO}_{\mathrm{X}}$ emissions on the UDDS using the Cruise mode and the Transient mode as the cycles used for the correlation use rows 21 through 26 in column 2 also shown in Equation 7. The error statistics for this correlation would be in rows 27 through 30 of column 2. 
Table 4: Overall summary for two-dimensional regression and errors for data on four cycles and $\mathrm{NO}_{\mathrm{X}}$ emissions for all vehicles

\begin{tabular}{|c|c|c|c|}
\hline $\mathrm{NO}_{\mathrm{X}}(\mathrm{g} / \mathrm{mile})$ & Cruise & Cruise & Cruise \\
\hline Constant & 0.250 & 3.130 & -0.222 \\
\hline \multicolumn{4}{|l|}{ Cruise } \\
\hline Transient & 0.059 & -0.337 & $\ldots$ \\
\hline UDDS & 0.799 & 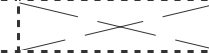 & 0.041 \\
\hline AC5080 & 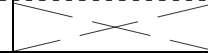 & 1.323 & 1.009 \\
\hline Max Error & 14.058 & 12.770 & 13.497 \\
\hline$R^{2-}$ & 0.647 & 0.751 & 0.727 \\
\hline Sqrt Sum of Square Error & 4.725 & 4.001 & 4.192 \\
\hline Average Error & 3.527 & 2.849 & 3.078 \\
\hline$N_{\mathbf{X}}(\mathrm{g} / \mathrm{mile})$ & Transient & Transient & Transient \\
\hline Constant $\ldots . . .$. & 5.141 & 9.401 & 5.695 \\
\hline Cruise & 0.023 & 0.266 & $\cdots$ \\
\hline Transient & & 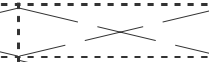 & $\cdots$ \\
\hline UDDS & 0.828 & & 0.836 \\
\hline AC5080 & & 1.095 & 0.011 \\
\hline Max Error & 8.197 & 8.755 & 7.721 \\
\hline$R^{2-}$ & 0.822 & 0.700 & 0.746 \\
\hline Sqrt Sum of Square Error & 2.972 & 3.556 & 3.271 \\
\hline Average Error & 2.282 & 2.922 & 2.433 \\
\hline $\mathrm{NO}_{\mathrm{X}}(\mathrm{g} / \mathrm{mile})$ & UDDS & UDDS & UDDS \\
\hline Constant & -1.102 & 4.444 & 1.857 \\
\hline Cruise & 0.281 & 0.011 & \\
\hline Transient & 0.735 & & 0.275 \\
\hline UDDS & & & \\
\hline $\mathrm{AC} 5080$ & & 0.952 & 0.739 \\
\hline Max Error & 11.060 & 4.601 & 4.120 \\
\hline$R^{2-}$ & 0.862 & 0.896 & 0.920 \\
\hline Sqrt Sum of Square Error & 2.800 & 2.136 & 1.875 \\
\hline Average Error & 1.912 & 1.664 & 1.441 \\
\hline $\mathrm{NO}_{\mathrm{X}}(\mathrm{g} / \mathrm{mile})$ & AC5080 & AC5080 & AC5080 \\
\hline Constant & -2.106 & -1.736 & -2.260 \\
\hline Cruise & 0.457 & 0.202 & \\
\hline Transient & 0.479 & $\ldots \ldots$ & 0.004 \\
\hline UDDS & 2 & 0.733 & 0.927 \\
\hline AC5080 & $x^{2}$ & 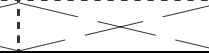 & 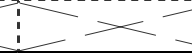 \\
\hline Max Error & 6.054 & 5.162 & 5.414 \\
\hline $\mathrm{R}^{-\overline{2}^{-}}$ & 0.870 & 0.917 & 0.896 \\
\hline Sqrt Sum of Square Error & 2.352 & 1.875 & 2.101 \\
\hline Average Error & 1.741 & 1.317 & 1.578 \\
\hline
\end{tabular}


Table 5: Overall summary for two-dimensional regression and errors for data on four cycles and $\mathrm{NO}_{\mathrm{X}}$ emissions excluding vehicles of model years 1995-1999

\begin{tabular}{|c|c|c|c|}
\hline $\mathrm{NO}_{\mathrm{X}}(\mathrm{g} / \mathrm{mile})$ & Cruise & Cruise & Cruise \\
\hline Constant & -0.219 & -0.701 & -0.651 \\
\hline \multicolumn{4}{|l|}{ Cruise } \\
\hline Transient & 0.405 & 0.251 & \\
\hline UDDS & 0.318 & & 0.381 \\
\hline $\mathrm{AC} 5080$ & & 0.638 & 0.519 \\
\hline Max Error & 4.372 & 4.273 & 3.292 \\
\hline $\mathrm{R}^{-2}$ & 0.869 & 0.888 & 0.893 \\
\hline Sqrt Sum of Square Error & 1.952 & 1.712 & 1.672 \\
\hline Average Error & 1.595 & 1.318 & 1.437 \\
\hline $\mathrm{NO}_{\mathrm{X}}(\mathrm{g} / \mathrm{mile})$ & Transient & Transient & Transient \\
\hline Constant & 3.405 & 2.063 & 1.863 \\
\hline Cruise & 0.606 & 0.427 & \\
\hline \multicolumn{4}{|l|}{ Transient } \\
\hline UDDS & 0.487 & & 0.096 \\
\hline $\mathrm{AC} 5080$ & & 0.868 & 1.166 \\
\hline Max Error & 6.172 & 5.768 & 6.307 \\
\hline $\mathrm{R}^{-2}$ & 0.884 & 0.892 & 0.880 \\
\hline Sqrt Sum of Square Error & 2.388 & 2.230 & 2.354 \\
\hline Average Error & 1.897 & 1.759 & 1.782 \\
\hline $\mathrm{NO}_{\mathrm{X}}(\mathrm{g} / \mathrm{mile})$ & UDDS & UDDS & UDDS \\
\hline Constant & -0.822 & 1.250 & 1.056 \\
\hline Cruise & 0.544 & 0.390 & \\
\hline Transient & 0.557 & & 0.058 \\
\hline \multicolumn{4}{|l|}{ UDDS } \\
\hline AC5080 & & 0.780 & 1.080 \\
\hline Max Error & 10.862 & 3.585 & 5.188 \\
\hline $\mathrm{R}^{-}$ & 0.873 & 0.921 & 0.908 \\
\hline Sqrt Sum of Square Error & 2.555 & 1.690 & 1.826 \\
\hline Average Error & 1.645 & 1.358 & 1.402 \\
\hline $\mathrm{NO}_{\mathrm{X}}(\mathrm{g} / \mathrm{mile})$ & AC5080 & AC5080 & AC5080 \\
\hline Constant & 0.874 & 0.808 & -0.120 \\
\hline Cruise & 0.461 & 0.348 & \\
\hline Transient & 0.370 & & 0.308 \\
\hline UDDS & & 0.512 & 0.474 \\
\hline \multicolumn{4}{|l|}{$\mathrm{AC} 5080$} \\
\hline Max Error & 4.379 & 4.914 & 4.125 \\
\hline $\mathrm{R}^{2}$ & 0.915 & 0.924 & 0.941 \\
\hline Sqrt Sum of Square Error & 1.455 & 1.369 & 1.210 \\
\hline Average Error & 1.042 & 0.860 & 0.857 \\
\hline
\end{tabular}




\subsubsection{PM PREDICTION}

As with the $\mathrm{NO}_{\mathrm{X}}$ correlations, the PM correlations are displayed in Table 6 and in Figure 33 through Figure 38. Since PM is not as strongly affected by timing as $\mathrm{NO}_{\mathrm{X}}$, the 1995 to 1999 model year vehicles were not removed for additional study. Figure 6 shows distance-specific PM values for the fleet on the Transient mode compared with the predicted emissions for the Transient mode. This prediction was based on AC5080 and Cruise mode measurements. The coefficients in Table 6 show that the Cruise mode has almost no role to play in the prediction of AC5080, when the Transient mode is used. The AC5080 dominates the equation, so that one might conclude that the AC5080 is capable of predicting Transient mode PM emissions (typical of urban truck activity) as well as Figure 33 and Figure 34 would indicate. In other words, The AC5080 would prove to be a satisfactory inspection and maintenance (IM) test for urban truck emissions abatement programs.

One older vehicle (A 1979 Caterpillar with E-55/59 designation E55CRC-16) was an exceptionally high PM emitter and stands alone in Figure 33. Figure 34 shows the same data without this vehicle. There is a strong overall trend, but some of the low emitting vehicles have poorly predicted PM because the single high emitting vehicle forces the best-fit equation to have a substantial negative intercept. For example, the nine lowest PM vehicles are all substantially over-predicted, with the lowest emitting vehicle over-predicted by a factor of 2.5 . This single high emitter raises an interesting issue, and begs the decision whether (i) to optimize the fit (on a percent error basis, and perhaps with a forced zero intercept) for all vehicles, so that the emissions of each vehicle would be reasonably predicted, or (ii) to optimize the prediction of total PM mass emissions from the whole data set on the cycle in question. Option (i) would more closely satisfy inspection and maintenance needs, while (ii) would favor inventory applications, provided the use (as vehicle miles traveled) of all the vehicles in the dataset were similar. 


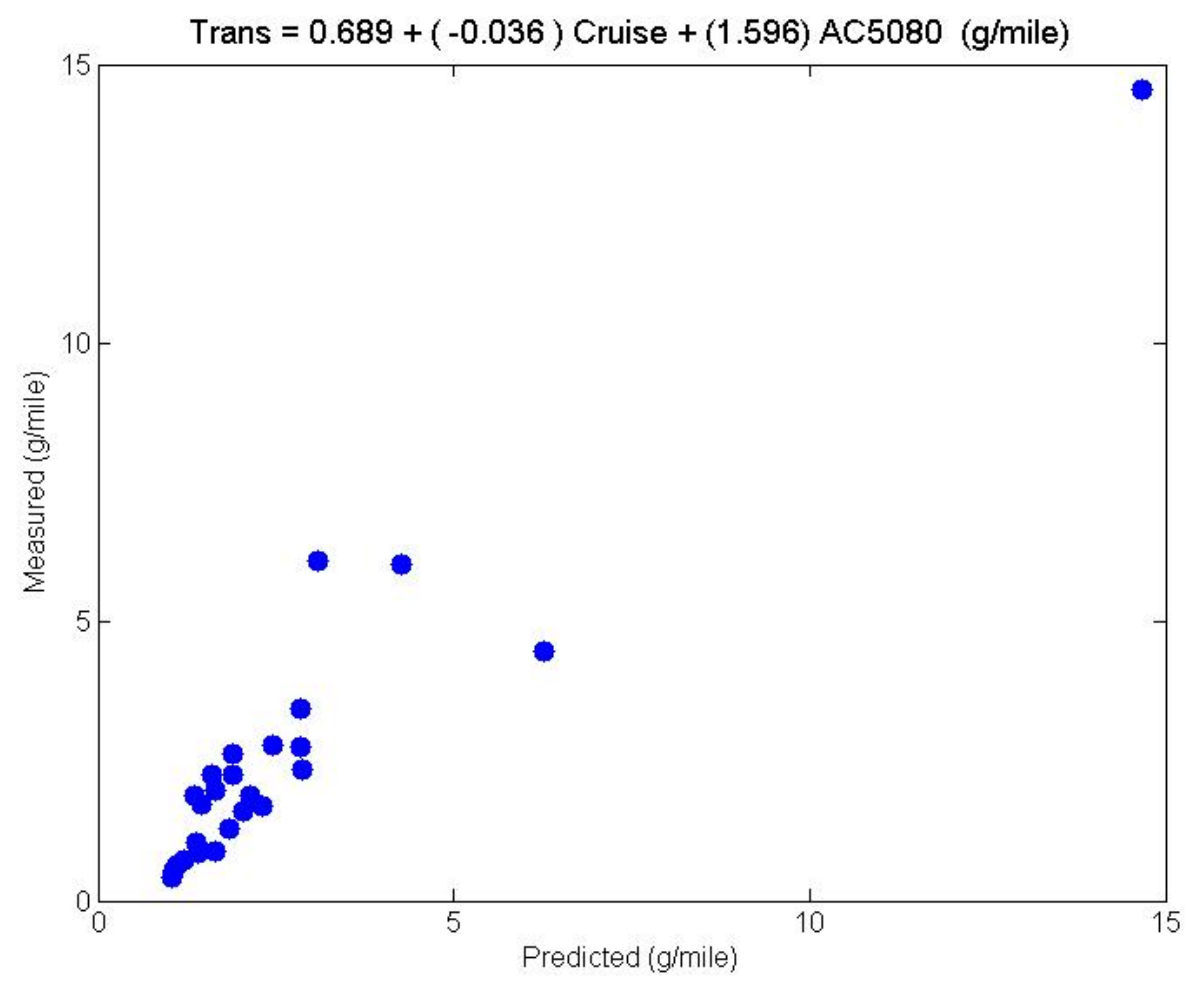

Figure 33: Parity plot of measured versus predicted PM in $\mathrm{g} /$ mile on Transient mode as a function of PM in $\mathrm{g} / \mathrm{mile}$ on Cruise mode and PM in $\mathrm{g} / \mathrm{mile}$ on AC5080 for all vehicles

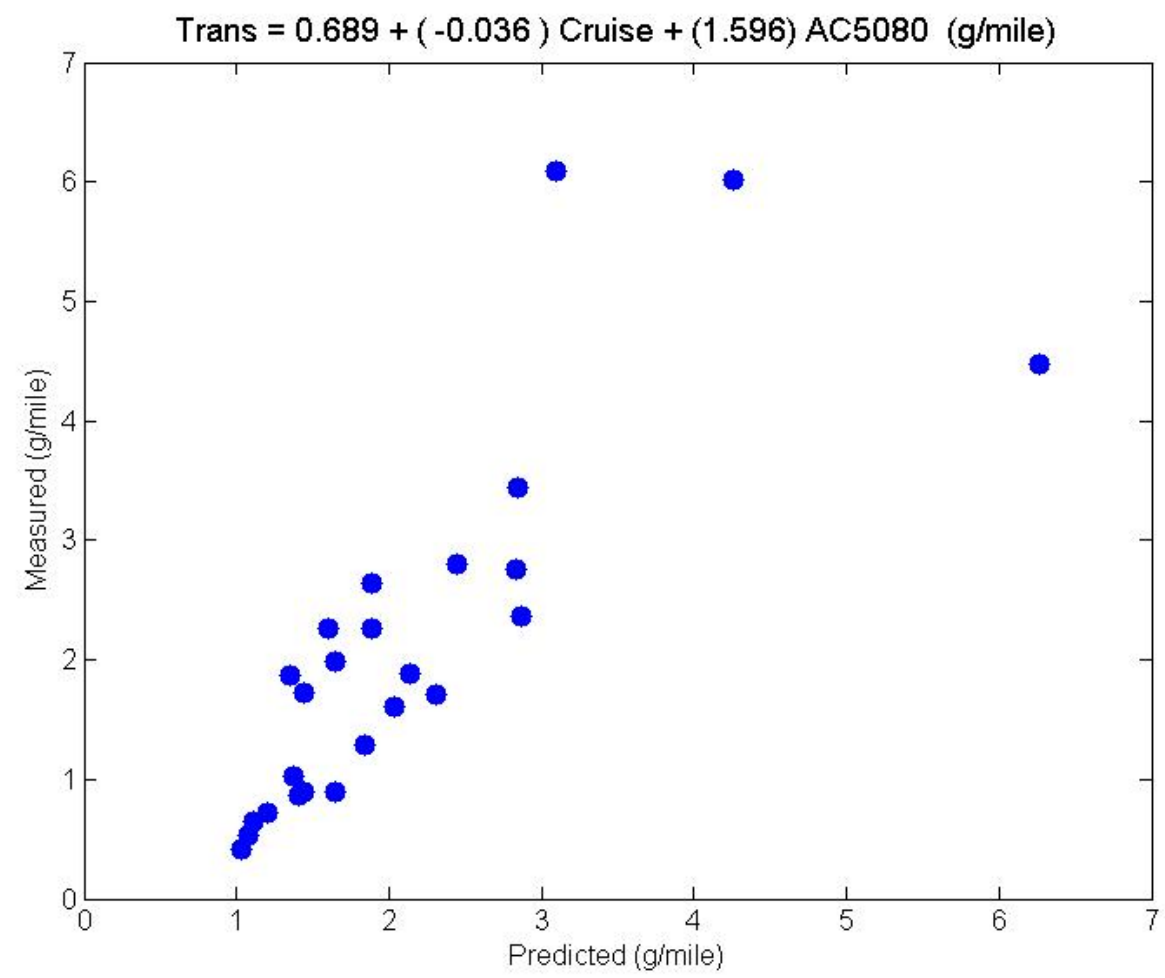

Figure 34: Magnified parity plot of measured versus predicted PM in $\mathrm{g} /$ mile on Transient mode as a function of PM in $\mathrm{g} / \mathrm{mile}$ on Cruise mode and PM in $\mathrm{g} / \mathrm{mile}$ on AC5080 
Figure 35 (all PM data) and Figure 36 (with the highest emitter excluded) show that the ability of the AC5080 and Cruise mode to predict UDDS emissions is far superior to their ability to predict Transient mode emissions. The same problem of a high intercept arises due to the highest emitter, but to a lesser extent than in predicting the Transient mode. As in the case of $\mathrm{NO}_{\mathrm{X}}$ prediction (Figure 31), the AC5080 played a far higher role in predicting UDDS emissions than Cruise mode emissions. In Figure 37 and Figure 38 similar data are displayed for the case where the UDDS emissions have been predicted using the Transient and Cruise modes. The modes are quite evenly weighted in the equation. Interestingly, the correlation is not strong, with wide data scatter amongst the higher emitting vehicles. This is in contrast to the same predictive strategy for $\mathrm{NO}_{\mathrm{X}}$, where the correlation was far better.

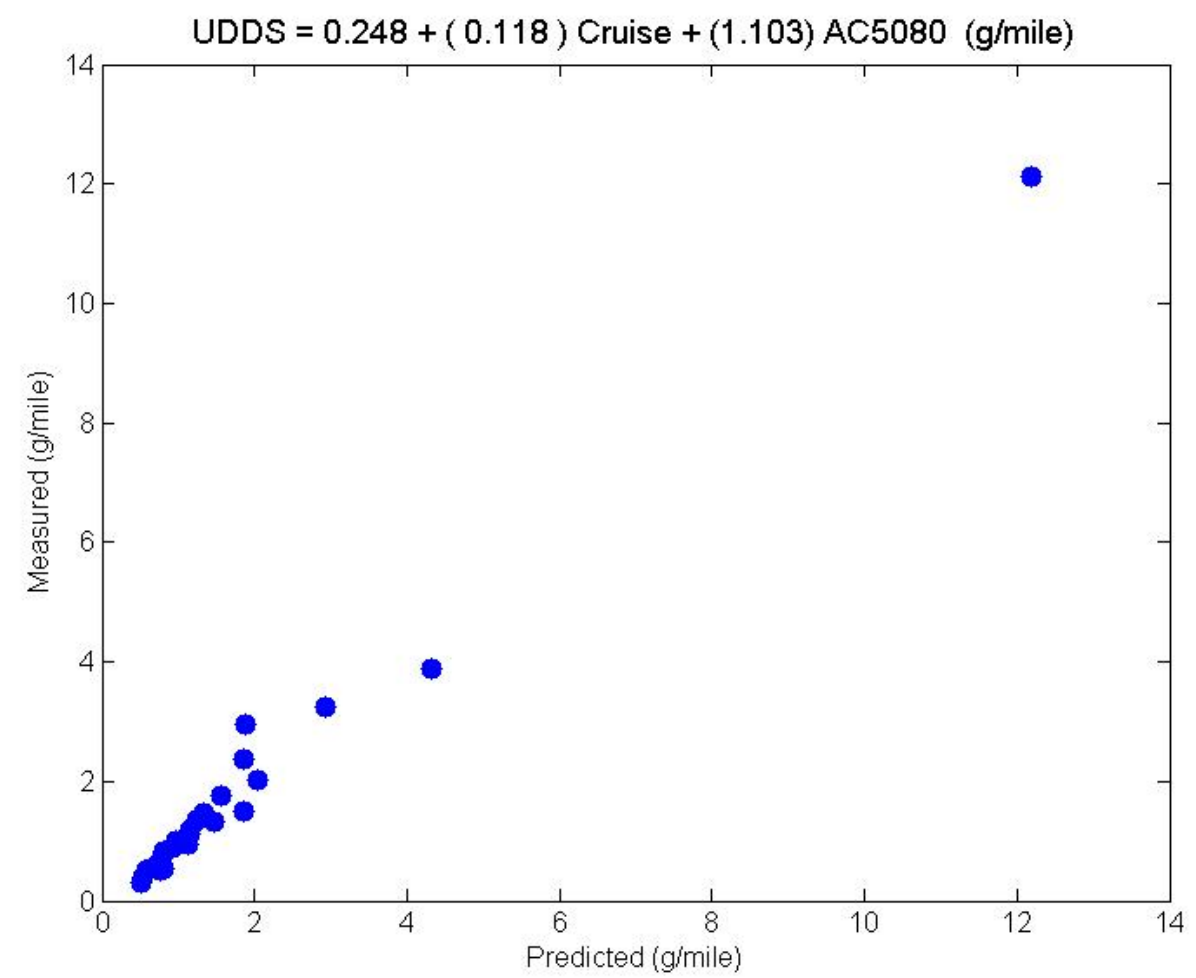

Figure 35: Parity plot of measured versus predicted PM in g/mile on UDDS as a function of PM in g/mile on Cruise mode and PM in g/mile on AC5080 for all vehicles 


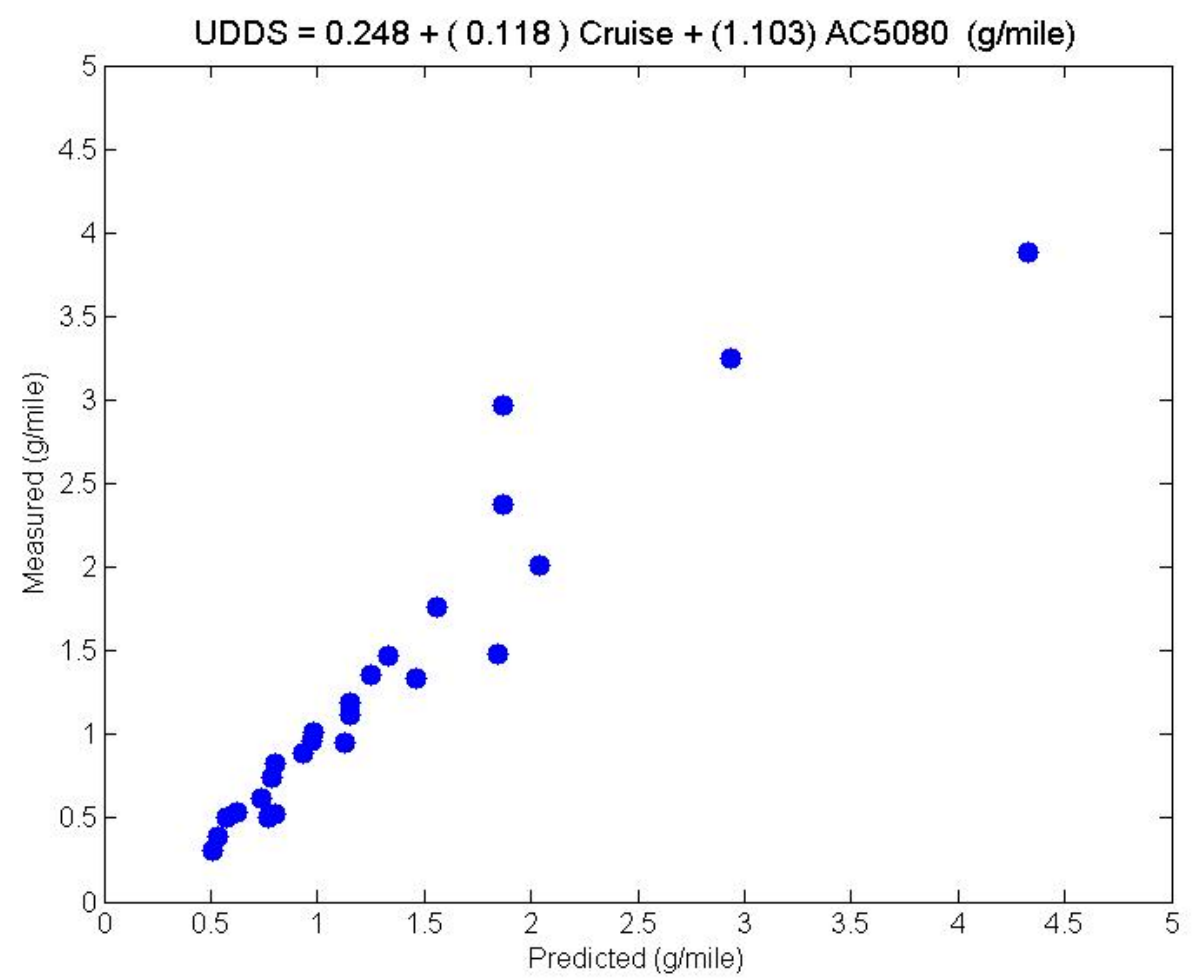

Figure 36: Magnified parity plot of measured versus predicted PM in g/mile on UDDS as a function of PM in $\mathrm{g} /$ mile on Cruise mode and PM in $\mathrm{g} /$ mile on AC5080

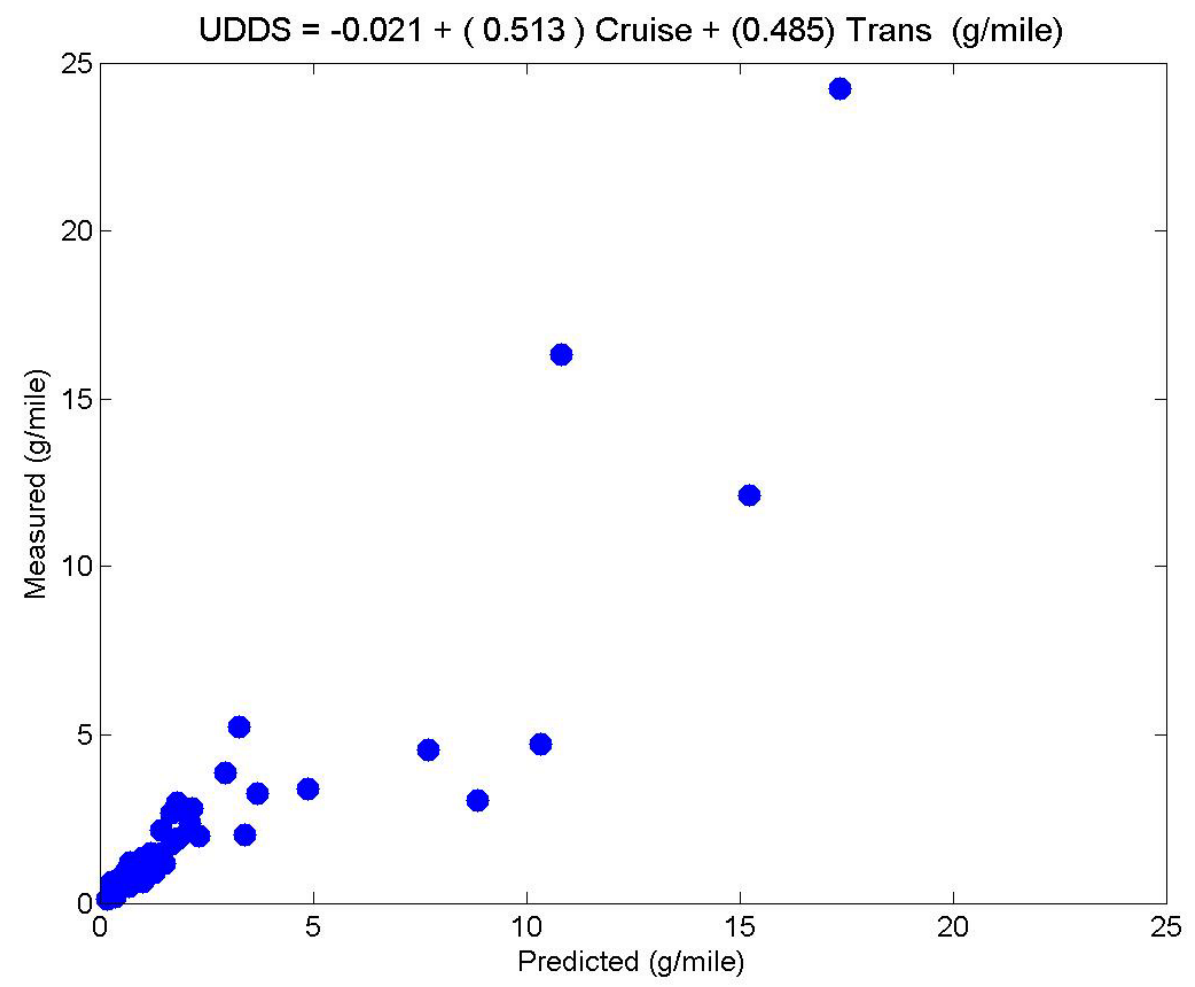

Figure 37: Parity plot of measured versus predicted PM in g/mile on UDDS as a function of PM in g/mile on Cruise mode and PM in $\mathrm{g} /$ mile on Transient mode for all vehicles 


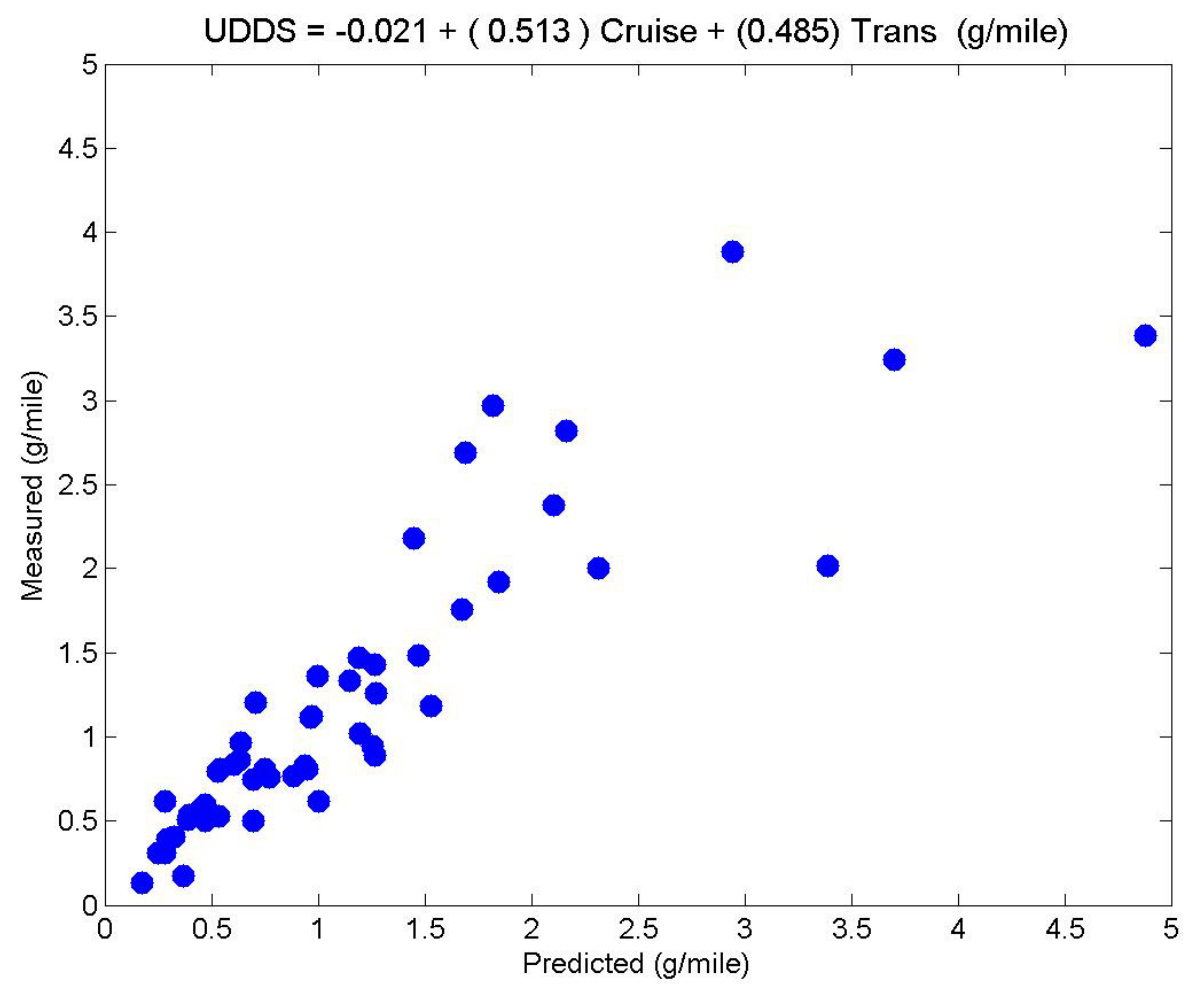

Figure 38: Magnified parity plot of measured versus predicted PM in g/mile on UDDS as a function of PM in $\mathrm{g} / \mathrm{mile}$ on Cruise mode and PM in $\mathrm{g} /$ mile on Transient mode for all vehicles

Table 6: Overall summary for two-dimensional regression and errors for data on four cycles and PM emissions for all vehicles

\begin{tabular}{|c|c|c|c|}
\hline PM (g/mile) & Cruise & Cruise & Cruise \\
\hline Constant & -0.072 & -0.863 & -1.027 \\
\hline \multicolumn{4}{|l|}{ Cruise } \\
\hline Transient & 0.101 & -0.035 & \\
\hline UDDS & 0.372 & & 0.970 \\
\hline AC5080 & & 1.708 & 0.395 \\
\hline Max Error & 10.083 & 3.461 & 2.586 \\
\hline $\mathrm{R}^{--}$ & 0.627 & 0.911 & 0.921 \\
\hline Sqrt Sum of Square Error & 1.476 & 0.895 & 0.843 \\
\hline Average Error & 0.504 & 0.581 & 0.624 \\
\hline PM cycle (g/mile) & Transient & Transient & Transient \\
\hline Constant & 0.936 & 0.689 & 0.599 \\
\hline Cruise & 0.286 & -0.036 & \\
\hline \multicolumn{4}{|l|}{ Transient } \\
\hline UDDS & 1.000 & & 0.845 \\
\hline AC5080 & & 1.596 & 0.440 \\
\hline Max Error & 12.844 & 2.991 & 3.111 \\
\hline $\mathrm{R}^{2-}$ & 0.763 & 0.897 & 0906 \\
\hline Sqrt Sum of Square Error & 2.486 & 0.898 & 0.859 \\
\hline Average Error & 1.282 & 0.664 & 0.628 \\
\hline
\end{tabular}




\begin{tabular}{|l|l|l|l|}
\cline { 2 - 4 } PM cycle (g/mile) & UDDS & UDDS & UDDS \\
\hline Constant & -0.021 & 0.248 & 0.070 \\
\hdashline Cruise & 0.513 & 0.118 & \\
\hline Transient & 0.485 & & 0.102 \\
\hline UDDS & & & \\
\hline AC5080 & 6.881 & 1.103 & 1.141 \\
\hline Max Error & 0.802 & 0.983 & 1.056 \\
\hline $\mathrm{R}^{2}$ & 0.963 & 0.983 \\
\hline Sqrt Sum of Square Error & 1.732 & 0.294 & 0.299 \\
\hline Average Error & 0.805 & 0.190 & 0.189 \\
\hline PM cycle (g/mile) & $\mathbf{A C 5 0 8 0}$ & $\mathbf{A C 5 0 8 0}$ & $\mathbf{A C 5 0 8 0}$ \\
\hline Constant & 0.128 & -0.052 & -0.104 \\
\hdashline Cruise & 0.309 & 0.031 & \\
\hdashline Transient & 0.287 & & 0.033 \\
\hline UDDS & & 0.716 & 0.717 \\
\hline AC5080 & & & \\
\hline Max Error & 1.642 & 0.752 & 0.747 \\
\hdashline $\mathrm{R}^{2}$ & 0.951 & 0.981 & 0.981 \\
\hdashline Sqrt Sum of Square Error & 0.381 & 0.237 & 0.237 \\
\hdashline Average Error & 0.210 & 0.138 & 0.142 \\
\hline
\end{tabular}

\subsection{CONCLUSIONS}

Emissions from two separate cycles have been used to predict the emissions from a third cycle, for a fleet of heavy-duty vehicles tested in California. One might intuitively expect that a cycle that contains both transient and cruise (freeway) behavior (such as the UDDS) might be well predicted by a combination of emissions values from two modes that exemplify the separate behaviors, such as the Cruise mode and the Transient mode of the HHDDT. However, the correlation was not outstanding for either $\mathrm{PM}$ or $\mathrm{NO}_{\mathrm{X}}$. This is only one example of predictions that were not intuitively obvious in their fit. Overall, it was found that both $\mathrm{PM}$ and $\mathrm{NO}_{\mathrm{X}}$ could be reasonably predicted, but some low emitting vehicles had substantial percentage error in prediction because the optimization approach minimized the sum of square errors of actual distance-specific emissions. This would be optimal for inventory purposes, but would be suboptimal when considering a single low emitting vehicle. For correlations that would address single vehicles, an approach that minimized percentage errors might prove superior.

In the case of $\mathrm{NO}_{\mathrm{X}}$ predictions, off-cycle timing strategies did assault the predictive ability of the approach, and a dataset that excluded 1995 to 1999 vehicle model years allowed for better prediction than the whole data set. 


\section{Emission Trends for Medium Duty Trucks and Heavy Heavy-Duty Trucks at Multiple Operating Weights}

\subsection{INTRODUCTION}

Emissions modeling for meeting environmental standards in the United States of America and Europe have largely been concentrated on HHDDT. The previous two sections have looked at the ability to correlate emissions between cycles. This section examines the weight effect on medium heavy duty trucks (MHDT) and HHDDT for the emissions of $\mathrm{NO}_{\mathrm{X}}, \mathrm{CO}_{2}$, $\mathrm{PM}$, carbon monoxide (CO) and hydrocarbons (HC) over a cycle. The database used vehicles from the E55/59 study. There were fifteen diesel MHDT (MHDDT) spanning model years $1974-2000$. Four gasoline MHDT (MHDGT) spanning model years 1987 - 2001 were also examined. The emissions of $\mathrm{NO}_{\mathrm{X}}$ and PM were of concern for the MHDDT and HHDDT, while CO and HC were of concern for the MHDGT.

There have been studies which have examined weight effects on heavy duty vehicles such as McCormick et al. [31] and Gajendran et al. [24]. These studies have had access to very limited databases. Other studies have looked at average grade of highways on emissions and fuel economy [32] and effect of payload and vehicle configuration change in units of grams per tonkilometer [33]. This section examined the relationship of weight to $\mathrm{NO}_{\mathrm{X}}$ as concluded by these papers and identified shortfalls or trends based on a dataset of 38 HHDDT vehicles spanning engine model years 1974 - 2003, part of the E-55/59 study. The vehicles were run on various cycles on WVU's Translab.

The $\mathrm{NO}_{\mathrm{X}}$ emissions data was analyzed for each vehicle. Fleet wide average data is presented for species of $\mathrm{NO}_{\mathrm{X}}$ along with $\mathrm{PM}, \mathrm{CO}_{2}$ and $\mathrm{HC}$.

\subsection{LITERATURE REVIEW}

McCormick et al. [31] evaluated three vehicles to compare in-use emissions to engine FTP emissions. This evaluation looked at weight effects on only one vehicle and concluded that there were considerable effects of vehicle weight on emitted $\mathrm{PM}, \mathrm{NO}_{\mathrm{X}}$ and $\mathrm{CO}$. Fuel consumption based emissions were unaffected by weight.

Clark et al. [11] examined weight effects for the vehicles during the E-55/59 phase 1.5. They looked at effects of weight on the Transient mode and the HHDDT_s mode for $\mathrm{NO}_{\mathrm{X}}$ and PM. 
$\mathrm{NO}_{\mathrm{X}}$ was shown to increase with increase in test weight from $30,000 \mathrm{lbs}$ to $66,000 \mathrm{lbs}$. PM showed an increase when the vehicle weight was increased from 30,000 lbs to 56,000 lbs but no significant increase when the weight was increased to $66,000 \mathrm{lbs}$.

Gajendran et al. [24] predicted that, for HHDDT, the change in emitted $\mathrm{NO}_{\mathrm{X}}$ would be proportional to the weight change of the vehicle. Thus, an $\mathrm{X} \%$ increase in weight would correlate to a $\frac{50}{100} \times \%$ increase in the $\mathrm{NO}_{\mathrm{X}}$.

Similarly, Brodrick et al. [34] found that an X \% increase in weight would result in a $\frac{40}{100} \times \%$ increase in emitted $\mathrm{NO}_{\mathrm{X}}$ for HHDDT. This conclusion is valid for the average emitted $\mathrm{NO}_{\mathrm{X}}$ for a large fleet.

Bishop et at. [35] reported an increase in $\mathrm{NO}_{\mathrm{X}}$ emissions on the uphill sections of the testing route and a $10 \%$ reduction on the downhill portion. The testing route was the European Highway A1 and the vehicles used were in-use heavy-duty trucks. A remote sensing instrumentation and measurement technique called Fuel Efficient Automobile Test (FEAT) was used. They also found a difference of $14 \%$ in the amount of NO between loaded and unloaded HDDT. The fuel specific emissions of $\mathrm{CO}, \mathrm{HC}$ and $\mathrm{NO}$ were found to increase with increase in altitude.

Burgard et al. [36] showed that fuel specific $\mathrm{NO}_{\mathrm{X}}$ has little or no effect with respect to weight. The vehicles used were 1,542 in-use heavy-duty diesel vehicles. The measurements were acquired using two University of Denver Remote Sensing FEAT 3000 units. This emission did show change with odometer reading.

\subsection{TESTING PROCEDURE AND VEHICLES}

This section evaluates the weight effect on Creep mode, Cruise mode, HHDDT_s mode, medium heavy duty truck cruise mode (MHDTCR cycle) [37], medium heavy duty truck high-speed transient mode (MHDTHI cycle) [37], medium heavy duty truck low-speed transient mode (MHDTLO cycle) [37], Transient mode, and UDDS. All the vehicles used were part of the E55/59 Study. 
The bins used in this section to group the vehicles were based on the US Environmental protection agency's (EPA) emissions regulations changes based on model year (MY). Changing PM standards may affect $\mathrm{NO}_{\mathrm{X}}$ there is known to be a trade-off between $\mathrm{NO}_{\mathrm{X}}$ and $\mathrm{PM}$ emissions, particularly as a result of injection timing changes.

Bin 1. Vehicles required to meet the $0.25 \mathrm{~g} / \mathrm{bhp}-\mathrm{hr}$ of PM with MY $1965-1984$

Bin 2. Vehicles required to meet the $0.25 \mathrm{~g} / \mathrm{bhp}-\mathrm{hr}$ of PM with MY $1985-1993$

Bin 3. Vehicles complying with the $0.1 \mathrm{~g} / \mathrm{bhp}-\mathrm{hr}$ of PM and a $5 \mathrm{~g} / \mathrm{bhp}-\mathrm{hr}$ of $\mathrm{NO}_{\mathrm{X}}$ with MY $1994-1997$

Bin 4. Vehicles complying with the $0.1 \mathrm{~g} / \mathrm{bhp}-\mathrm{hr}$ of PM and a $4 \mathrm{~g} / \mathrm{bhp}-\mathrm{hr}$ of $\mathrm{NO}_{\mathrm{X}}$ with MY 1998

Bin 5. Vehicles belonging to the post consent decree with MY 1999 - 2002

Bin 6. Vehicles required to meet the $2 \mathrm{~g} / \mathrm{bhp}-\mathrm{hr} \mathrm{NO}_{\mathrm{X}}$ with MY 2003 - 2005

Fifteen MHDDT and four MHDGT were analyzed. Out of the fifteen MHDDT, nine were tested on the HHDDT_s mode. All fifteen were tested on MHDTCR cycle, MHDTHI cycle and MHDTLO cycle. The six vehicles not tested on the HHDDT_s mode belonged to bins 1 (1 vehicle), 3 (2 vehicles) and 5 (3 vehicles). The four MHDGT were analyzed over HHDDT_s mode, MHDTCR cycle, MHDTHI cycle and MHDTLO cycle. The MY grouping for the MHDDT for the MHDGT are shown in Table 7.

There were 38 HHDDT tested on Creep mode, Cruise mode and Transient mode. Only 10 HHDDT were tested on HHDDT_s, 1 each from bins 1, 2 and 3; 2 each from bins 4 and 6, and 3 from bin 5. One vehicle, a 1985 International was considered as two vehicles as it was run as-is and then with a re-flashed ECU. Table 7 shows the distribution of these vehicles grouped in bins outlining changes in EPA's emissions requirements.

Table 7: Vehicle MY distribution

\begin{tabular}{|c|c|c|c|}
\hline Bin & HHDDT & MHDDT & MHDGT \\
\hline $1965-1984$ & 6 & 2 & 0 \\
\hline $1985-1993$ & 13 & 4 & 3 \\
\hline $1994-1997$ & 5 & 5 & 0 \\
\hline $1998-1998$ & 5 & 0 & 0 \\
\hline $1999-2002$ & 7 & 4 & 1 \\
\hline $2003-2005$ & 2 & 0 & 0 \\
\hline Total & 38 & 15 & 4 \\
\hline
\end{tabular}


The vehicles used for this study were those for which emissions data existed for more than one test weights for the same cycle. The emissions for the different weights of each vehicle are grouped by cycle and plotted on a linear graph.

The legend entries in the figures for individual vehicles used the vehicle naming convention from the E-55/59 program. Here E55CRC-XX refers to the vehicle from the E-55/59 program and XX designates the vehicle number assigned in the order in which the vehicle was recruited for testing.

\subsection{MHDT RESULTS}

\subsubsection{DIESEL MHDT (MHDDT)}

Test data for only seven vehicles on the HHDDT_s mode were available for analysis. Figure 39 shows the weight- $\mathrm{NO}_{\mathrm{X}}$ trend for this cycle. It is seen that there is no consistency in emission trends between vehicles.

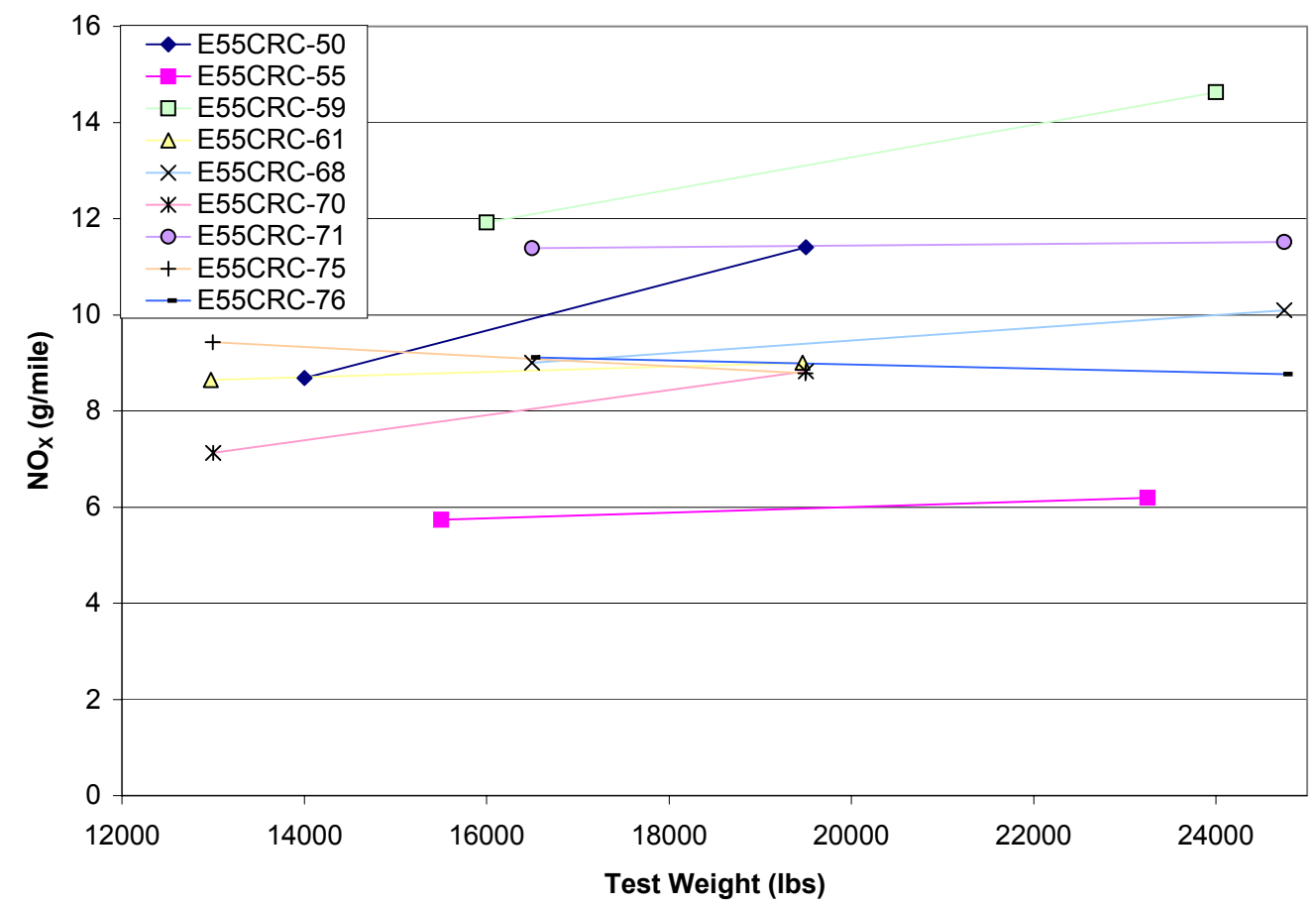

Figure 39: $\mathrm{NO}_{\mathrm{X}}$ emission trends for different vehicles at various operating weights on the HHDDT_s mode

Figure 40, Figure 41 and Figure 42 show the emissions with respect to weight for the MHDTCR cycle, the MHDTHI cycle and the MHDTLO cycle respectively. These cycles were specifically created by CARB for the E-55/59 study. The MHDTCR cycle showed that vehicle emissions 
either increase or decrease, with an increase in weight. The MHDTHI and MHDTLO cycles showed increase in emissions with increase in weight. This behavior was attributed to the average accelerations of the three cycles. The MHDTCR cycle has the lowest average acceleration of the three at $0.19 \mathrm{mph} / \mathrm{sec}$ compared to that of the MHDTHI cycle and the MHDTLO cycle at $0.43 \mathrm{mph} / \mathrm{sec}$ and $0.45 \mathrm{mph} / \mathrm{sec}$ respectively.

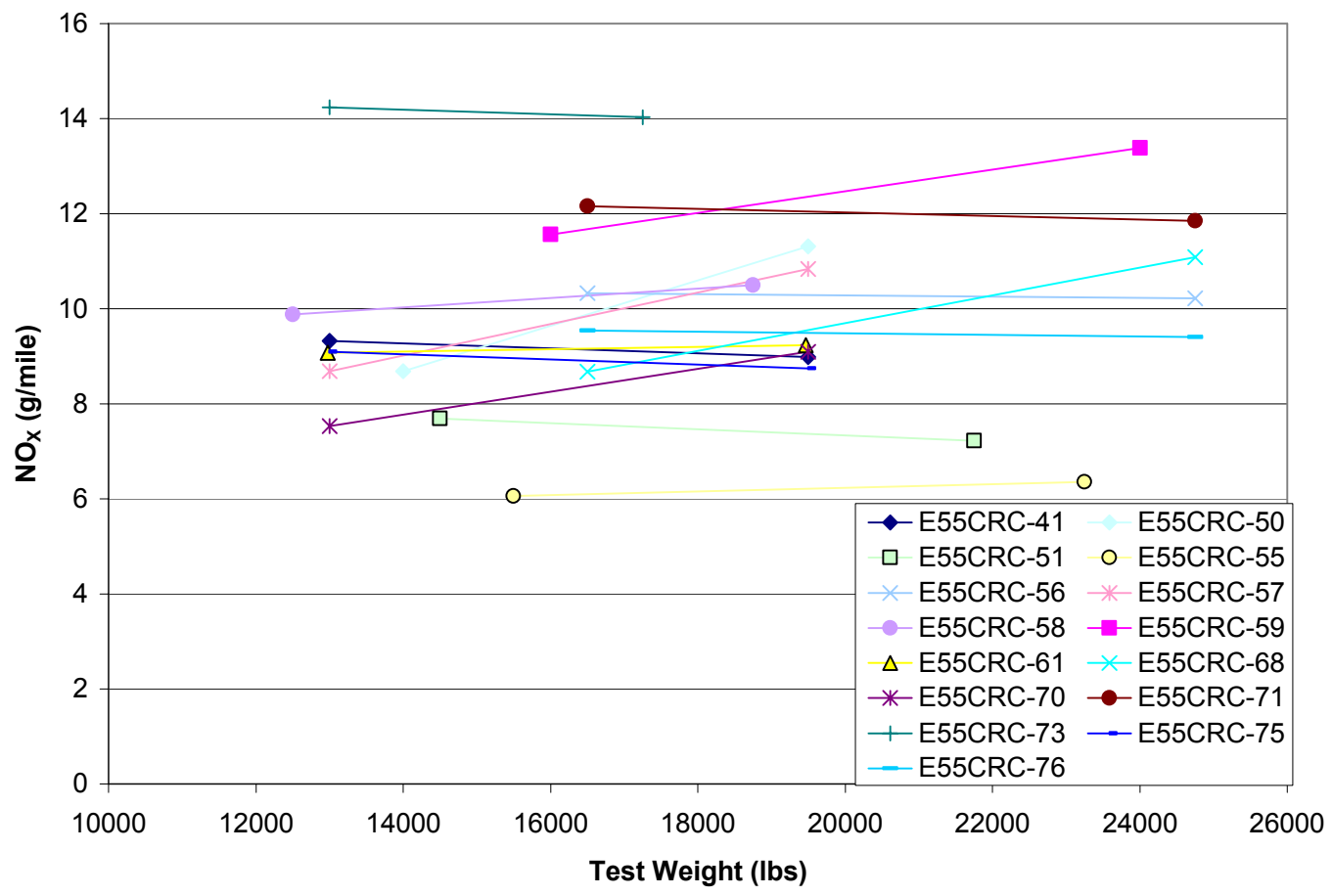

Figure 40: $\mathrm{NO}_{\mathrm{X}}$ emission trends for different vehicles at various operating weights on the MHDTCR cycle 


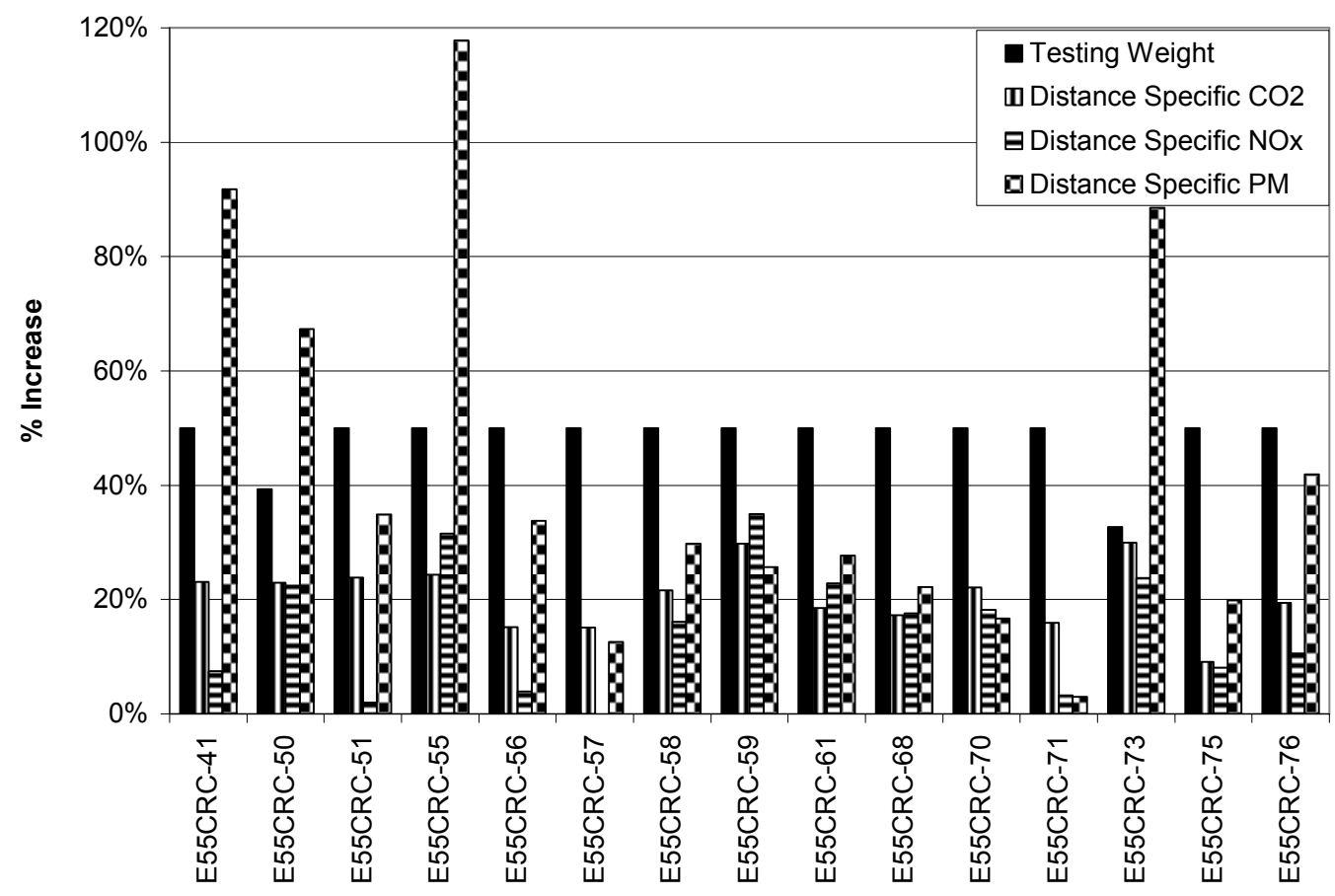

Figure 41: Increase in distance specific emissions relative to increase in operating weight on the MHDTHI cycle

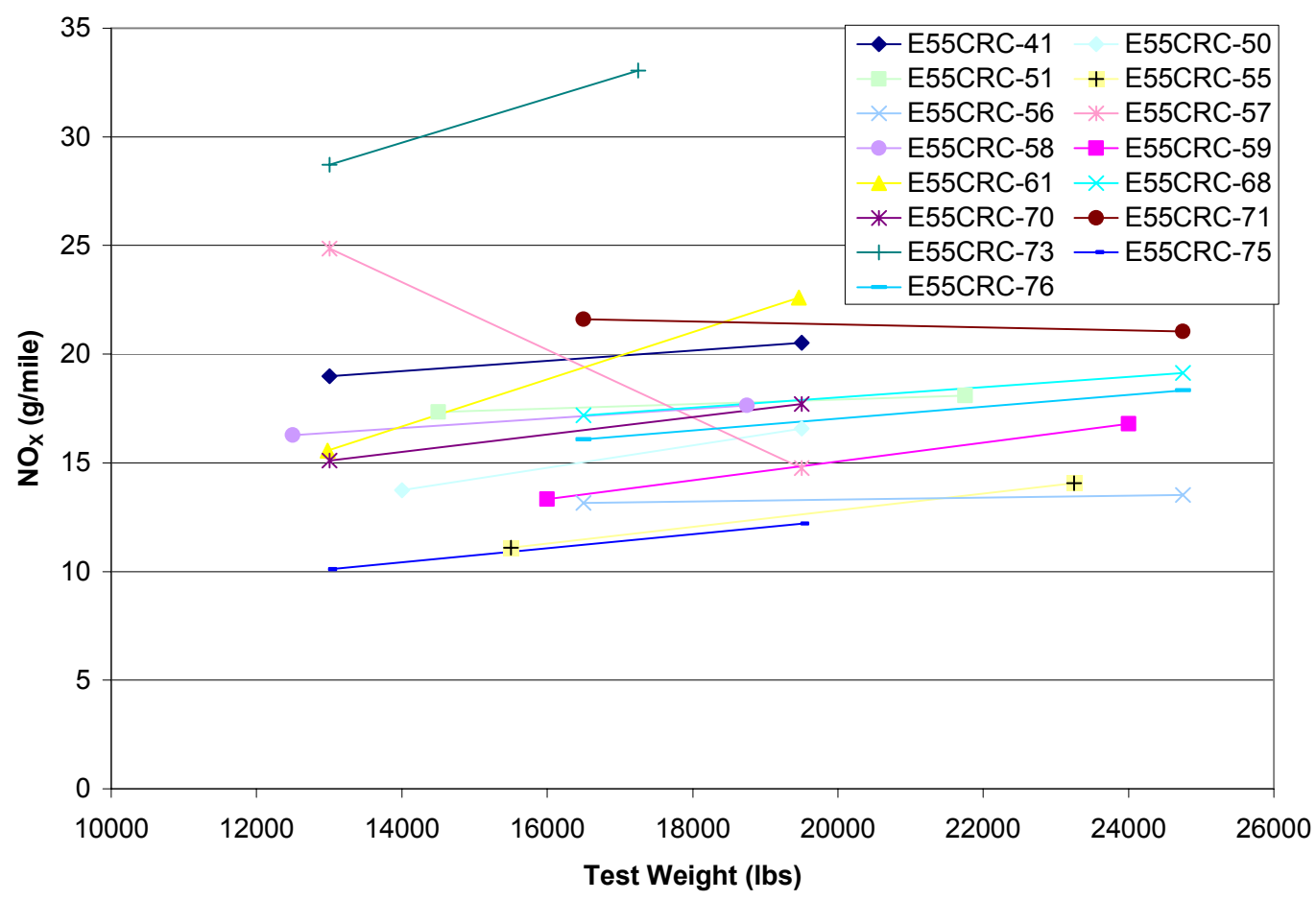

Figure 42: $\mathrm{NO}_{\mathrm{X}}$ emission trends for different vehicles at various operating weights on the MHDTLO cycle

The UDDS showed similar emissions behavior to the MHDTLO cycle for the $\mathrm{NO}_{\mathrm{X}}$ as shown in Figure 43. It was seen that besides one vehicle (E55CRC-57, a 2000 Freightliner FL60 with a 
1999 Caterpillar 3126), the emissions of all the vehicles increased with increase in weight or showed a marginal decrease with increase in weight. The reason for this behavior was attributed to a faulty coolant sensor.

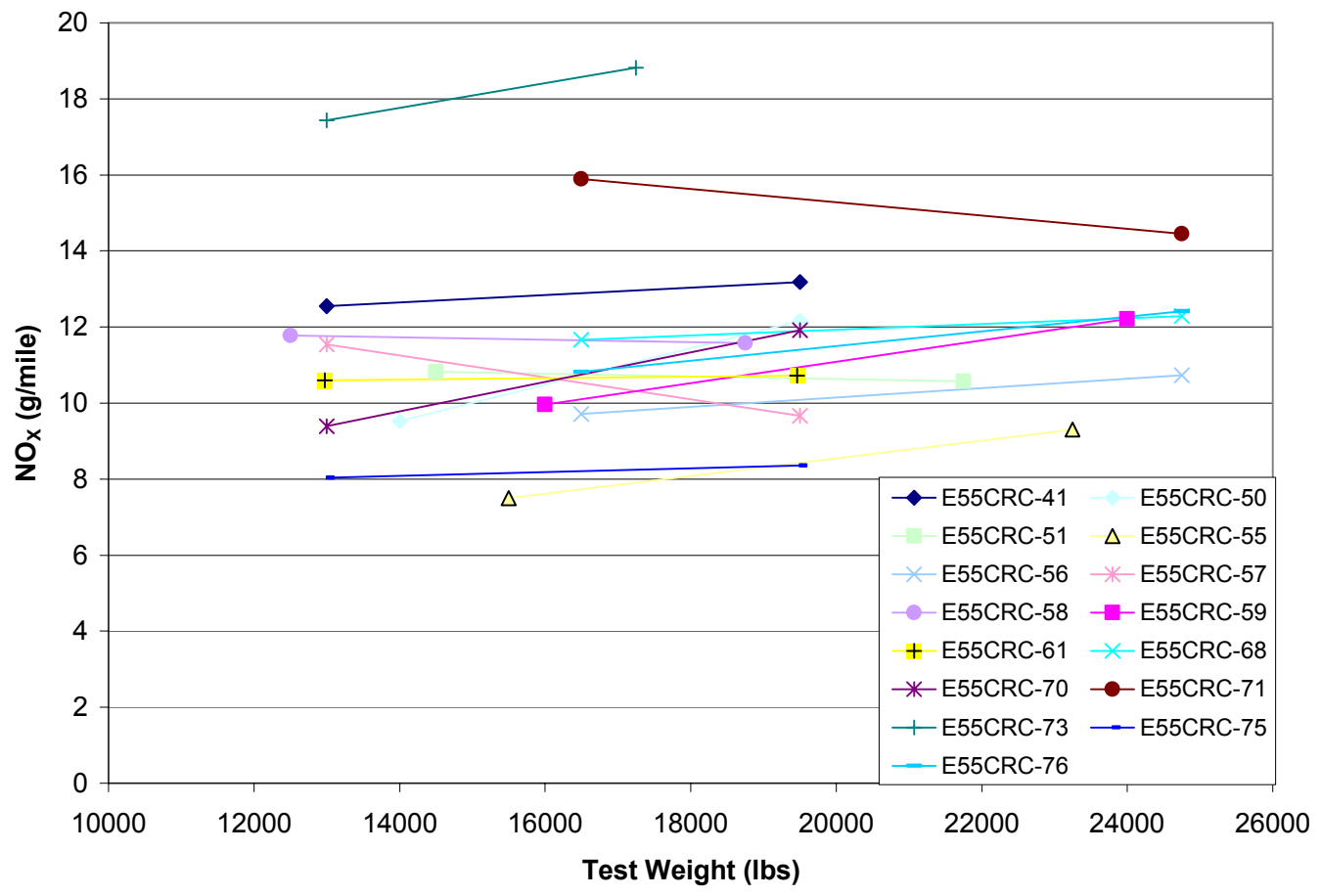

Figure 43: $\mathrm{NO}_{\mathrm{X}}$ emission trends for different vehicles at various operating weights on the UDDS

Similar to the $\mathrm{NO}_{\mathrm{X}}$ emissions, the emissions of $\mathrm{CO}, \mathrm{CO}_{2}, \mathrm{HC}$ and $\mathrm{PM}$ were analyzed. They showed no consistent trends for prediction based on weight. All the emissions, when averaged for each cycle, did show an increase relative to the increase in weight. This average increase in terms of percent can be seen in Figure 44. 


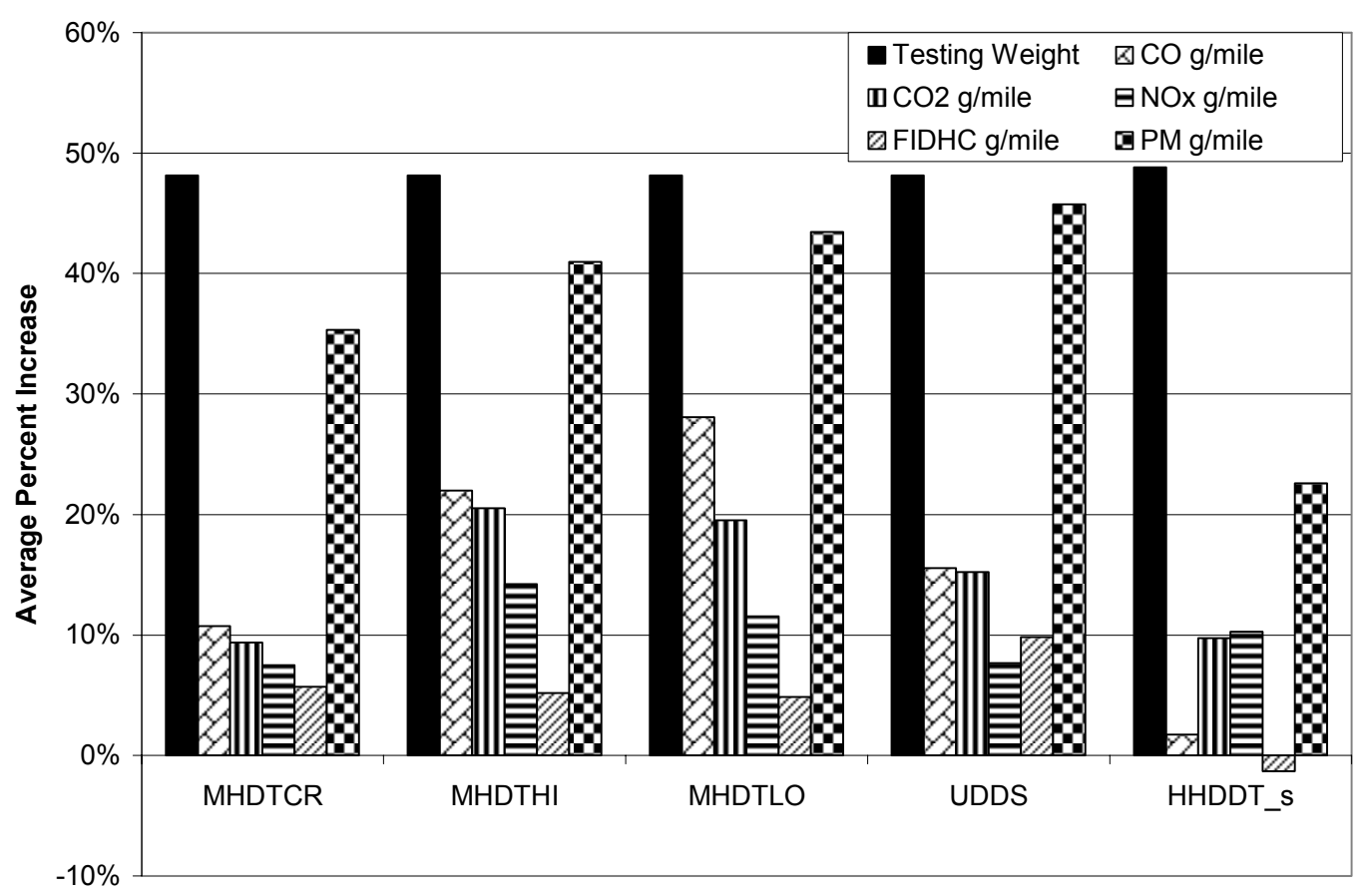

Figure 44: Average percent increase of the weight and various emissions for the different cycles for the MHDDT

\subsubsection{GASOLINE MHDT (MHDGT)}

Figure 45 shows the average percent increase of emissions for the four MHDGT for a $50 \%$ increase in weight. An increase in weight showed an increase in emissions for $\mathrm{CO}_{2}, \mathrm{NO}_{\mathrm{X}}, \mathrm{CO}$ and HC. This increase in emissions had no relationship to weight change. 


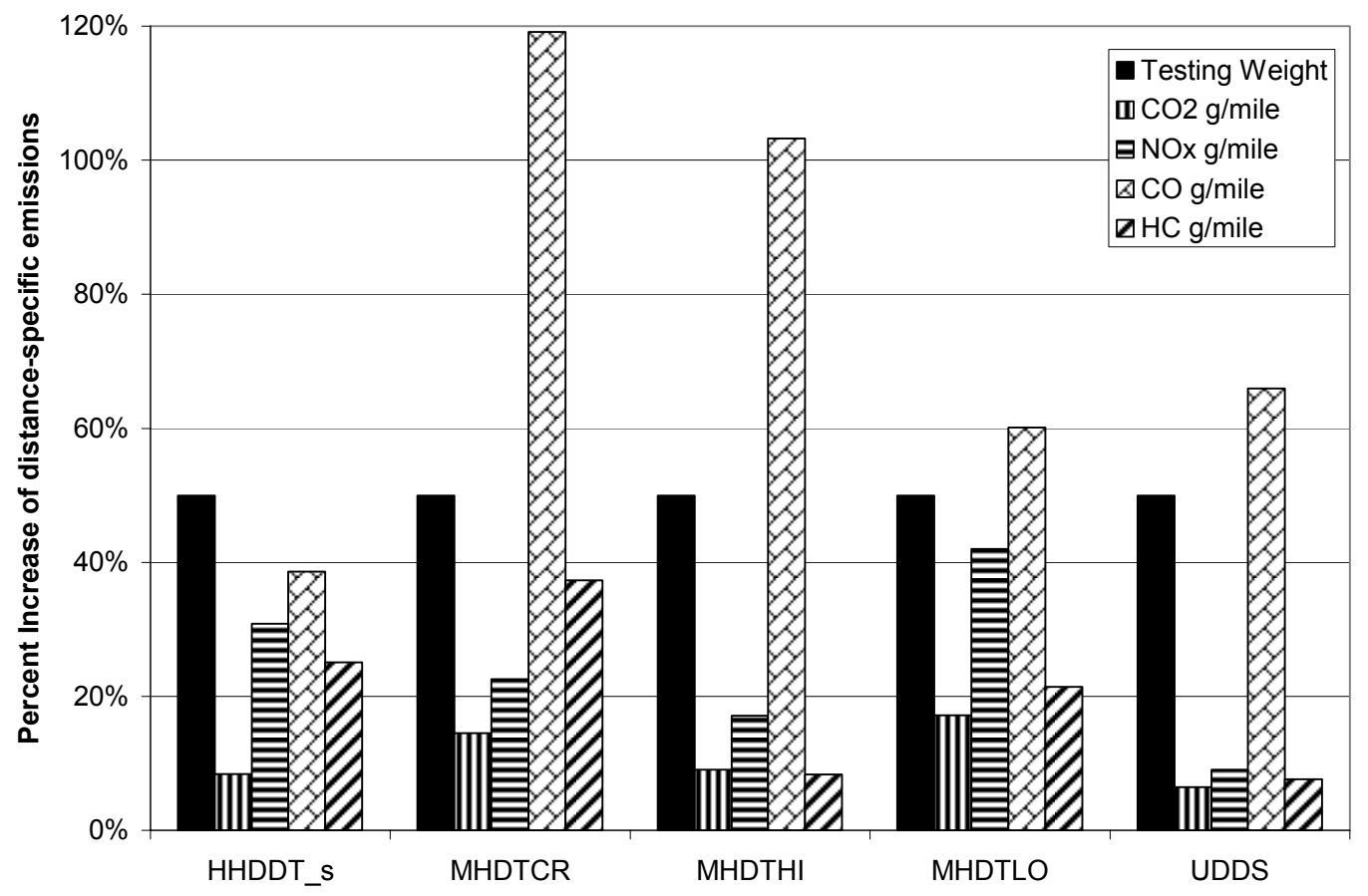

Figure 45: Average percent increase of the weight and various emissions for the different cycles for the MHDGT

The fuel specific emissions for $\mathrm{NO}_{\mathrm{x}}, \mathrm{CO}$ and $\mathrm{HC}$ were also analyzed. Figure 46 shows the result of this analysis for each of the five cycles. It was seen that the fuel specific values for these emissions varied greatly. 


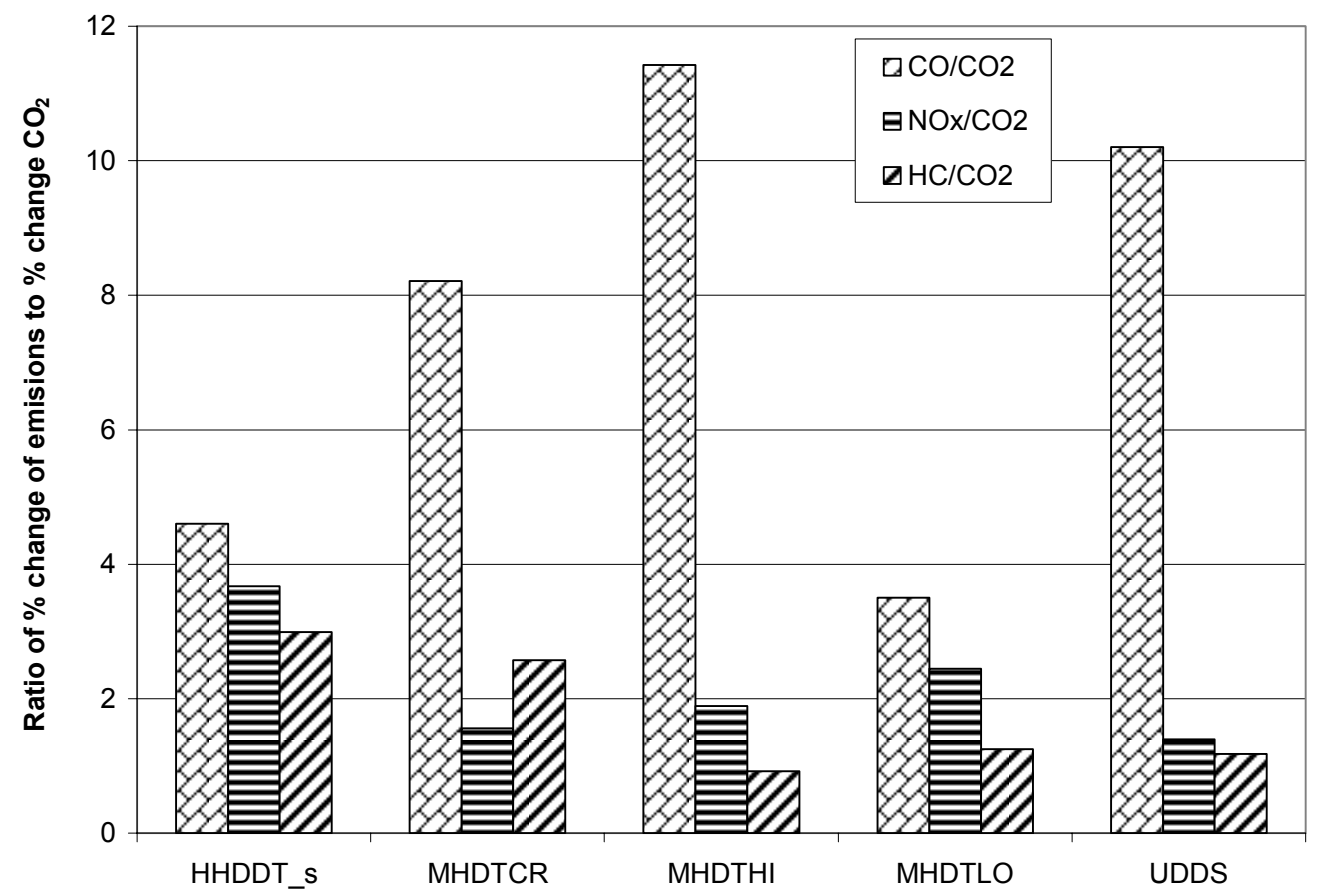

Figure 46: Increase in fuel specific emissions in terms of $\%$ change of emissions to $\%$ change of $\mathrm{CO}_{2}$ for the MHDGT

\subsection{HHDDT RESULTS}

The cycles: Creep mode, Cruise mode, and Transient mode, showed some form of consistent linear predictability for interpolating the emitted $\mathrm{NO}_{\mathrm{X}}$. The accuracy of these predictions depended on the range of the weight difference. The smaller the difference, the higher the confidence in the accuracy. In cycles with high average velocities, $\mathrm{NO}_{\mathrm{X}}$ emissions were unpredictable using weight. The high average velocity increased the relevance of the drag term in the road load equation contributing to increased power demand and, thus, emissions. Extrapolation of this data based solely on weight factors resulted in intangible errors.

When comparing emissions on different cycles relative to weight, the weight effects did not show similar trends for different vehicles. If the slope of the emissions difference was considered as an interpolative estimator of the $\mathrm{NO}_{\mathrm{X}}$, then the variation from the average of the calculated slope for a cycle varied by as much as $480 \%$. This made accurately predicting $\mathrm{NO}_{\mathrm{X}}$ emissions improbable.

Figure 47 shows the $\mathrm{NO}_{\mathrm{X}}$ trends at different weights for the Creep mode. The distance specific emissions increased and decreased with increase in weight. The cause of this unpredictable trend was attributed to the Creep mode characteristics. The Creep mode is dominated by idle and is 
therefore almost weight independent and is influenced by auxiliary loads [25]. A fleet-wide distance specific increase for $\mathrm{X} \%$ increase in weight for $\mathrm{NO}_{\mathrm{X}}$ was $\frac{8.67}{100} \mathrm{X} \%$ and for $\mathrm{CO}_{2}$ was $\frac{9.01}{100} \mathrm{X} \%$. The fuel specific emissions of $\mathrm{NO}_{\mathrm{X}}$ were consistent with $\mathrm{CO}_{2}$ emissions. Fuel specific PM emissions decreased with increase in weight.

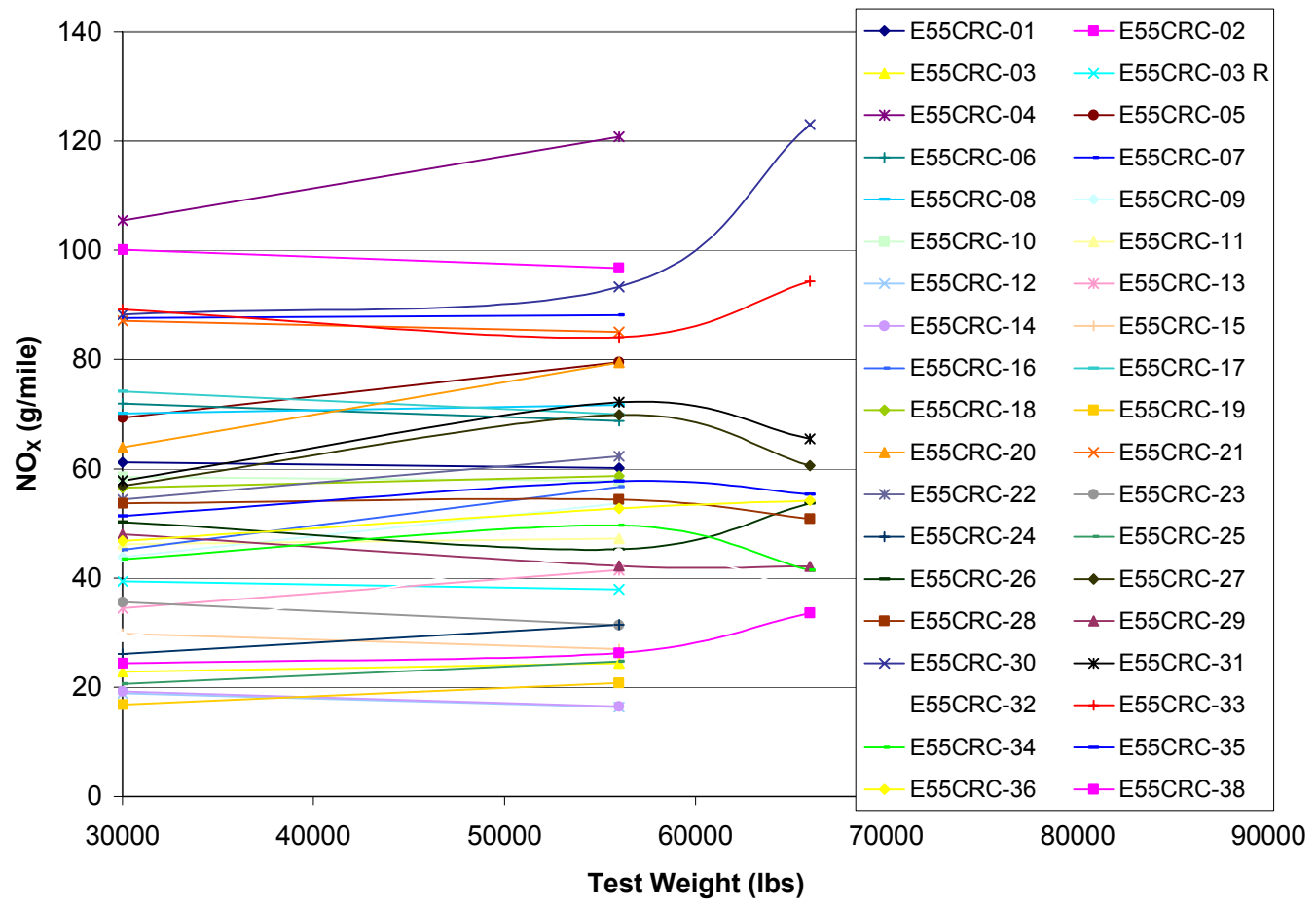

Figure 47: $\mathrm{NO}_{\mathrm{X}}$ emission trends for different vehicles at multiple operating weights on the Creep mode $\mathrm{NO}_{\mathrm{X}}$ emissions on the Cruise mode share the same results as those on the Creep mode. Figure 48 shows no consistent trends in distance specific emissions from one vehicle to the other, for the 38 vehicles at various tests weights. Fuel specific $\mathrm{NO}_{\mathrm{X}}$ emissions showed a direct relationship to the emitted $\mathrm{CO}_{2}$. The average slope of $\mathrm{NO}_{\mathrm{X}}$ change for the 38 vehicles for a weight change from $30,000 \mathrm{lbs}$ to $56,000 \mathrm{lbs}$ was $2.17 \mathrm{E}-4$. Similarly, the average slope for a weight change from $56,000 \mathrm{lbs}$ to $66,000 \mathrm{lbs}$ was $-1.48 \mathrm{E}-5$. The average slope for a weight change from $30,000 \mathrm{lbs}$ to $66,000 \mathrm{lbs}$ was $1.05 \mathrm{E}-4$. A fleet-wide distance specific increase for $\mathrm{X}$ $\%$ increase in weight for $\mathrm{NO}_{\mathrm{X}}$ was $\frac{44.64}{100} \mathrm{X} \%$ and for $\mathrm{CO}_{2}$ was $\frac{39.14}{100} \mathrm{X} \%$. 


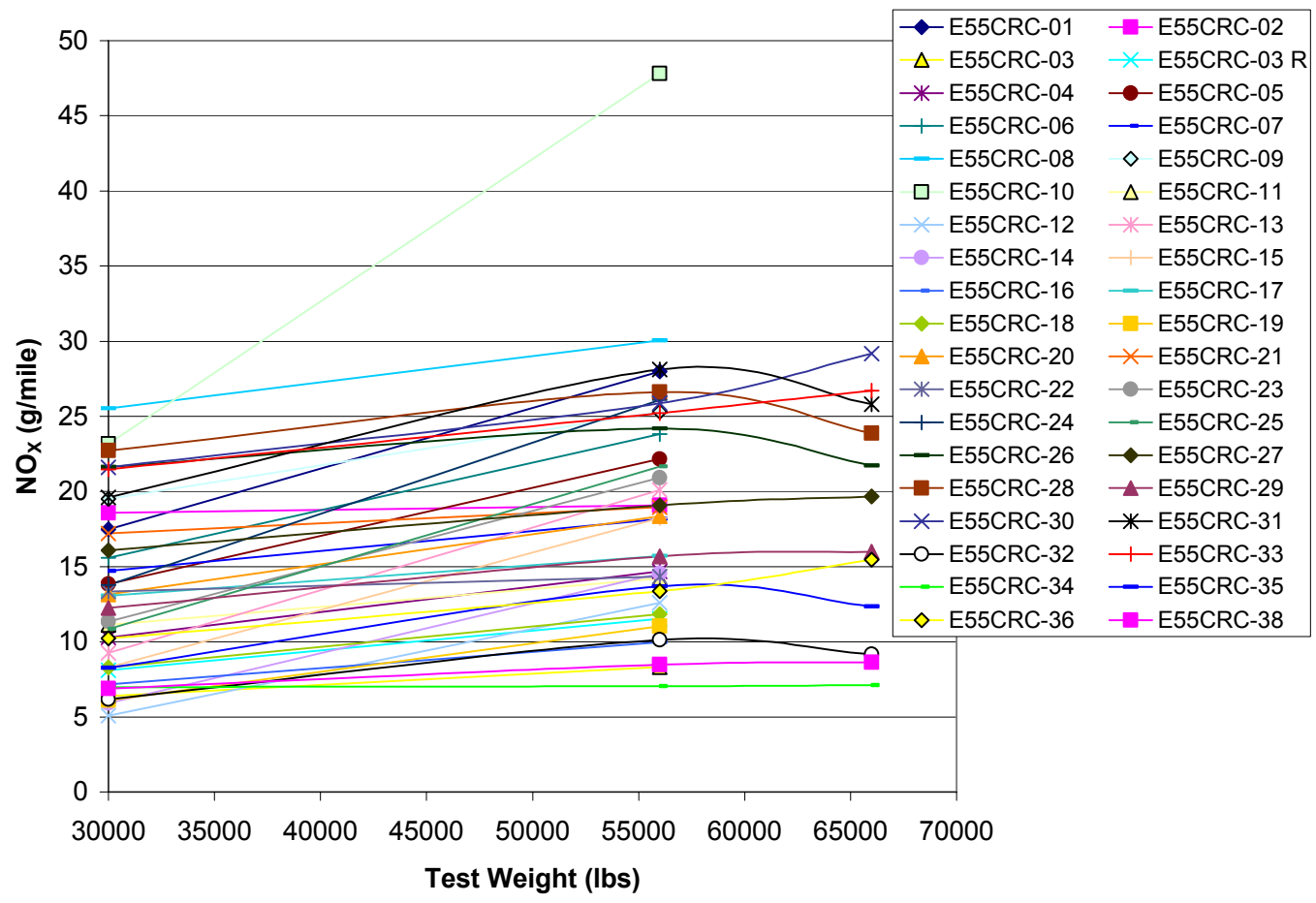

Figure 48: $\mathrm{NO}_{\mathrm{X}}$ emission trends for different vehicles at various operating weights on the Cruise mode The HHDDT_s mode showed the same unpredictable trends of $\mathrm{NO}_{\mathrm{X}}$ emissions prediction for the distance specific case (Figure 49). The fuel specific emissions remained consistent with variations in $\mathrm{CO}_{2}$ emissions. A fleet-wide distance specific increase for $\mathrm{X} \%$ increase in weight for $\mathrm{NO}_{\mathrm{X}}$ was $\frac{26.29}{100} \mathrm{X} \%$ and for $\mathrm{CO}_{2}$ was $\frac{23.63}{100} \mathrm{X} \%$. 


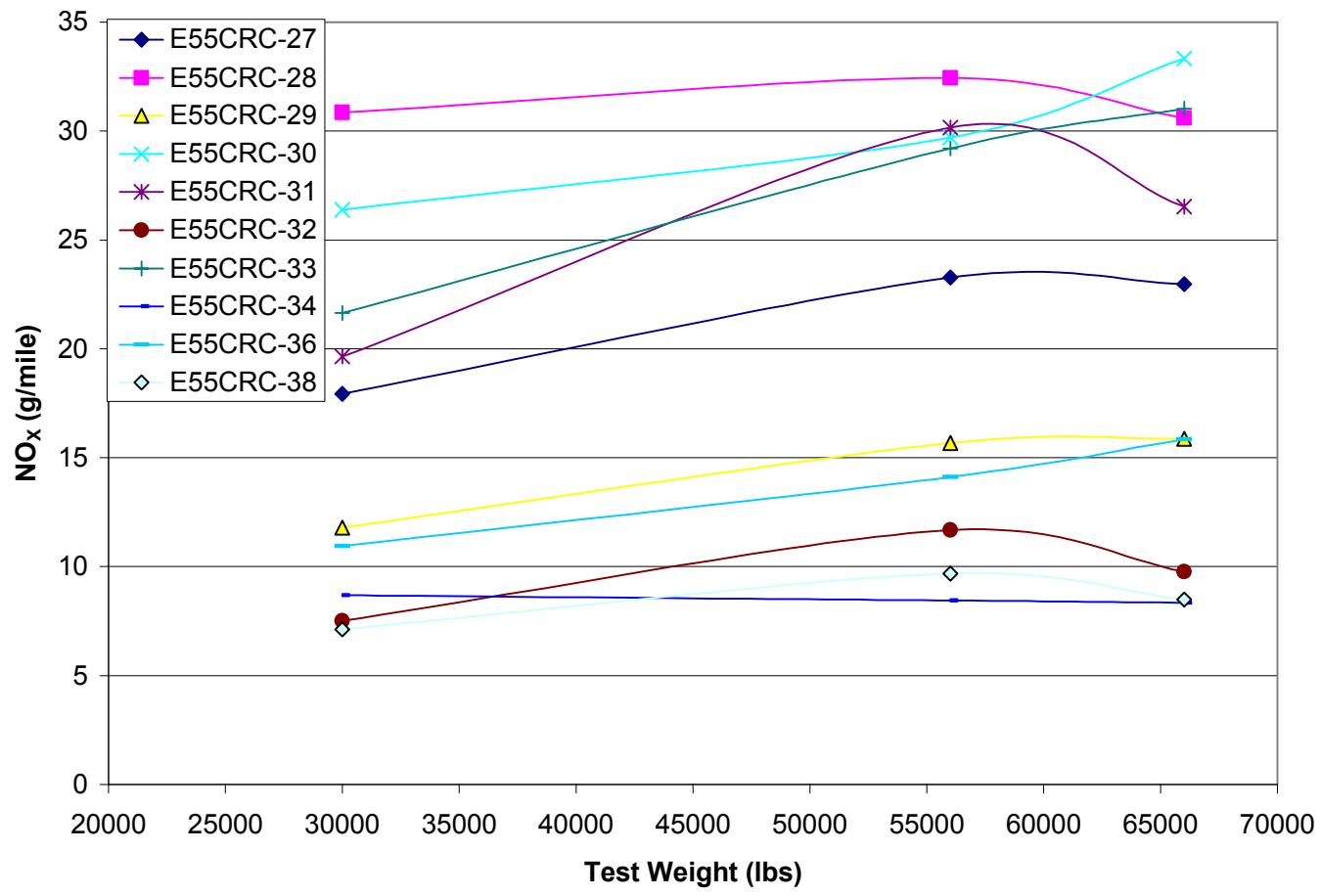

Figure 49: $\mathrm{NO}_{\mathrm{X}}$ emission trends for different vehicles at various operating weights on the HHDDT_s mode

Transient mode emissions maintained positive slope trends for $\mathrm{NO}_{\mathrm{X}}$ emissions when the test weight was increased from $30,000 \mathrm{lbs}$ to $56,000 \mathrm{lbs}$. When the test weight is increased to 66,000 lbs, it shows unpredictable trends. 


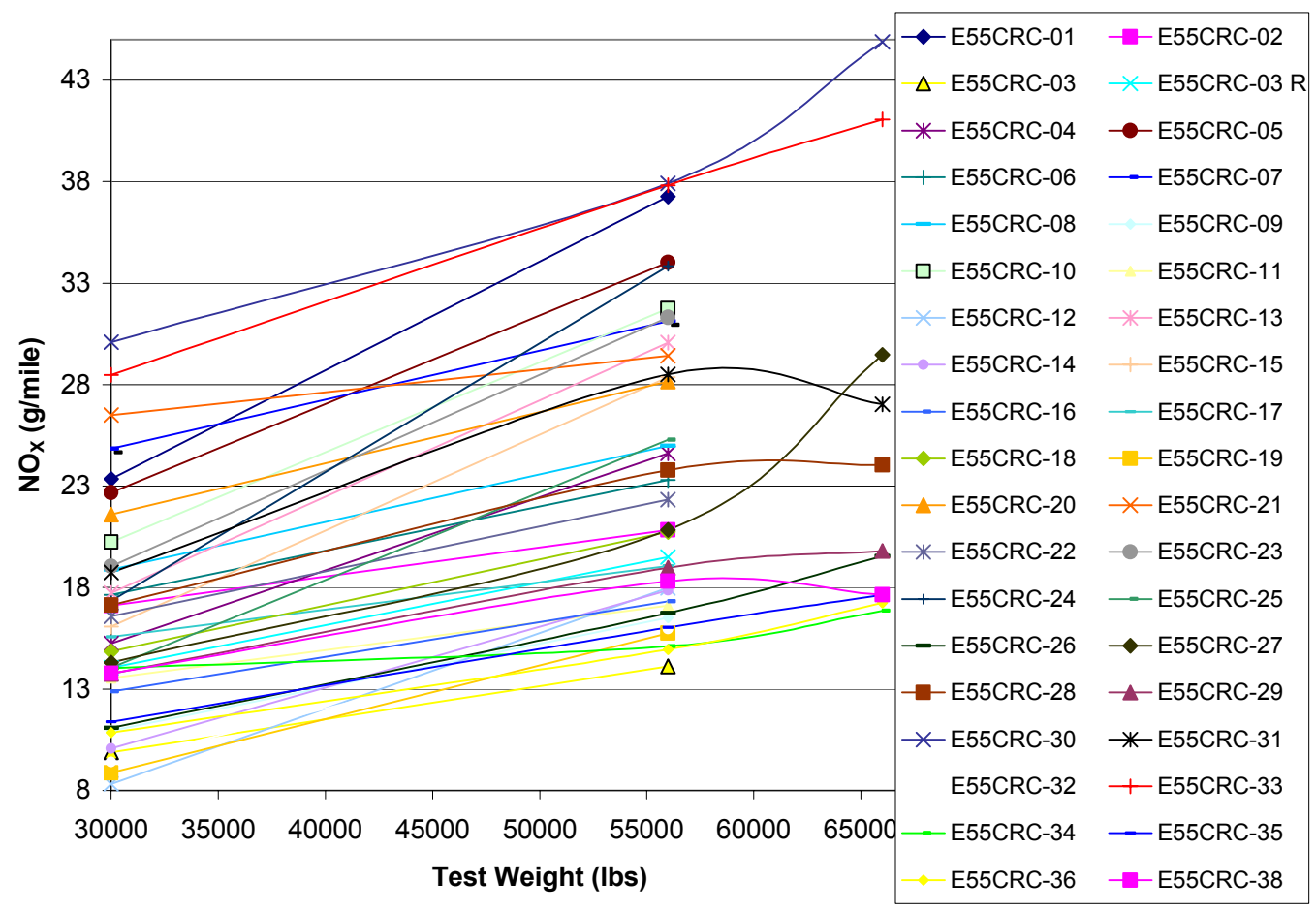

Figure 50: $\mathrm{NO}_{\mathrm{X}}$ emission trends for different vehicles at various operating weights on the Transient mode The fleet wide averages for the $\mathrm{CO}_{2}$ emission ratios, as shown in Figure 51 indicate no changes in fueling strategies relative to weight or load increase. The $\mathrm{NO}_{\mathrm{X}}$ emissions shown in Figure 52 have shown a step decrease in the $\mathrm{NO}_{\mathrm{X}}$ behavior at the $2003 \mathrm{MY}$. This seems to be a result of advanced engine technology such as EGR resulting from the need to adhere to tighter emissions standards. When increasing the test vehicle's weight, the change in $\mathrm{NO}_{\mathrm{X}}$ and $\mathrm{CO}_{2}$ emissions share the same trend. This shows $\mathrm{NO}_{\mathrm{X}}$ dependency directly related to fueling of heavy duty trucks. 


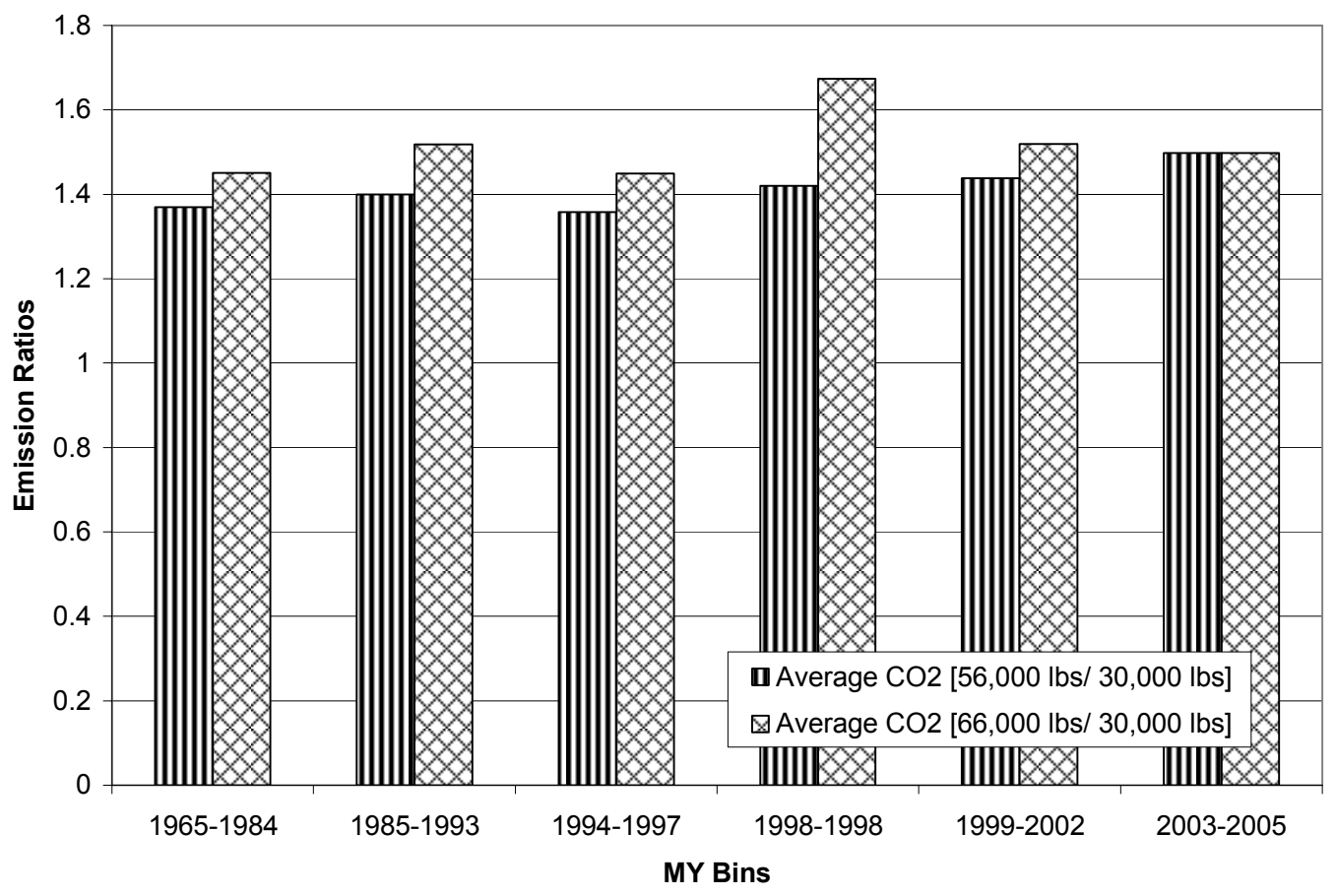

Figure 51: Transient mode $\mathrm{CO}_{2}$ averages

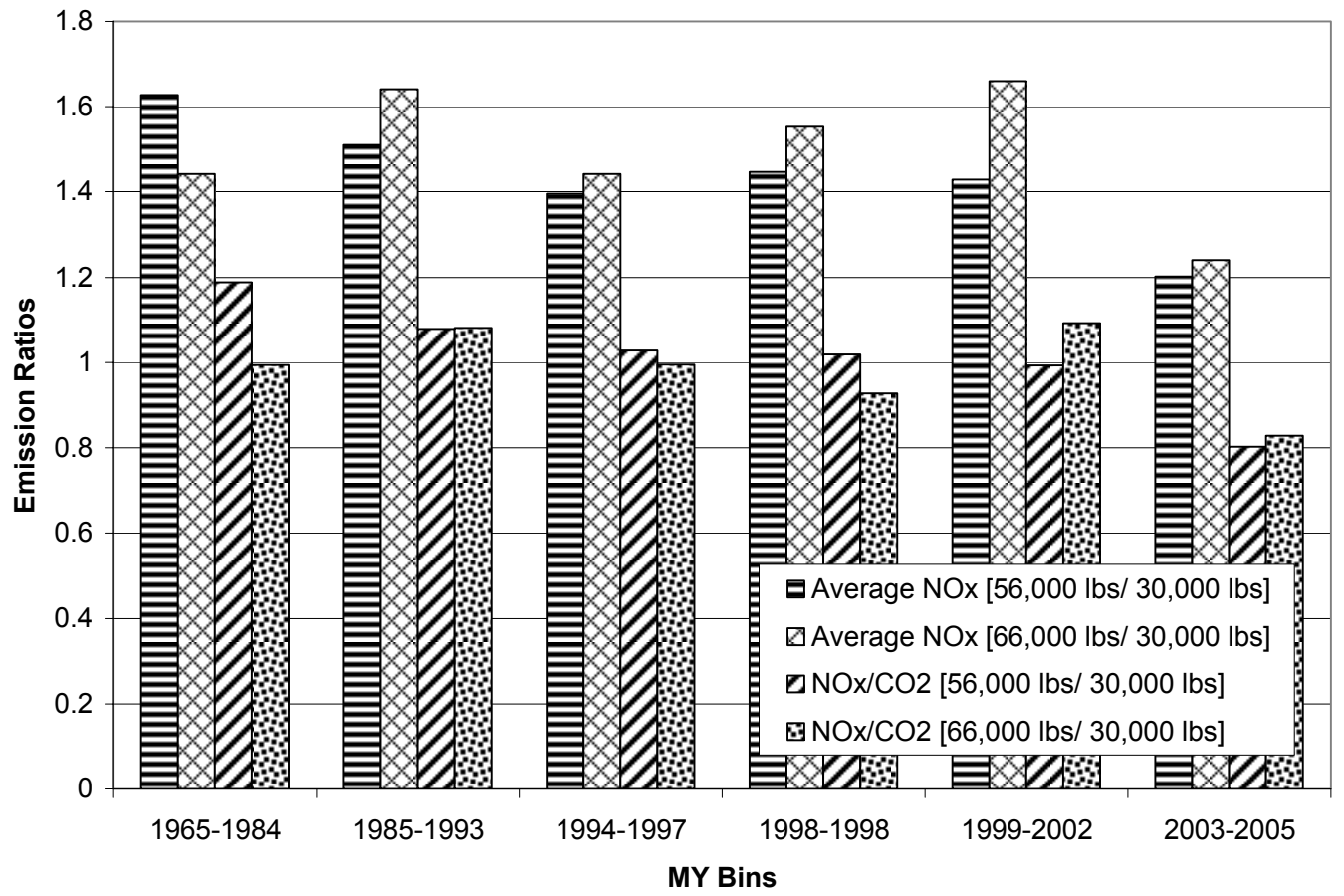

Figure 52: Transient mode $\mathrm{NO}_{\mathrm{X}}$ averages

PM, while maintaining fairly constant change in emitted values relative to weight, did not share the one-to-one relationship with $\mathrm{CO}_{2}$ as can be seen in Figure 53. PM emissions were not affected by model year. PM does seem to follow the trend of reduced change in emissions with 
larger weight differences. This indicates that higher fueling rates reduce the emissions of PM relative to weight, which is seen in the PM to $\mathrm{CO}_{2}$ ratios being less than 1.0. The newest model year vehicles show some change in engine control and design, which leads to lower PM for maximum loading of $66,000 \mathrm{lbs}$ compared to the 30,000 lbs scenario. Another reason for lowered PM with higher loading could be a cause of driving characteristics, where the driver may select higher gears at higher weights.

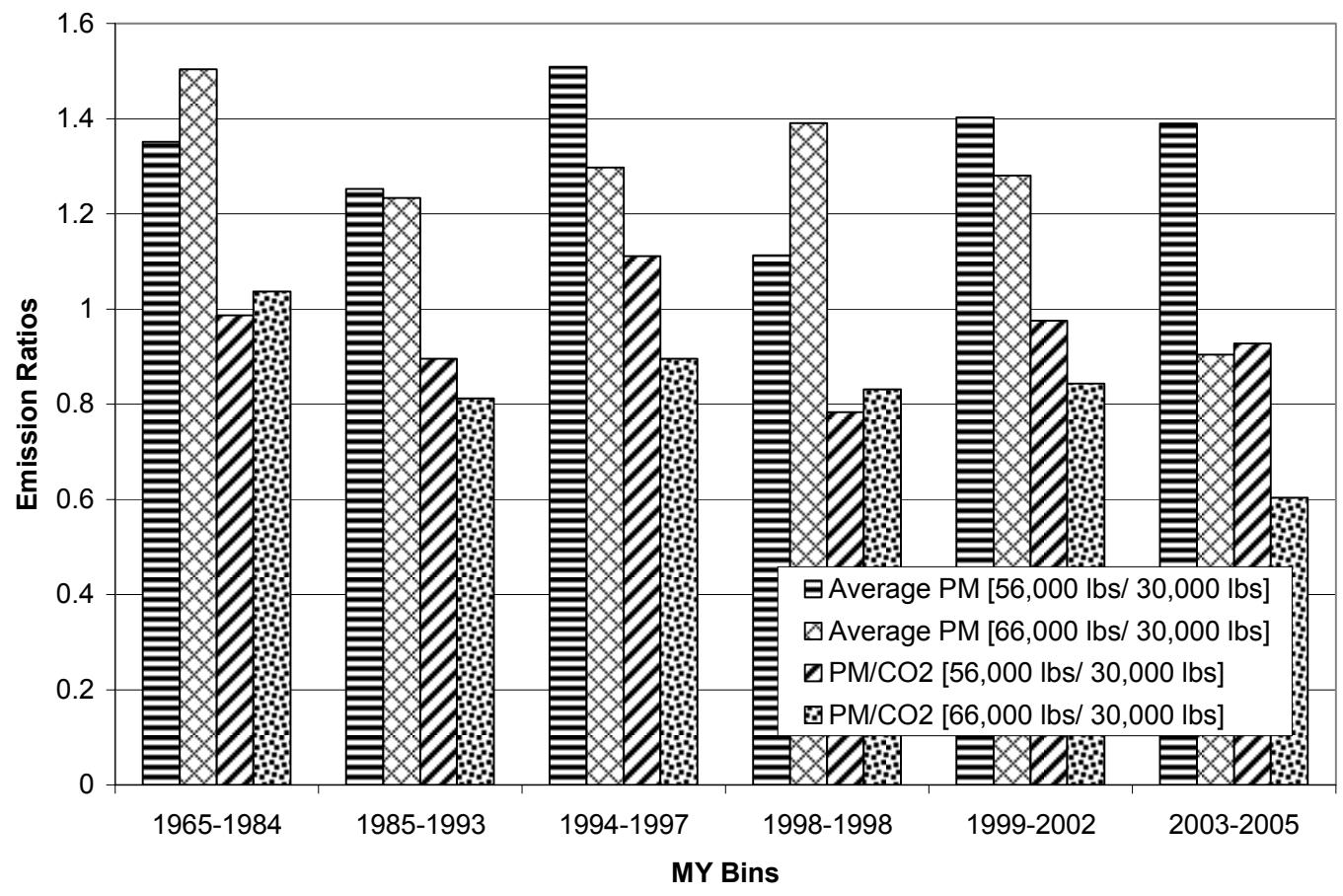

Figure 53: Transient mode PM averages

Figure 54 shows ratios of the average emitted emissions at 56,000 lbs to 30,000 lbs across the fleet of vehicles for the five cycles. $\mathrm{NO}_{\mathrm{X}}$ emissions increased at the same rate as those of $\mathrm{CO}_{2}$. But $\mathrm{HC}$ and PM ratios dropped with increased loading. Figure 55 shows the emitted ratios of $66,000 \mathrm{lbs}$ to $30,000 \mathrm{lbs}$ with the same conclusion as above. The figures also show that the weight effects are the largest for cycles with average speeds between $10 \mathrm{mph}$ and $40 \mathrm{mph}$. This occurs due to the dominance of idle at low average speeds and that of wind drag at high average speeds. 


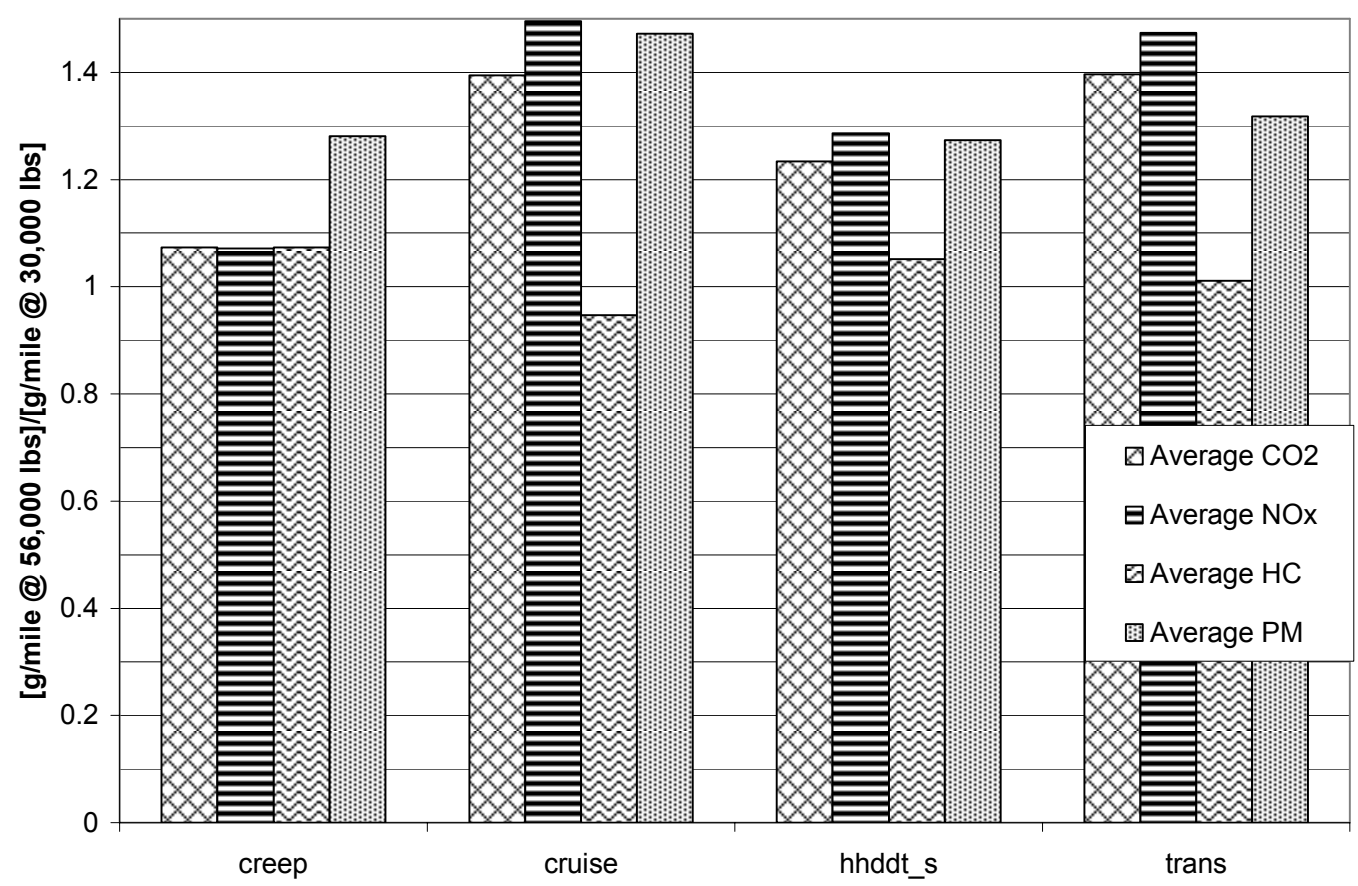

Figure 54: Ratios of the fleet wide averages for the vehicles at 56,000 lbs to $30,000 \mathrm{lbs}$

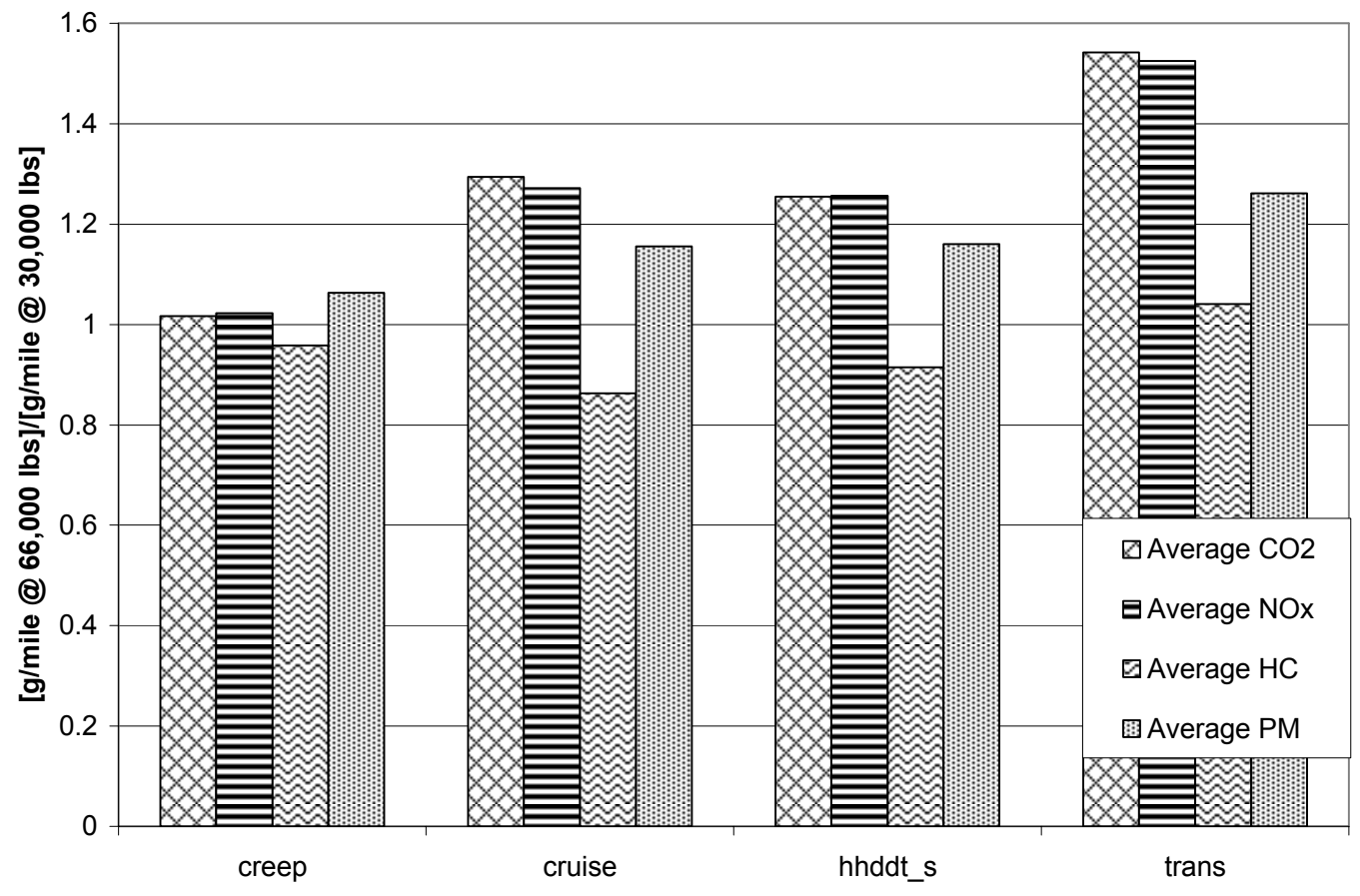

Figure 55: Ratios of the fleet wide averages for the vehicles at $66,000 \mathrm{lbs}$ to $30,000 \mathrm{lbs}$

Figure 56 shows change in emitted $\mathrm{NO}_{\mathrm{X}}$ for a weight difference from $30,000 \mathrm{lbs}$ to $56,000 \mathrm{lbs}$. Figure 57 shows weight difference from 30,000 lbs to 66,000 lbs and its corresponding increase in $\mathrm{NO}_{\mathrm{X}}$. It can be seen that there are large deviations in the increase in production of $\mathrm{NO}_{\mathrm{X}}$, 
relative to the base weight. Solid bars with white dots show the error resulting from the calculations of these emissions using the technique suggested by Gajendran et al. [24] and are labeled as 'Gajendran's Prediction Error.' The current dataset shows that instead of a $\frac{50}{100}$ X \% [24] or a $\frac{40}{100} \mathrm{X} \%$ [34] increase in $\mathrm{NO}_{\mathrm{X}}$ relative to an $\mathrm{X} \%$ increase in weight, a $\frac{47}{100} \mathrm{X} \%$ increase in $\mathrm{NO}_{\mathrm{X}}$ gives a more accurate estimate. For $\mathrm{CO}_{2}$, the data showed that an $\mathrm{X} \%$ increase in weight corresponded to a $\frac{46}{100} \mathrm{X} \%$ increase in emissions on the Transient mode.

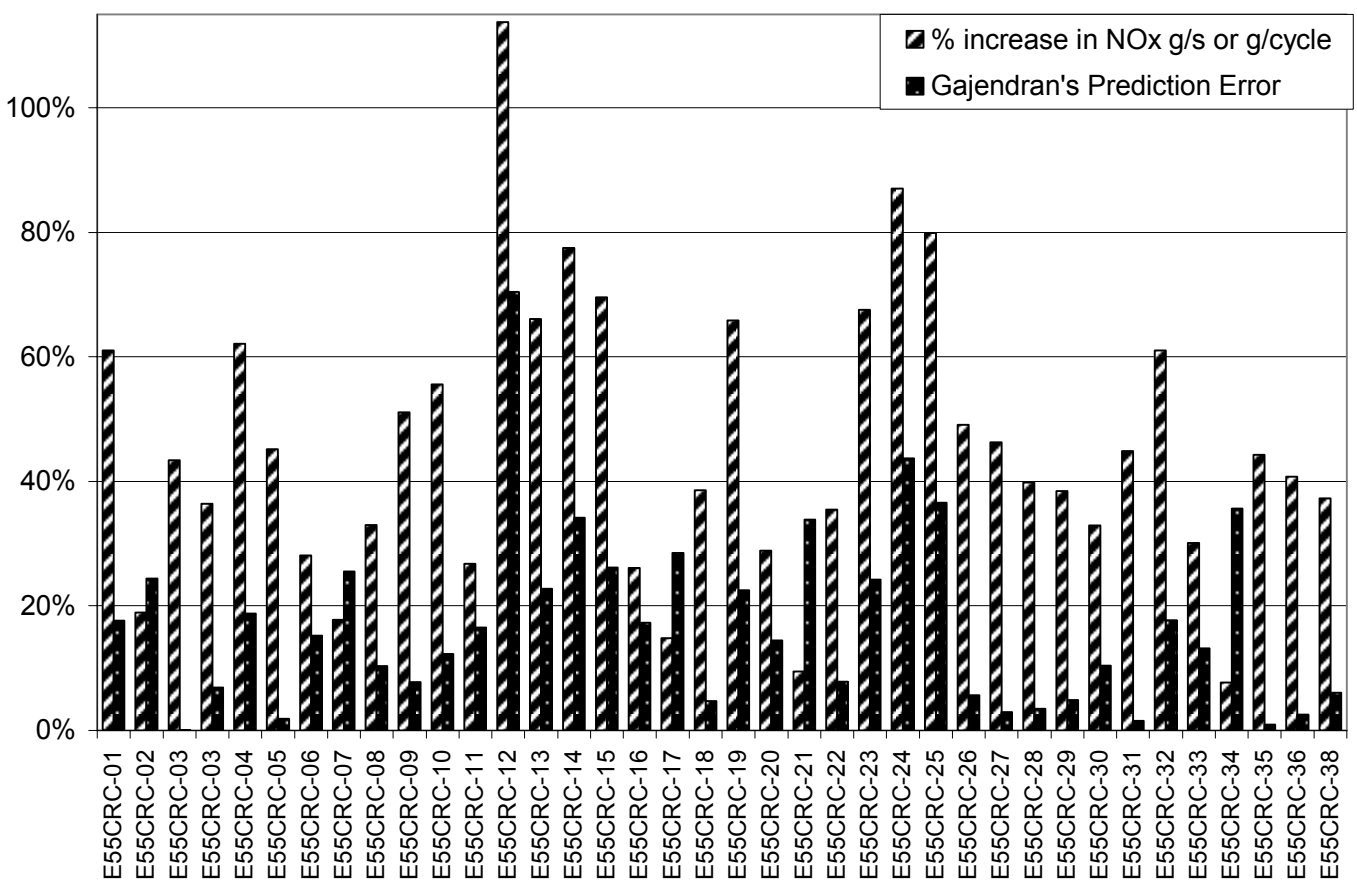

Figure 56: Ratio of Transient mode $\mathrm{NO}_{\mathrm{X}}$ emissions on vehicles tested at 30,000 lbs and 56,000 lbs (86.67 $\%$ increase in weight) 


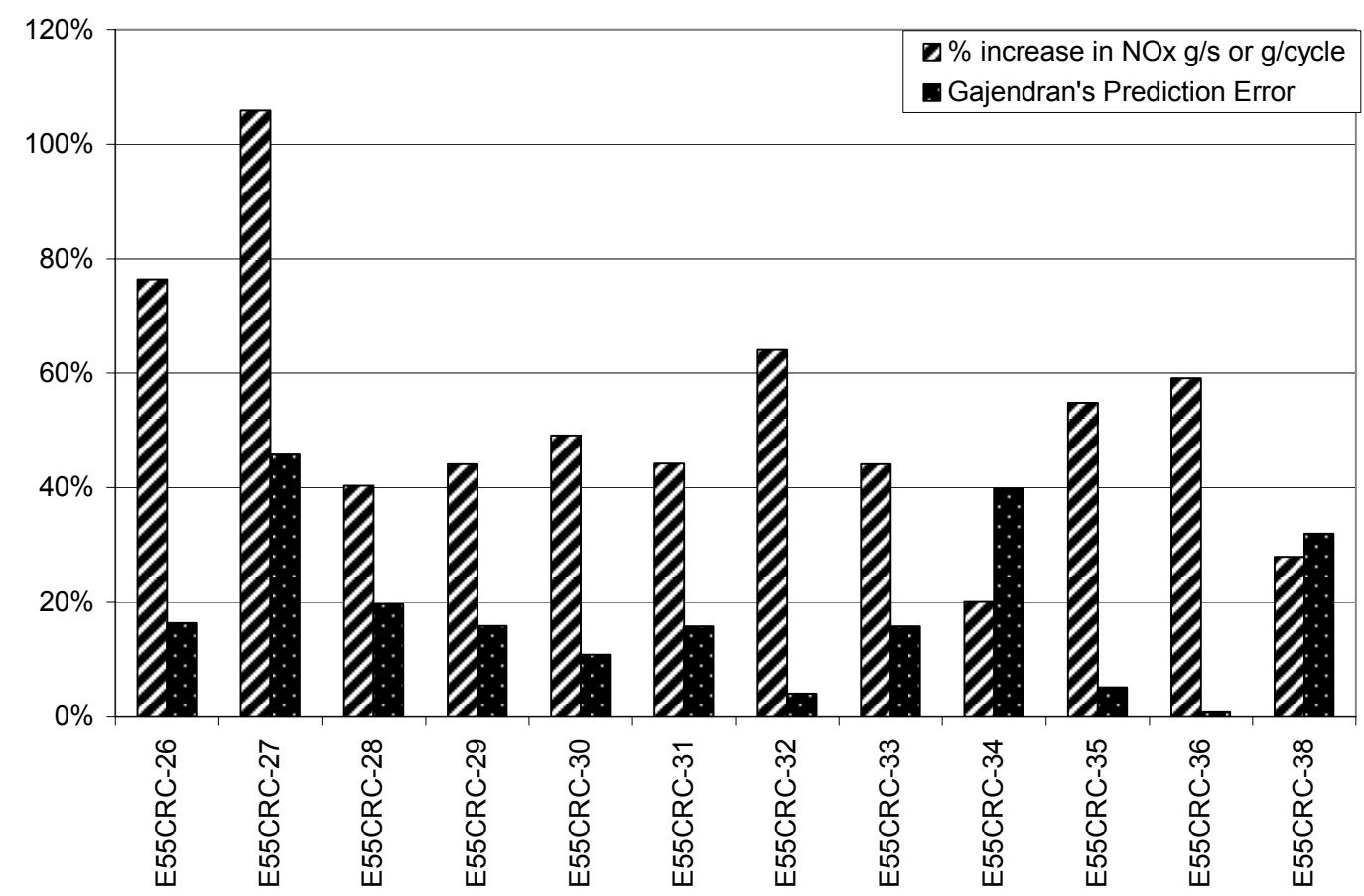

Figure 57: Ratio of Transient mode $\mathrm{NO}_{\mathrm{X}}$ emissions on vehicles tested at 30,000 lbs and 66,000 lbs (120\% increase in weight)

\subsection{CONCLUSIONS}

The vehicle weight has a significant effect on the emissions of $\mathrm{NO}_{\mathrm{X}}, \mathrm{PM}, \mathrm{HC}$ and $\mathrm{CO}_{2}$ of a vehicle. There is no definitive trend for HDT on a particular cycle for emission values at different weights. This makes individual vehicle emissions predictions inconsistent when using limited or singular emissions measurement values to predict its behavior at different weights. Fleet wide generalization such as that hypothesized by Gajendran et al. [24] and Brodrick et al. [34] were invalid for MHDT. With a single MHDT, the ability to predict emissions by interpolation or extrapolation was not evaluated due to lack of data at more than two weights for each vehicle.

Gasoline MHDT showed no consistent change with respect to weight. Fuel specific values for these trucks also varied greatly.

Fuel specific $\mathrm{NO}_{\mathrm{X}}$ emissions do not vary much with test weights for HHDDT. For fleet wide HHDDT generalization for distance specific $\mathrm{NO}_{\mathrm{X}}$, an $\mathrm{X} \%$ change in weight, changes $\mathrm{NO}_{\mathrm{X}}$ by $\frac{47}{100} \times \%$. Due to the empirical nature of these hypothesis, different databases and their size would effect the value of the numerical constant. With a single HHDDT, the ability to predict 
emissions at $56,000 \mathrm{lbs}$ by interpolating between $30,000 \mathrm{lbs}$ and $66,000 \mathrm{lbs}$ shows some level of consistency. Prediction by extrapolation shows erratic results. 


\section{Cycle Based Emissions Factors for Predicting $\mathrm{CO}_{2}$, NOx and PM}

\subsection{INTRODUCTION}

Historically, it has not been possible to compare the emissions behavior from two heavy-duty vehicles if they were tested on different cycles. Taylor et al. [10] used four dissimilar modes of the new California HHDDT test schedule to generate emissions predictions for the HHDDT on the UDDS. Taylor's method used the speed-time trace of the cycles to calculate weighting factors that were used to predict the emissions. The preparation of this method required no knowledge of emissions, but the factors thus calculated were later relaxed by using some emissions data to reduce the error. Sections 4 and 5 showed that it was possible to correlate emissions from one or two cycles to a third cycle. These one and two dimensional correlations did not identify the properties responsible for such a correlation. Section 6 examined the influence of weight on the emissions, but showed weight alone to be a poor predictor of emissions.

Here, a linear technique is presented which relies on emissions data and the speed-time trace to calculate emissions factors that are vehicle specific. It predicts levels of regulated emissions on a cycle using data from other cycles on which the vehicle has not been tested. The model presented uses two variables and three constants, requiring emissions data from three cycles. The method can be expanded based on the quantity of emissions data available from more than three distinct cycles to increase its predictive accuracy by employing additional variables. This linear technique can potentially be used with data from one or two cycles. If the cycles can be divided into various phases, with different characteristics such as idle, cruise and transient driving, each phase (or "bag") within a cycle can be treated as a unique cycle, provided that data can be compiled for the phases. This may not be possible for the case of PM where only cycleaveraged data are usually available [38].

\subsection{THEORY}

Emissions are load and cycle dependent $[39,40]$. Hence, intrinsic properties such as velocity and acceleration are used to characterize the cycles. Taylor et al. [10] used four variables, viz. average speed, stops per mile, percent idle and kinetic energy to develop a technique to translate emissions data between cycles. These variables were set up in a four by four matrix using three 
different cases, where each case used a linear combination of the emissions from three of the four variables and a constraint of the resulting coefficients summing to unity. The three values for each of the four coefficients were then averaged. In an attempt to decrease the predictive error, the averaged coefficients were used on a known set of vehicles and then corrected based on the resulting errors. The corrected coefficients were then used to predict emissions for the rest of the fleet. This method, while effective within a statistical error margin, was affected by engine technology changes and 'off-cycle' behavior. Thus, there is a need to develop a method that depends on both, the vehicles emissions and the speed-time trace to help better predict emissions.

The road-load equation gives information about the power requirement of a vehicle during operation. Since emissions are load dependent and the road-load equation gives vehicle power demand; the road-load equation can be used to predict emissions. In this section, the road-load equation was reorganized and presented in terms of vehicle and cycle properties that resulted in an equation useful in predicting emissions. The evaluated emitted species were $\mathrm{CO}_{2}, \mathrm{NO}_{\mathrm{X}}$ and PM. $\mathrm{CO}_{2}$ is not strongly affected by transients, but is load based. $\mathrm{NO}_{\mathrm{X}}$ is affected by load, and off-cycle behavior makes it dependent on the transients. PM depends on both load and transient behavior.

The cycles were characterized in terms of their velocity and acceleration and impulse power. The characteristics of interest were determined by evaluating the road load equation shown in Equation 8.

Equation 8

$\mathrm{P}_{\mathrm{D}}=\mathrm{P}_{\mathrm{aux}}+\frac{\left(\mathrm{m} \frac{\partial \mathrm{v}}{\partial \mathrm{t}} \mathrm{v}\right)+\left(\mathrm{mg}_{\mathrm{a}} \mathrm{C}_{\mathrm{R}} \mathrm{v}\right)+\left(0.5 \rho \mathrm{C}_{\mathrm{D}} \mathrm{A}_{\mathrm{F}} \mathrm{v}^{3}\right)}{\eta}$

This equation can be split into five terms,

Term $\mathrm{A}-\left[\mathrm{P}_{\mathrm{D}}\right]=$ Total power demand by vehicle from engine

Term $\mathrm{B}-\left[\mathrm{P}_{\mathrm{aux}}\right]=\mathrm{A}$ constant attributed to auxiliary load (lights, compressors, $\mathrm{A} / \mathrm{C}$ )

Term $\mathrm{C}-\left[\mathrm{m} \frac{\partial \mathrm{v}}{\partial \mathrm{t}} \mathrm{v}\right]=$ Constant mass, variable acceleration and variable velocity 
Term D $-\left[\mathrm{mg}_{\mathrm{a}} \mathrm{C}_{\mathrm{R}} \mathrm{v}\right]=$ Constant mass, constant acceleration due to gravity, constant rolling resistance and variable velocity

Term $\mathrm{E}-\left[0.5 \rho \mathrm{C}_{\mathrm{D}} \mathrm{A}_{\mathrm{F}} \mathrm{v}^{3}\right]=$ Constant density, constant wind drag coefficient, constant frontal cross sectional area and variable velocity

The constants were associated with the vehicle and the environment. The variables were associated with the cycle, as a result of its speed-time nature. The road load and auxiliary load can be gathered into four discrete terms for any given cycle. One may view these terms extensively, in which case they are (i) cycle duration (in time), (ii) distance traveled (which is the integral of the velocity over the cycle duration), (iii) the integral of the cube of the velocity over the cycle (to account for wind drag) and (iv) an integral measure associated with acceleration loads (such as the integral of positive values of $\frac{\partial v}{\partial t}$ or $v \frac{\partial v}{\partial t}$ over the whole cycle). In practice, cycles are usually characterized by a discrete set of speed-time points, and so the process of integration is actually a summation. If these terms are viewed intensively (per unit time), (i) becomes unity, (ii) becomes average velocity, (iii) becomes the average value of $v^{3}$ and (iv) becomes an average of positive values of $\frac{\partial v}{\partial t}$ or $v \frac{\partial v}{\partial t}$ over the cycle.

Rearranging Equation 8 in terms of constants and variables would then result in Equation 9, which is extensive.

\section{Equation 9}

$\mathrm{E}_{\mathrm{M}}=\mathrm{K}_{\mathrm{b}}+\mathrm{K}_{\mathrm{c}} \sum\left(\mathrm{v} \frac{\partial \mathrm{v}}{\partial \mathrm{t}}\right)+\mathrm{K}_{\mathrm{d}} \sum(\mathrm{v})+\mathrm{K}_{\mathrm{e}} \sum\left(\mathrm{v}^{3}\right)$

- V - calculated by summing the instantaneous velocities.

- $\frac{\partial \mathrm{v}}{\partial \mathrm{t}}$ - calculated by considering those points of the speed-time trace that had an acceleration value greater than zero. 
- $\quad \mathrm{v} \frac{\partial \mathrm{v}}{\partial \mathrm{t}}$ - calculated by multiplying the $\mathrm{v}$ and the $\frac{\partial \mathrm{v}}{\partial \mathrm{t}}$ components for every point where the $\frac{\partial \mathrm{v}}{\partial \mathrm{t}}$ term was greater than zero.

Equation 9 shows that velocity, inertial power and acceleration (part of the inertial power term) are the three primary terms. The $\mathrm{v}^{3}$ term addresses non-linear behavior of load with respect to speed. The $\mathrm{v}^{3}$ term can be characterized as a resolution term for velocity. The values of $v, \frac{\partial v}{\partial t}$ and $v \frac{\partial v}{\partial t}$ were calculated from the cycle's targeted speed-time trace (except for CSHVR). These properties were made intensive by dividing them by the time of the cycle or number of points over which the cycle is defined, thus resulting in their average values. The results for eight different cycles are shown in Table 8.

These terms were put into a linear form, first using a simple case of velocity and acceleration as shown in Equation 10 and then using the velocity and the inertial power term as shown in Equation 11.

Equation 10

$\mathrm{E}_{\mathrm{M}}=\mathrm{K}_{0}+\left[\mathrm{K}_{1} \overline{\mathrm{v}}\right]+\left[\mathrm{K}_{2} \frac{\overline{\partial \mathrm{v}}}{\partial \mathrm{t}}\right]$

Equation 11

$\mathrm{E}_{\mathrm{M}}=\mathrm{K}_{0}+\left[\mathrm{K}_{1} \overline{\mathrm{v}}\right]+\left[\mathrm{K}_{2} \overline{\left(\mathrm{v} \frac{\partial \mathrm{v}}{\partial \mathrm{t}}\right)}\right]$

Equation 10 and Equation 11 were used with the known values of emissions and cycle properties on the Cruise mode, Idle mode and Transient mode to calculate the values for the vehicular constants $\mathrm{K}_{0}, \mathrm{~K}_{1}$ and $\mathrm{K}_{2}$ for each of the two equations. An example of the matrix using Equation 10 is shown in Equation 12. These vehicle constants were then used to predict the emissions of $\mathrm{CO}_{2}, \mathrm{NO}_{\mathrm{X}}$ and PM for the Creep mode, CSHVR, HHDDT_s mode, Highway cycle and UDDS. 
Equation 12

$\left[\begin{array}{lll}1 & \overline{\mathrm{V}}_{\text {Cruise }} & \frac{\overline{\partial \mathrm{v}}}{\partial \mathrm{t}} \\ 1 & \overline{\mathrm{V}}_{\text {Idle }} & \frac{\overline{\partial \mathrm{v}}^{\text {Cruise }}}{\partial \mathrm{t}} \\ 1 & \overline{\mathrm{V}}_{\text {Transient }} & \frac{\frac{\partial \mathrm{v}}{\partial \mathrm{t}}_{\text {Transient }}}{}\end{array}\right]\left[\begin{array}{l}\mathrm{K}_{0} \\ \mathrm{~K}_{1} \\ \mathrm{~K}_{2}\end{array}\right]=\left[\begin{array}{l}\mathrm{E}_{\mathrm{M}_{\text {Cruise }}} \\ \mathrm{E}_{\mathrm{M}_{\text {Idle }}} \\ \mathrm{E}_{\mathrm{M}_{\text {Transient }}}\end{array}\right]$

Speed correction factors used in modeling tools like MOBILE6.2 (Environmental Protection Agency's (EPA) Vehicle Emission Modeling Software) [20] are one dimensional versions of this method.

When calculating the average errors to quantify the performance of the equations to predict the emissions, the following two equations were used:

Equation 13

Average Error $=\frac{\sum(\text { Predicted }- \text { Measured })}{\text { Number of Measurements }}$

Equation 14

Abs Average Error $=\frac{\sum \mid \text { Predicted }- \text { Measured } \mid}{\text { Number of Measurements }}$

\subsection{DATA FOR ANALYSIS}

This analysis used the data collected as part of the Gasoline-Diesel PM Split Study and E-55/59 program. The first test case used three vehicles common to both studies. This gave a wider range of cycles, schedules and routes data for use for this analysis than just using one of the two studies. The Gasoline-Diesel PM Split Study was conducted at 46,000 lbs, and the E-55/59 study was conducted at 30,000 $\mathrm{lbs}$ and $56,000 \mathrm{lbs}$ for the three vehicles. The vehicles were: a 1994 Freightliner with a Detroit Diesel Series 60 (E55CRC-01), a 1995 Freightliner with a Caterpillar 3406B (E55CRC-02) and a 1985 International with a Cummins NTCC-300 (E55CRC-03). The emissions data from the E-55/59 study were linearly interpolated for 46,000 lbs. An emissions database was created with three vehicles and six different cycles: Creep mode, Cruise mode, CSHVR, Transient mode, Idle mode and Highway cycle. 
The linear method using Equation 10 and Equation 11 was used on the HHDDT part of the E55/59 program ranging from model years 1969 - 2005. All the vehicles were not tested on the same set of cycles. Hence, 56 vehicles were used for the Creep mode and UDDS predictions and 27 vehicles were used for the HHDDT_s mode prediction.

\subsection{RESULTS}

\subsubsection{THE LINEAR FORM USING THE ACCELERATION TERM}

The values for average velocity, acceleration and inertial power as defined in the theory section are presented in Table 8 for all test cycles used. This list was used for obtaining the results using both Equation 10 and Equation 11. The CSHVR is not included in this table as it does not follow a speed-time trace. While evaluating the results for the three vehicles in Table 9 for the CSHVR, the speed-time trace of those three vehicles from the chassis dynamometer testing on the CSHVR was taken and averaged to produce "estimated CSHVR" cycle properties. The average velocity was $14.44 \mathrm{mph}$, average inertial power was $5.23 \mathrm{mph}-\mathrm{mph} / \mathrm{sec}$ and average acceleration was 0.31 $\mathrm{mph} / \mathrm{sec}$ for the estimated CSHVR. It should be noted that this route has drive sections that force full power operation.

Results shown in Table 9 used Equation 10. The table shows the measured values of $\mathrm{NO}_{\mathrm{X}}$ from the Cruise mode, Transient mode and the Idle mode used to calculate the vehicle constants designated by " $\mathrm{K}$ " using Equation 10. These values of $\mathrm{K}$ were then used to predict the $\mathrm{NO}_{\mathrm{X}}$ and compare them to the measured values for each vehicle on the Highway cycle, CSHVR and Creep mode. Emissions on the Highway cycle were predicted with a maximum error of $14.55 \%$. CSHVR was better predicted than the Highway cycle or the Creep mode, with an average error of $1.75 \%$ and an absolute average error of $4.78 \%$. The percent errors may be high but the mass difference is small compared with other cycles.

The value of $\mathrm{K}_{2}$ for E55CRC-02 is negative because transients suppress off-cycle emissions. $\mathrm{K}$ values vary much from truck to truck. This implies that different trucks have different types of activity that contribute more or less to emissions. 
Table 8: Cycle statistics for seven cycles

\begin{tabular}{|l|r|r|r|}
\hline & $\begin{array}{l}\text { Average } \\
\text { velocity }\end{array}$ & $\begin{array}{l}\text { Average inertial } \\
\text { power }\end{array}$ & $\begin{array}{l}\text { Average } \\
\text { acceleration }\end{array}$ \\
\hline & $\overline{\mathrm{v}}$ & $\overline{\mathrm{v} \frac{\partial \mathrm{v}}{\partial \mathrm{t}}}$ & \multicolumn{2}{c}{$\overline{\frac{\partial \mathrm{v}}{\partial \mathrm{t}}}$} \\
\hline & $\mathrm{mph}$ & $\mathrm{mph}-\mathrm{mph} / \mathrm{sec}$ & $\mathrm{mph} / \mathrm{sec}$ \\
\hline Creep & 1.64 & 0.23 & 0.07 \\
\hline Cruise & 39.88 & 3.86 & 0.12 \\
\hline Idle & 0.00 & 0.00 & 0.00 \\
\hline Transient & 14.92 & 5.06 & 0.29 \\
\hline Highway & 33.96 & 5.20 & 0.18 \\
\hline UDDS & 18.83 & 6.41 & 0.31 \\
\hline HHDDT_s & 49.88 & 8.04 & 0.21 \\
\hline estimated & 14.44 & 5.23 & 0.31 \\
CSHVR & & & \\
\hline
\end{tabular}

Table 9: Calculated $\mathrm{K}_{0}, \mathrm{~K}_{1}$ and $\mathrm{K}_{2}$ and predicted $\mathrm{NO}_{\mathrm{X}}$ for three HHDDT at 46,000 lbs using Equation 10

\begin{tabular}{|c|c|c|c|c|c|}
\hline \begin{tabular}{|c|} 
K based on \\
Cruise, Idle \\
and \\
Transient
\end{tabular} & & Cycle & $\begin{array}{c}\text { Measured } \\
\text { NO }_{\mathbf{X}} \\
(\mathrm{g} / \mathrm{min})\end{array}$ & $\begin{array}{c}\text { Predicted } \\
\text { NO }_{\mathbf{X}} \\
(\mathrm{g} / \mathrm{min})\end{array}$ & Error \\
\hline \multirow{6}{*}{$\begin{array}{l}\mathrm{K}_{0}=1.366 \\
\mathrm{~K}_{1}=0.352 \\
\mathrm{~K}_{2}=3.890\end{array}$} & \multirow{6}{*}{ 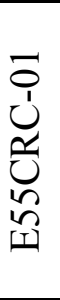 } & Cruise & 15.87 & --- & --- \\
\hline & & Idle & 1.37 & -- & 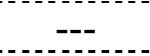 \\
\hline & & Transient & 7.75 & --- & -- \\
\hline & & Highway & 14.84 & 14.03 & $-5.50 \%$ \\
\hline & & Creep & 1.68 & 2.21 & $31.58 \%$ \\
\hline & & CSHVR & 8.03 & 7.67 & $-4.54 \%$ \\
\hline \multirow{6}{*}{$\begin{array}{l}\mathrm{K}_{0}=1.961 \\
\mathrm{~K}_{1}=0.281 \\
\mathrm{~K}_{2}=-5.400\end{array}$} & \multirow{6}{*}{ 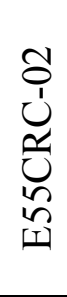 } & Cruise & 12.54 & --- & $\therefore$ \\
\hline & & Idle & 1.96 & -- & -- \\
\hline & & Transient & 4.59 & -- & -- \\
\hline & & Highway & 10.63 & 10.54 & $-0.87 \%$ \\
\hline & & Creep & 2.72 & 2.05 & $-24.62 \%$ \\
\hline & & CSHVR & 4.06 & 4.33 & $6.82 \%$ \\
\hline \multirow{6}{*}{$\begin{array}{l}\mathrm{K}_{0}=0.375 \\
\mathrm{~K}_{1}=0.106 \\
\mathrm{~K}_{2}=3.563\end{array}$} & \multirow{6}{*}{ 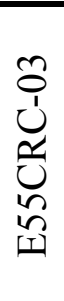 } & Cruise & 5.03 & -- & -- \\
\hline & & Idle & 0.38 & -- & - \\
\hline & & Transient & 3.00 & -- & -- \\
\hline & & Highway & 5.41 & 4.62 & $-14.55 \%$ \\
\hline & & Creep & 0.66 & 0.80 & $20.11 \%$ \\
\hline & & CSHVR & 2.93 & 3.02 & $2.97 \%$ \\
\hline
\end{tabular}

Equation 10 was then used on 56 vehicles at 56,000 lbs. Results are presented as parity plots for predicted versus measured values. Figure 58 shows that the $\mathrm{CO}_{2}$ prediction had a consistent over-prediction of $31.8 \%$. The best fit line on the figure shows the amount of over-prediction. 
This indicates that using only the variables of velocity and acceleration to predict the Creep mode is insufficient. A concern may be that the Creep mode consists mainly of idle operation, leading to poor use of velocity and acceleration as variables. But using more variables to predict this mode would require data from more cycles. The $\mathrm{NO}_{\mathrm{X}}$ prediction shown in Figure 59 has an error ranging from $0.09 \%$ to 2.9 times the emitted value. Table 10 shows the overall statistics of the Creep mode prediction using this linear method involving average velocity and average acceleration for $\mathrm{CO}_{2}, \mathrm{NO}_{\mathrm{X}}$ and $\mathrm{PM}$.

Figure 58, Figure 60 and Figure 62 have been magnified to help the reader visualize the emissions of the predicted versus measured parity plot. The diagonal line across each of the parity plots indicates zero error.

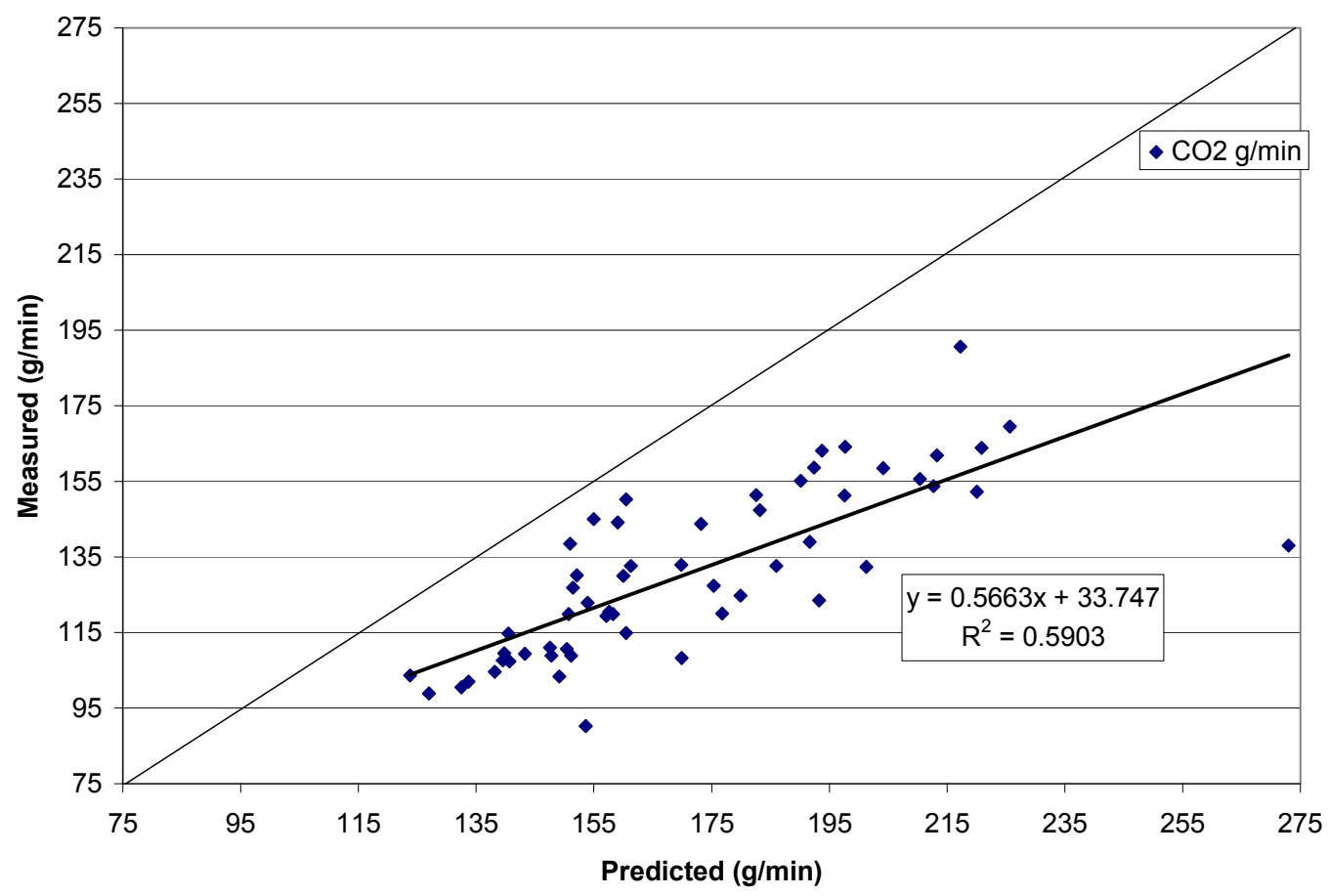

Figure 58: Predicted versus measured $\mathrm{CO}_{2}$ values of 56 HHDDT at 56,000 lbs on the Creep mode using Equation 10 


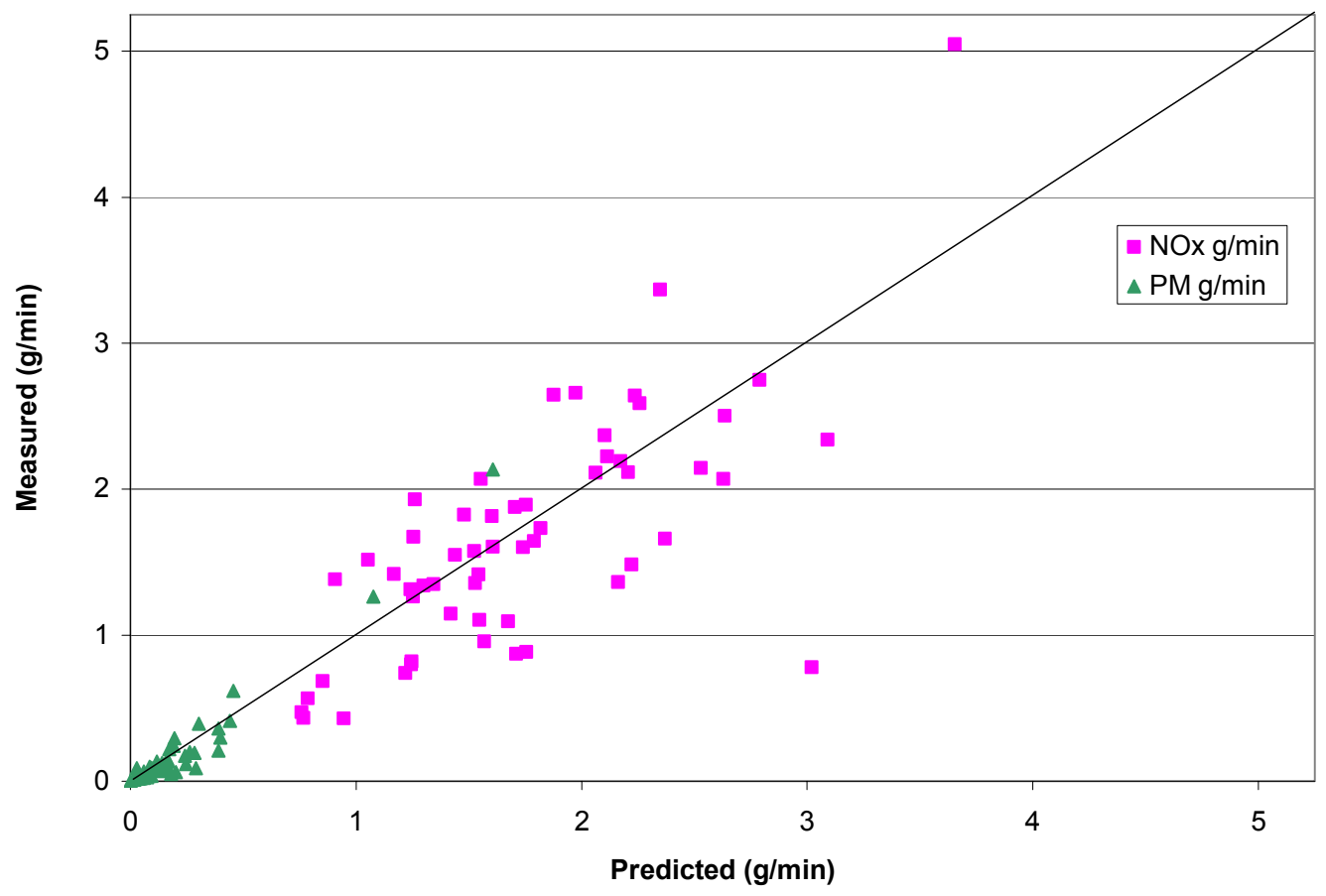

Figure 59: Predicted versus measured $\mathrm{NO}_{\mathrm{X}}$ and PM values of 56 HHDDT at 56,000 lbs on the Creep mode using Equation 10

Table 10: Statistics of the measured and predicted values for the 30 HHDDT at 56,000 lbs on the Creep mode using Equation 10

\begin{tabular}{|c|c|c|c|c|c|c|c|c|c|}
\hline & \multicolumn{3}{|c|}{ Measured } & \multicolumn{3}{|c|}{ Predicted } & \multicolumn{3}{|c|}{ Error } \\
\hline & $\begin{array}{c}\mathrm{CO}_{2} \\
\mathrm{~g} / \mathrm{min}\end{array}$ & $\begin{array}{l}\mathrm{NO}_{\mathrm{X}} \\
\mathrm{g} / \mathrm{min}\end{array}$ & $\begin{array}{c}\mathrm{PM} \\
\mathrm{g} / \mathrm{min}\end{array}$ & $\begin{array}{c}\mathrm{CO}_{2} \\
\mathrm{~g} / \mathrm{min}\end{array}$ & $\begin{array}{l}\mathrm{NO}_{\mathrm{X}} \\
\mathrm{g} / \mathrm{min}\end{array}$ & $\begin{array}{l}\mathrm{PM} \\
\mathrm{g} / \mathrm{min}\end{array}$ & $\mathrm{CO}_{2}$ & $\mathrm{NO}_{\mathrm{X}}$ & PM \\
\hline Average & 130.81 & 1.66 & 0.17 & 171.40 & 1.75 & 0.18 & $31.78 \%$ & $18.70 \%$ & $48.93 \%$ \\
\hline Std Dev & 22.32 & 0.81 & 0.33 & 30.28 & 0.62 & 0.26 & $15.27 \%$ & $51.77 \%$ & $71.45 \%$ \\
\hline $\begin{array}{l}\text { Abs } \\
\text { Average }\end{array}$ & 130.81 & 1.66 & 0.17 & 171.40 & 1.75 & 0.18 & $31.78 \%$ & $32.78 \%$ & $59.83 \%$ \\
\hline $\begin{array}{l}\text { Aibs } \\
\text { Minimum }\end{array}$ & 90.27 & 0.43 & 0.00 & 123.79 & 0.76 & 0.00 & $6.79 \%$ & $0.09 \%$ & $0.59 \%$ \\
\hline $\mathrm{Abs} \mathrm{Max}$ & 190.59 & 5.05 & 2.13 & 273.00 & 3.65 & 1.61 & $97.75 \%$ & 288.33 & $279.33 \%$ \\
\hline
\end{tabular}

The $\mathrm{NO}_{\mathrm{X}}$ emissions for the UDDS have previously been characterized as being the average of the Cruise mode and Transient mode. This resulted in an error of $9.18 \%$ in predicting the $\mathrm{NO}_{\mathrm{X}}$ for UDDS compared to the other cycles at $12.82 \%$ and $32.78 \%$, since the equation used to predict this utilized the cycle properties of the Cruise mode and Transient mode, as shown in Figure 61. $\mathrm{CO}_{2}$ is predicted without any consistent over-prediction or under-prediction of the entire set as seen in Figure 60. The average error in prediction was $4.43 \%$. 


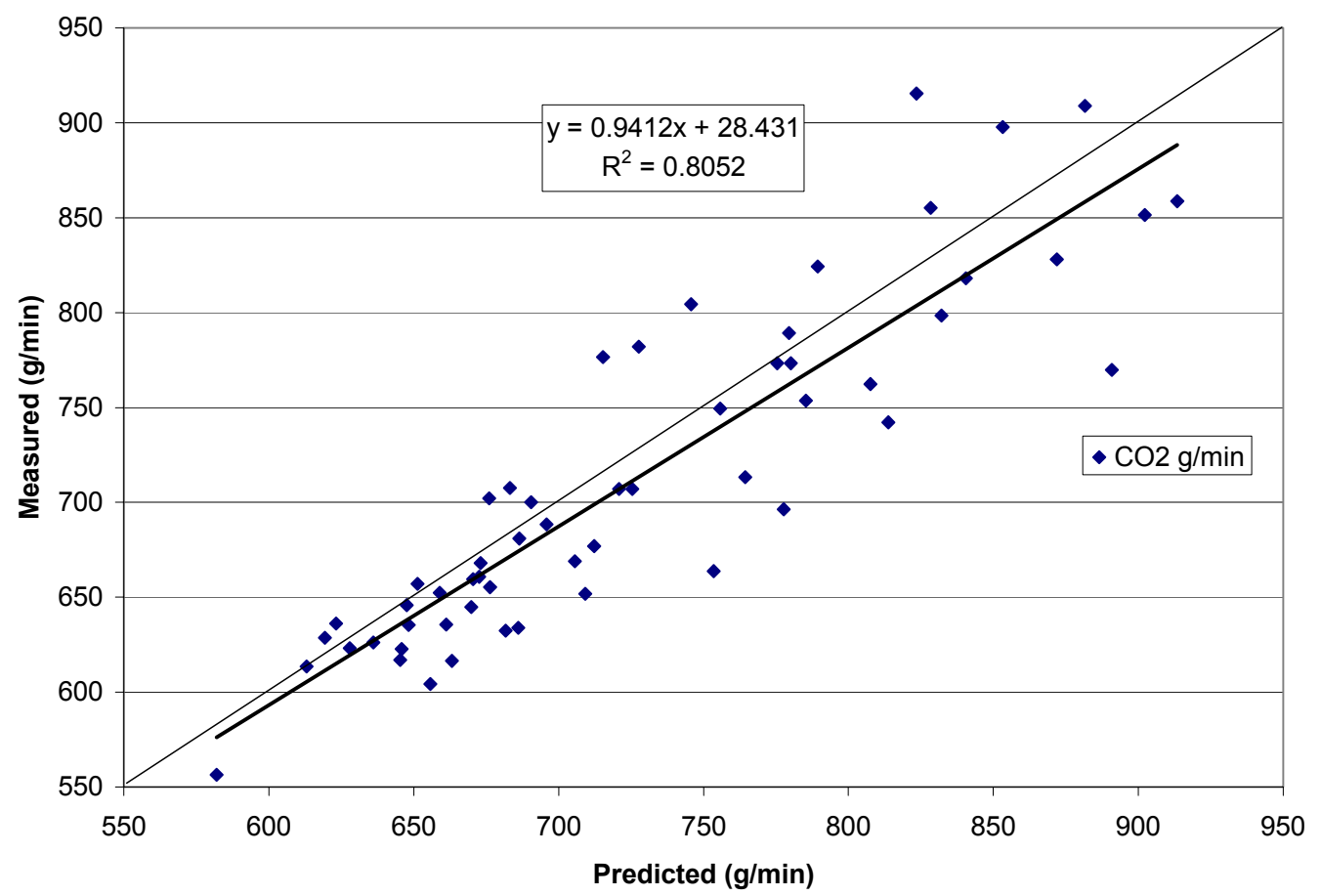

Figure 60: Predicted versus measured $\mathrm{CO}_{2}$ values of $56 \mathrm{HHDDT}$ at 56,000 lbs on the UDDS using Equation 10

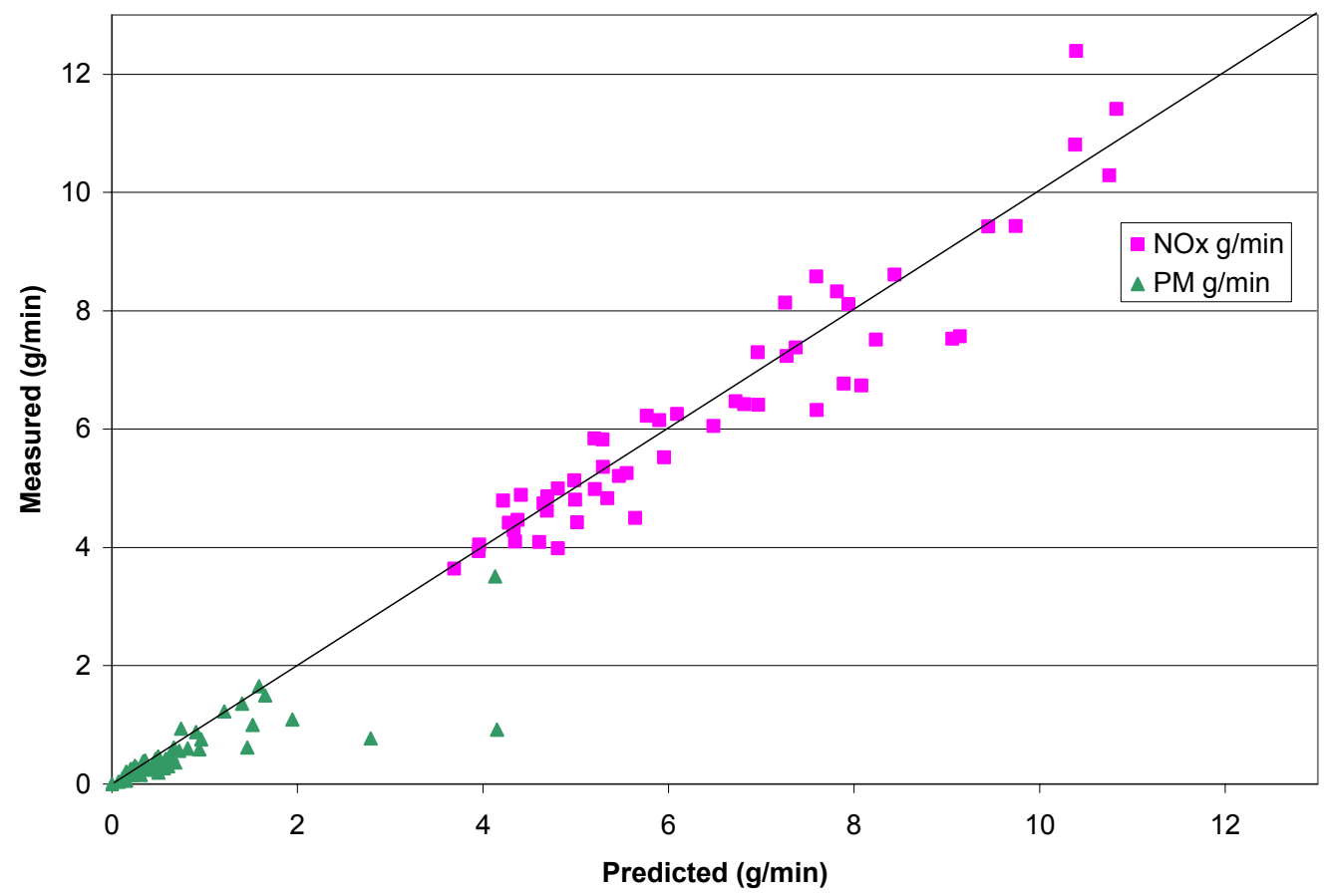

Figure 61: Predicted versus measured $\mathrm{NO}_{\mathrm{X}}$ and PM values of $56 \mathrm{HHDDT}$ at 56,000 lbs on the UDDS using Equation 10 
Table 11: Statistics of the measured and predicted values for the 30 HHDDT at 56,000 $\mathrm{lbs}$ on the UDDS using Equation 10

\begin{tabular}{|c|c|c|c|c|c|c|c|c|c|}
\hline & \multicolumn{3}{|c|}{ Measured } & \multicolumn{3}{|c|}{ Predicted } & \multicolumn{3}{|c|}{ Error } \\
\hline & $\begin{array}{c}\mathrm{CO}_{2} \\
\mathrm{~g} / \mathrm{min}\end{array}$ & $\begin{array}{l}\mathrm{NO}_{\mathrm{X}} \\
\mathrm{g} / \mathrm{min}\end{array}$ & $\begin{array}{c}\mathrm{PM} \\
\mathrm{g} / \mathrm{min}\end{array}$ & $\begin{array}{l}\mathrm{CO}_{2} \\
\mathrm{~g} / \mathrm{min}\end{array}$ & $\begin{array}{l}\mathrm{NO}_{\mathrm{X}} \\
\mathrm{g} / \mathrm{min}\end{array}$ & $\begin{array}{c}\mathrm{PM} \\
\mathrm{g} / \mathrm{min}\end{array}$ & $\mathrm{CO}_{2}$ & $\mathrm{NO}_{\mathrm{X}}$ & PM \\
\hline Average & 712.89 & 6.62 & 0.51 & 727.22 & 6.67 & 0.72 & $2.23 \%$ & $1.84 \%$ & $41.33 \%$ \\
\hline Std Dev & 87.66 & 2.59 & 0.55 & 83.58 & 2.46 & 0.85 & $5.22 \%$ & $10.22 \%$ & $68.00 \%$ \\
\hline $\begin{array}{l}\mathrm{Abs} \\
\text { Average }\end{array}$ & 712.89 & 6.62 & 0.51 & 727.22 & 6.67 & 0.72 & $4.43 \%$ & $7.73 \%$ & $45.97 \%$ \\
\hline $\begin{array}{l}\mathrm{Abs} \\
\text { Minimum }\end{array}$ & 556.46 & 3.64 & 0.00 & 581.93 & 3.69 & 0.00 & $0.08 \%$ & $0.17 \%$ & $0.37 \%$ \\
\hline $\mathrm{Abs}$ Max & 915.35 & 16.54 & 3.51 & 913.53 & 17.39 & 4.15 & $15.72 \%$ & $27.26 \%$ & $349.32 \%$ \\
\hline
\end{tabular}

The $\mathrm{CO}_{2}$ and $\mathrm{NO}_{\mathrm{X}}$ predictions were underestimated by $12 \%$ as seen in Figure 62 and Figure 63. Using the variables of velocity and acceleration to predict the HHDDT_s mode $\mathrm{CO}_{2}$ emissions from the Idle mode, Transient mode and Cruise mode indicated that the HHDDT_s mode was less transient than the other two modes. Thus, using acceleration as the only parameter other than velocity, resulted in an over-prediction of emissions. PM had an absolute average error of $22.07 \%$ as shown in Table 12 along with other statistical information on the accuracy of predictions.

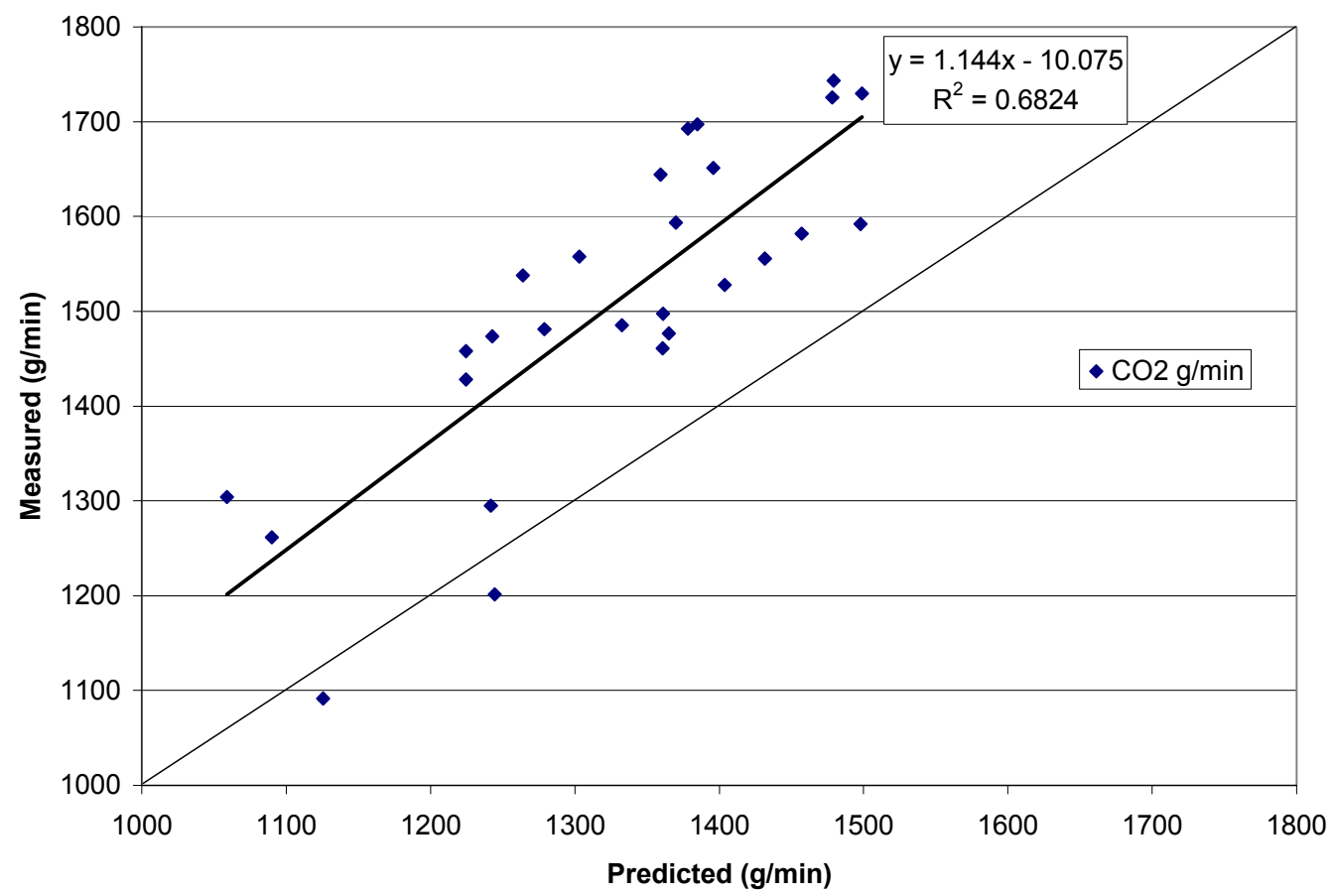

Figure 62: Predicted versus measured $\mathrm{CO}_{2}$ values of 27 HHDDT at 56,000 lbs on the HHDDT_s mode using Equation 10 


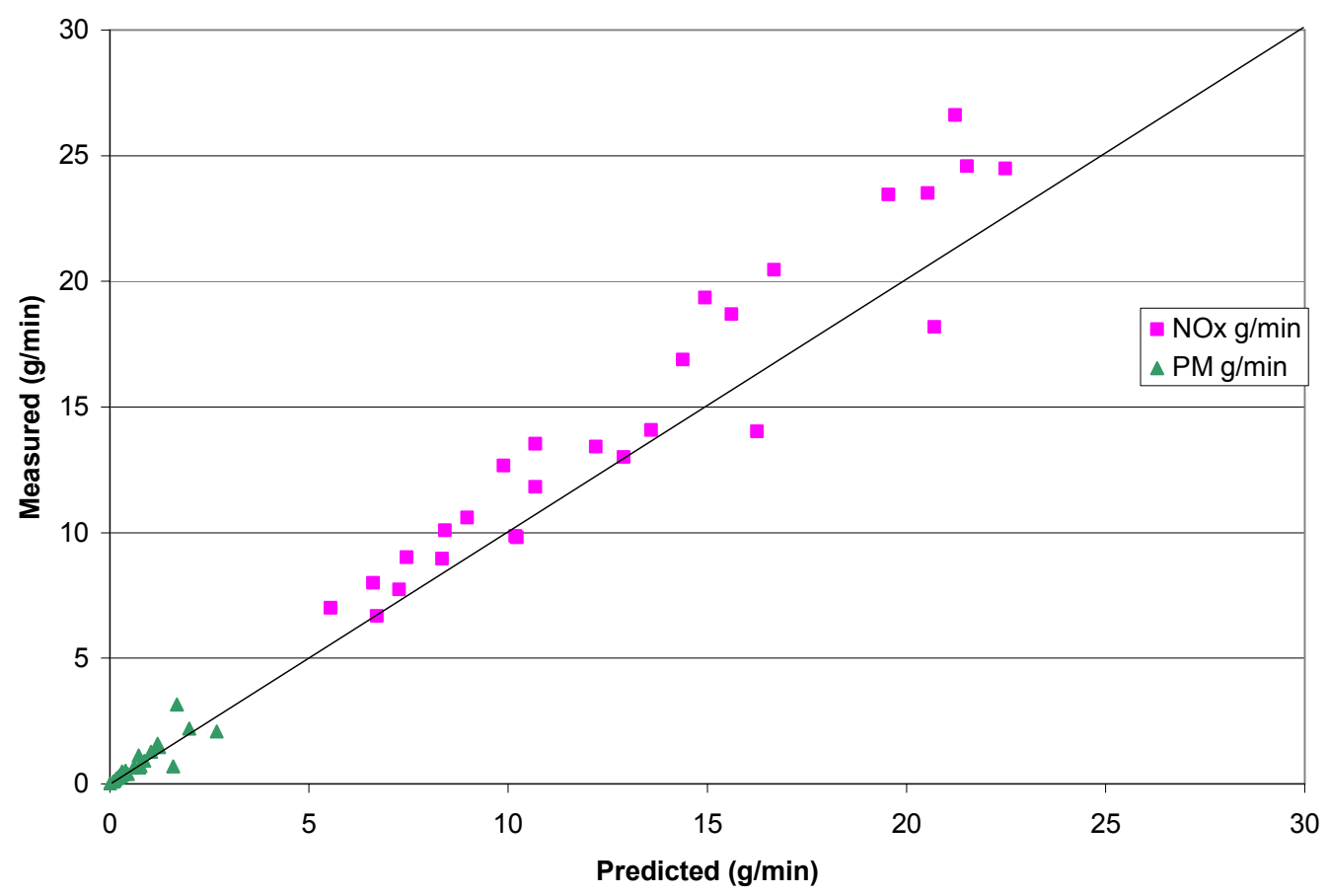

Figure 63: Predicted versus measured $\mathrm{NO}_{\mathrm{X}}$ and PM values of 27 HHDDT at 56,000 lbs on the HHDDT_s mode using Equation 10

Table 12: Statistics of the measured and predicted values for the 30 HHDDT at 56,000 $\mathrm{lbs}$ on the HHDDT_s mode using Equation 10

\begin{tabular}{|c|c|c|c|c|c|c|c|c|c|}
\hline & \multicolumn{3}{|c|}{ Measured } & \multicolumn{3}{|c|}{ Predicted } & \multicolumn{3}{|c|}{ Error } \\
\hline & $\begin{array}{c}\mathrm{CO}_{2} \\
\mathrm{~g} / \mathrm{min}\end{array}$ & $\begin{array}{l}\mathrm{NO}_{X} \\
\mathrm{~g} / \mathrm{min}\end{array}$ & $\begin{array}{c}\mathrm{PM} \\
\mathrm{g} / \mathrm{min}\end{array}$ & $\begin{array}{c}\mathrm{CO}_{2} \\
\mathrm{~g} / \mathrm{min}\end{array}$ & $\begin{array}{c}\mathrm{NO}_{\mathrm{X}} \\
\mathrm{g} / \mathrm{min}\end{array}$ & $\begin{array}{c}\mathrm{PM} \\
\mathrm{g} / \mathrm{min}\end{array}$ & $\mathrm{CO}_{2}$ & $\mathrm{NO}_{\mathrm{X}}$ & PM \\
\hline Average & 1509.05 & 14.68 & 0.79 & 1327.93 & 13.10 & 0.71 & $-11.62 \%$ & $-10.01 \%$ & $-8.02 \%$ \\
\hline Std Dev & 166.00 & 6.09 & 0.75 & 119.87 & 5.27 & 0.66 & $6.06 \%$ & $10.58 \%$ & $31.88 \%$ \\
\hline $\begin{array}{l}\text { Abs } \\
\text { Average }\end{array}$ & 1509.05 & 14.68 & 0.79 & 1327.93 & 13.10 & 0.71 & $12.12 \%$ & $12.82 \%$ & $22.07 \%$ \\
\hline $\mathrm{Abs}$ & & & & & & & & & \\
\hline Minimum & 1091.53 & 6.67 & 0.00 & 1059.05 & 5.55 & 0.00 & $3.10 \%$ & $0.61 \%$ & $5.92 \%$ \\
\hline $\mathrm{Abs} \mathrm{Max}$ & 1743.27 & 26.61 & 3.15 & 1498.92 & 22.49 & 2.68 & $18.79 \%$ & $22.72 \%$ & $129.69 \%$ \\
\hline
\end{tabular}

\subsubsection{THE LINEAR FORM USING THE INERTIAL POWER TERM}

Calculations resulting by the use of Equation 11 for the three HHDDT at 46,000 lbs showed similar predictive trends to the results using Equation 10. Highway cycle prediction was almost identical with an average error of $-6.26 \%$, while CSHVR was predicted with an average error of 4.95\%. This made Equation 10 a better predictor for CSHVR. Creep mode was predicted with an average error of $-2.11 \%$ and an absolute average error of $14.14 \%$. Thus for the three vehicles at 46,000 lbs, Highway cycle and Creep mode were better predicted by Equation 11 and CSHVR was better predicted by Equation 10 . 
Equation 11 was then used to predict the emissions for the Creep mode, UDDS and HHDDT_s mode using the same vehicles used to analyze Equation 10 from the E-55/59 study at 56,000 lbs.

In the case of the Creep mode, the use of Equation 10 over-predicted the $\mathrm{CO}_{2}$ emissions, while Equation 11 under-predicted them. Equation 11 seemed to be a more accurate predictor of all three species of emissions for the Creep mode.

Equation 11 consistently over-predicted $\mathrm{CO}_{2}$ emissions for UDDS by $9.18 \%$. The $\mathrm{NO}_{\mathrm{X}}$ prediction shown was consistent with that of Equation 10. The low error was attributed to the use of Cruise mode and Transient mode properties for the analysis.

Using Equation 11, the prediction of $\mathrm{CO}_{2}$ was improved by $5.8 \%$ and $\mathrm{NO}_{\mathrm{X}}$ was improved by 0.7\% for the HHDDT_s mode. PM was more accurately predicted using Equation 10.

\subsection{COMPARISON OF PREDICTABILITY BY THE TWO LINEAR EQUATIONS}

The two equations used were compared statistically in Figure 64 with standard deviation and absolute average error (Equation 14) to evaluate if either one showed better accuracy in prediction. Figure 64 shows that different emissions on dissimilar cycles were predicted with different levels of confidence for the two equations. From Figure 64, it was seen that all three species were better predicted by using Equation 11 for the Creep mode than by using Equation 10. The UDDS was better predicted on all three species using Equation 10. The $\mathrm{CO}_{2}$ on the HHDDT_s mode was better predicted using Equation 11. $\mathrm{NO}_{\mathrm{X}}$ was predicted equally by both equations. PM was better predicted using Equation 10. 


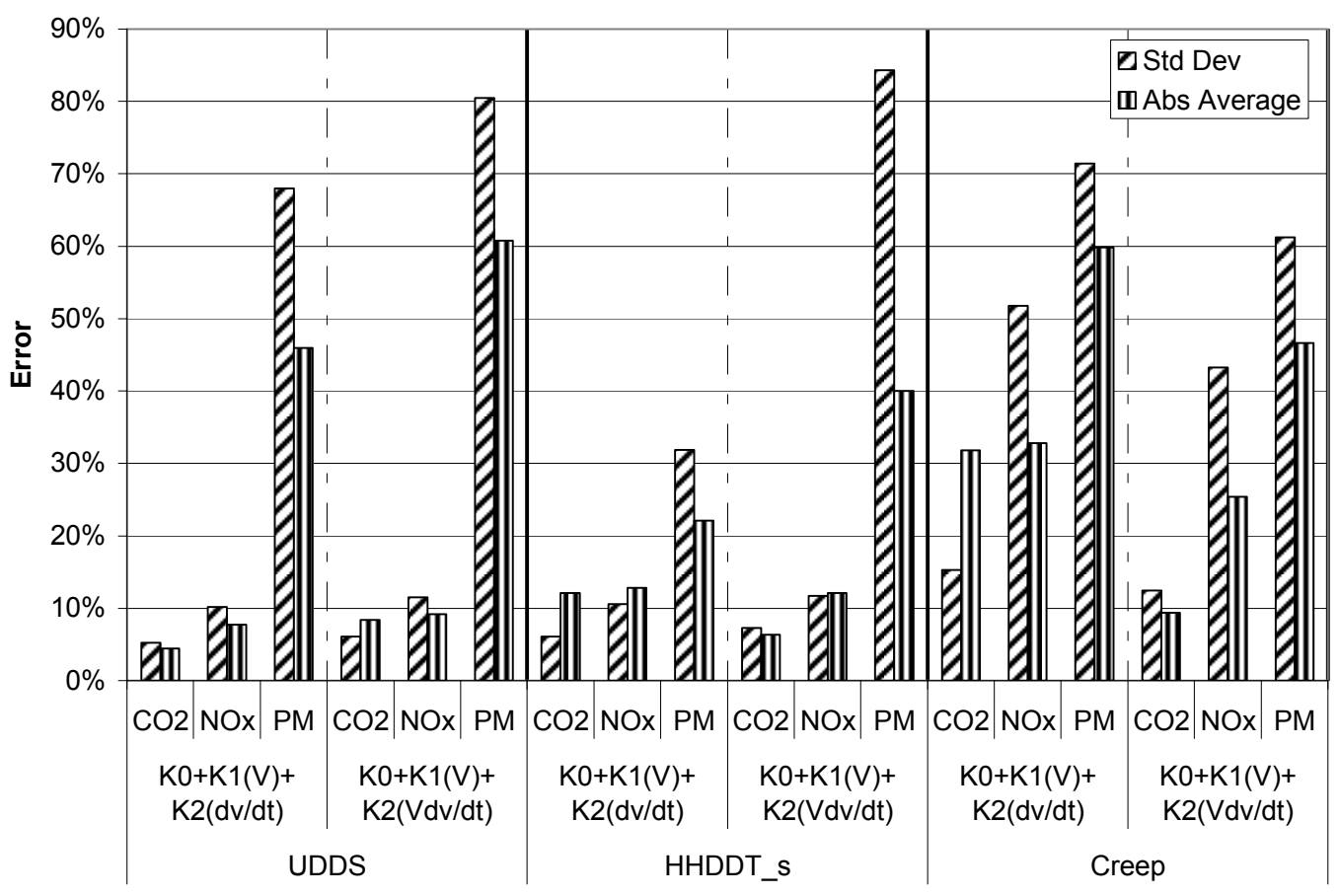

Figure 64: Statistical comparison of the percentage errors of predictions for the two methods for the three cycles: UDDS, HHDDT_s mode and Creep mode

\subsection{CONCLUSIONS}

Using this technique, PM seems to be the least predictable emission of $\mathrm{CO}_{2}, \mathrm{NO}_{\mathrm{X}}$ and PM. Like in most emissions modeling tools, $\mathrm{CO}_{2}$ remains the most predictable emissions. Other factors, such as engine model year and manual versus fuel injected technologies showed no effect on the predictive ability of this technique.

The accuracy of this linear technique is dependent on the number of terms used. Thus increasing the terms would result in better predictions, while making sure that variables already part of the linear equation are not used, like velocity and acceleration. This would also require that the vehicle had been tested on more cycles or that data are available for various phases. 


\section{Conclusions and Recommendations}

\subsection{CONCLUSIONS}

One-dimensional and two-dimensional regression models to calculate distance-specific emissions, specifically $\mathrm{NO}_{\mathrm{X}}$ and $\mathrm{PM}$, based on cycles showed a reasonable ability to predict these values. As expected, the multi-dimensional model showed better correlations than the onedimensional model. Predictions in both models were affected by off-cycle timing strategies for $\mathrm{NO}_{\mathrm{X}}$. Thus, excluding vehicles identified as off-cycle significantly improved the predictive ability of both models.

The one-dimensional regression showed the most confidence in correlating the Cruise mode and the Transient mode for $\mathrm{NO}_{\mathrm{X}}$ with an $\mathrm{R}^{2}$ of 0.83 for vehicles loaded at 56,000 lbs. PM was best correlated between AC5080 and UDDS with an $\mathrm{R}^{2}$ of 0.91 . The two-dimensional regression for all the cases examined had correlations greater than 0.87 for $\mathrm{NO}_{\mathrm{X}}$ when off-cycle vehicles were excluded. These regression models would be optimal for inventory purposes, but would be suboptimal when considering a single vehicle. For correlations that would address single vehicles, an approach that minimized percentage errors might prove superior.

Vehicle weight has a significant effect on the emissions of $\mathrm{NO}_{\mathrm{X}}, \mathrm{PM}, \mathrm{HC}$ and $\mathrm{CO}_{2}$ of a vehicle. Fleet wide generalizations on the effects of weight were invalid for MHDT. Gasoline MHDT showed no consistent change with respect to weight. Fuel specific values for MHDGT also varied greatly.

While evaluating the effects of weight on emissions, fuel specific $\mathrm{NO}_{\mathrm{X}}$ emissions did not vary much with test weights for HHDDT. For distance-specific fleet wide HHDDT generalization for $\mathrm{NO}_{\mathrm{X}}$, an $\mathrm{X} \%$ change in weight, changed $\mathrm{NO}_{\mathrm{X}}$ by $\frac{47}{100} \mathrm{X} \%$ for the Transient mode. With a single HHDDT, the ability to predict emissions by interpolating showed some level of consistency. Prediction by extrapolation showed erratic results.

Using the cycle based emissions factors technique, PM seems to be the least predictable emission of $\mathrm{CO}_{2}, \mathrm{NO}_{\mathrm{X}}$ and PM. Other factors, such as engine model year and manual versus fuel injected technologies showed no effect on the predictive ability of this technique. This technique showed potential for using cycle based parameters, like average speed, average acceleration and average 
inertial power, to predict the tailpipe emissions for a vehicle on a cycle which it had not tested on.

\subsection{RECOMMENDATIONS}

The next step in developing prediction models based on emissions factors for individual vehicles would be to express cycles and their emissions based on the properties of other cycles. These emissions factors would be calculated directly from the cycles speed-time trace. The resulting equation would be of form represented in Equation 15. This would eliminate the need of calculating vehicular constants as used in Section 7.

Equation 15

$E_{1}=L_{2} E_{2}+L_{3} E_{3}+L_{4} E_{4}$

Where the values of $\mathrm{E}$ are intensive properties and where $L_{2}, L_{3}$ and $L_{4}$ are found from

$\overline{\left(\frac{\partial \mathrm{v}}{\partial t}\right)_{1}}=L_{2} \overline{\left(\frac{\partial \mathrm{v}}{\partial t}\right)_{2}}+L_{3} \overline{\left(\frac{\partial \mathrm{v}}{\partial t}\right)_{3}}+L_{4} \overline{\left(\frac{\partial \mathrm{v}}{\partial t}\right)_{4}}$

$\overline{V_{1}}=L_{2} \overline{V_{2}}+L_{3} \overline{V_{3}}+L_{4} \overline{V_{4}}$

$1=L_{2}+L_{3}+L_{4}$

An initial calculation was performed using the Transient mode, Cruise mode and Idle mode to predict the emissions on the UDDS. The vehicles and data used were the same as those used in Section 7. The parity plots for this analysis are shown in Figure 65 and Figure 66. The average error in predicting the $\mathrm{CO}_{2}$ was $1.51 \%, \mathrm{NO}_{\mathrm{X}}$ was $0.01 \%$ and $\mathrm{PM}$ was $39.70 \%$. As expected, PM continued to be the least predictable of the three emissions species, but had a marginally smaller error compared to the linear technique used in Section 7. $\mathrm{NO}_{\mathrm{X}}$ and $\mathrm{CO}_{2}$ were considerably better predicted using this technique as compared to the linear technique used in Section 7. Whether this technique is a better tool for emissions translation between cycles would depend upon further analysis using other cycles. 


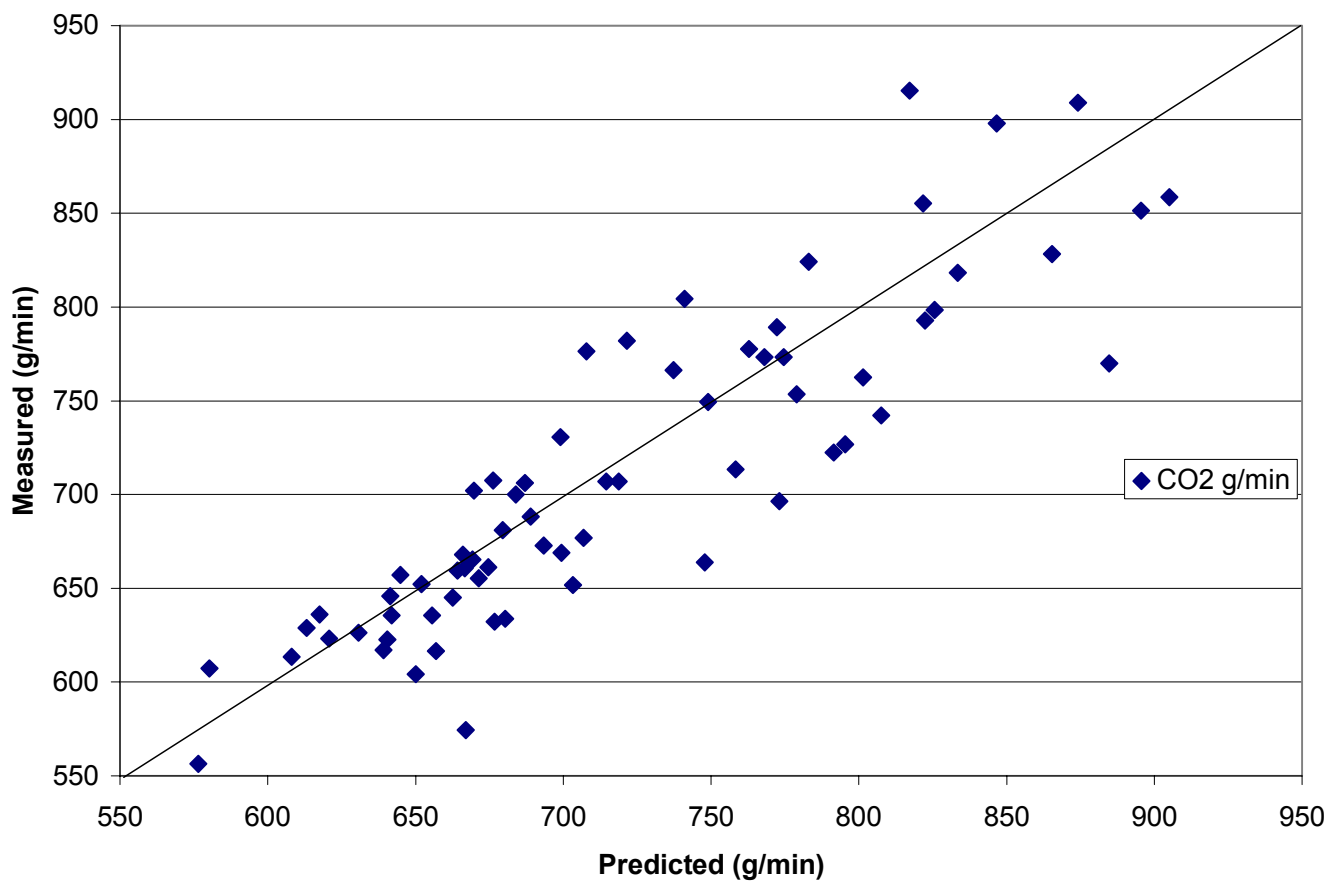

Figure 65: Magnified view of the emission species of $\mathrm{CO}_{2}$ on UDDS predicted using the Transient mode, Cruise mode and Idle mode

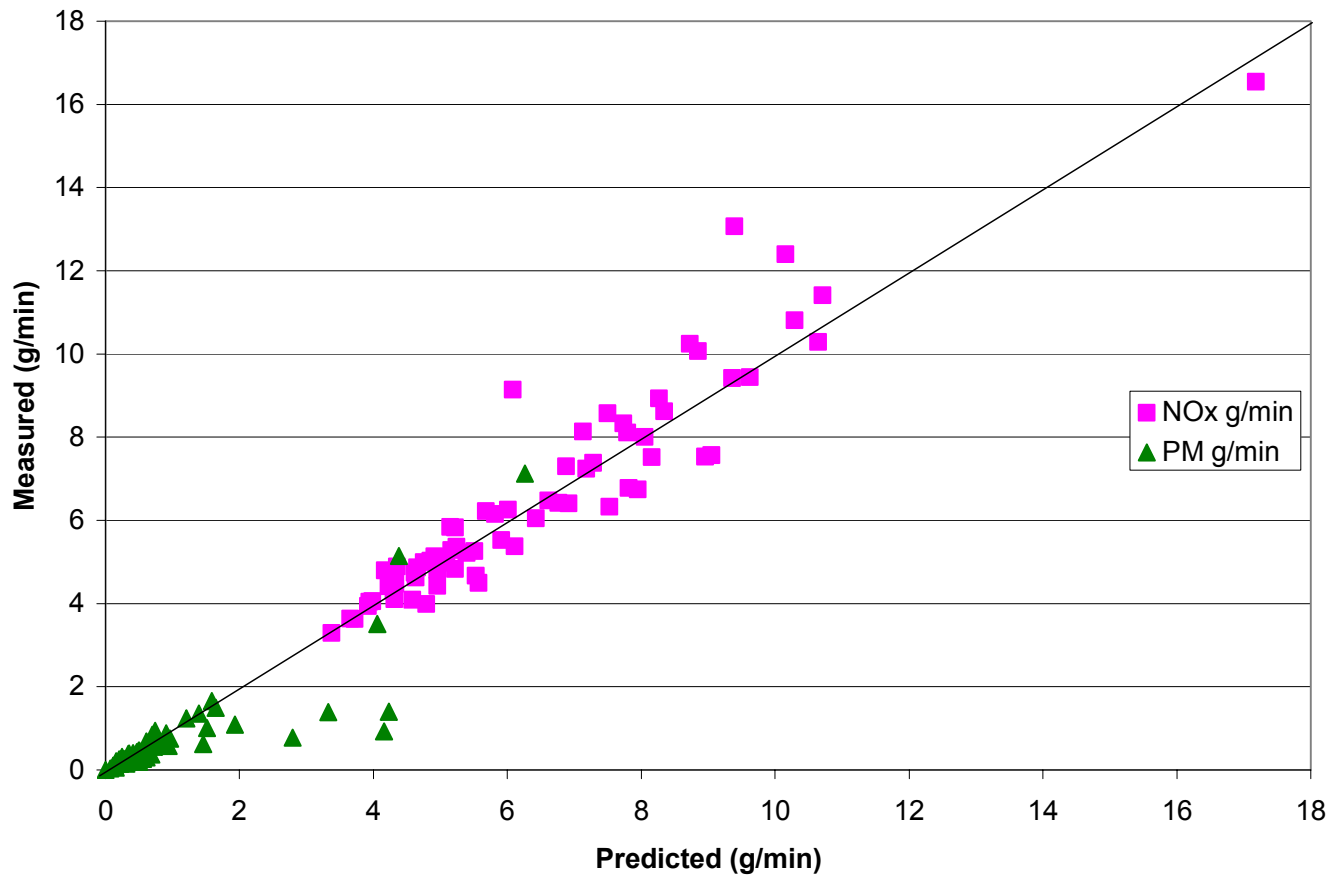

Figure 66: Emissions species of $\mathrm{NO}_{\mathrm{X}}$ and $\mathrm{PM}$ on UDDS predicted using the Transient mode, Cruise mode and Idle mode 


\section{References}

1. Lloyd, A.C. and Cackette, T.A., "Diesel Engines: Environmental Impact and Control," Journal of the Air \& Waste Management Association, Vol. 51, pp. 809-847, June 2001.

2. Yanowitz, J., Graboski, M.S., McCormick, R.L., "Prediction of In-Use Emissions of HeavyDuty Diesel Vehicles from Engine Testing," Environmental Science \& Technology, Vol. 36, No. 2, pp. 270-275, 2002.

3. Nine, R.D., Clark, N.N., Daley, J.J. and Atkinson, C.M., "Development of a heavy-duty chassis dynamometer driving route," Proc. Inst. Mech. Engrs. Part D., Jour. of Automobile Eng., Vol. 213, pp. 561-574.

4. Clark, N.N. and Lyons, D.W., "Class 8 Truck Emissions Testing: Effects of Test Cycles and Data on Biodiesel Operation," Transactions of the American Society of Agricultural Engineers, Vol. 42, No. 5, pp.1211-1219, 1999.

5. Vora, K.A., Clark, N.N., Nine, R.D., Gautam, M., Wayne, W.S., Thompson, G.J., and Lyons, D.W. "Correlation Study of PM and $\mathrm{NO}_{\mathrm{X}}$ for Heavy-Duty Vehicles Across Multiple Drive Schedules", SAE Fall 2004 Powertrain \& Fluid Systems Conference, SAE Paper 2004-013022.

6. Vora, K.A., Clark, N.N., Gautam, M. and Wayne, W.S. "Multidimensional Correlation Study Using Linear Regression of PM and $\mathrm{NO}_{\mathrm{X}}$ for Heavy Duty Diesel Vehicles," SAE World Congress 2005, SAE Paper 2005-01-1618.

7. Gautam, M., Clark, N.N., Lyons, D.W., Long,Jr., T., Howell, A., Loth, J., Palmer, G.M., and Bata, R.M., "Design Overview of a Heavy-Duty Mobile Vehicle Emissions Testing Laboratory," ASME DE-Vol. 40, Advanced Automotive Technologies, 1991.

8. Wang, W.G., Palmer, G.N., Bata, R.M., Clark, N.N., Gautam, M., and Lyons, D.W., "Determination of Heavy-Duty Vehicle Energy Consumption by a Chassis Dynamometer," SAE Transactions, Journal of Commercial Vehicles, Vol. 101, pp. 687-696, 1992.

9. Clark, N.N., Gautam, M., Bata, R.M., Loth, J., Palmer, G.M., Wang, W.G., and Lyons, D.W., "Design and Operation of a New Transportable Laboratory for Emissions Testing of Heavyduty Trucks and Buses," International Journal of Vehicle Design (Heavy Vehicle Systems) Vol. 2, No. 3/4, pp. 285-299, 1995.

10. Taylor, S.T., Clark, N.N., Gautam, M., and Wayne, W.S. "Diesel Emissions Prediction from Dissimilar Cycle Scaling," Journal of Automobile Engineering, Vol. 218, pp. 341-352, 2004.

11. Clark, N.N., Gautam, M., Wayne, W.S., Thompson, G., Lyons, D.W., and Nine, R.D., "Heavy Heavy-Duty Truck Regulated Emissions, Re-flash Benefits and Effect of Test Weight in the E55 Phase 1.5 Study," 14th Coordinating Research Council On-Road Vehicle Emissions Workshop, March 29-31, San Diego, CA, 2004.

12. Clark, N.N., Gautam, M., Wayne, W.S., Thompson, G.J., Lyons, D.W., Nine, R.D., Riddle, W.C., Staggs, B., Williams, V.A., Hall, T., and Thiagarajan, S., "Heavy-Duty Vehicle Chassis Dynamometer Testing for Emissions Inventory, Air Quality Modeling, Source Apportionment and Air Toxics emissions Inventory," Phase 1 Report, CRC Project E-55/E59, April 1, 2003.

13. Clark, N.N., Gautam, M., Wayne, W.S., Thompson, G.J., and Lyons, D.W., "California Heavy Heavy-Duty Diesel Truck Emissions Characterization for Project E-55/E-59 Phase 1.5," CRC Project E-55/E-59, August 20, 2004.

14. Clark, N.N., Gautam, M., Wayne, W.S., Thompson, G.J., and Lyons, D.W., "Heavy-Duty Vehicle Chassis Dynamometer Testing for Emissions Inventory, Air Quality Modeling, Source Apportionment and Air Toxics emissions Inventory," Phase 2 Report, CRC Project E55/E-59, July 12, 2005.

15. Clark, N.N., Gautam, M., Wayne, W.S., Thompson, G.J., and Lyons, D.W., "California Heavy Heavy-Duty Diesel Truck Emissions Characterization for Project E-55/E-59," Phase 3 draft, CRC Project E-55/E-59, November 11, 2005.

16. Clark, N.N., Wayne, W.S., Nine, R.D., Buffamonte, T.M., Hall, T., Rapp, B.L., Thompson, G., and Lyons, D.W., "Emissions from Diesel-Fueled Heavy-Duty Vehicles in Southern California," SAE/JSAE Spring Fuels \& Lubricants Meeting, Yokohama, Japan, JSAE Paper 20030232, SAE Paper 2003-01-1901, 2003. 
17. Clark, N.N., Wayne, W.S., Lyons, D.W., and Thompson, G.J. "Gasoline-Diesel PM Split Study: Heavy-Duty Exhaust Collection Phase," Final Report, National Renewable Energy Laboratory (NREL), September 23, 2002.

18. EMFAC, "Background Material: EMFAC2002 Release," April 2003, CARB, April 6 2004 http://www.arb.ca.gov/msei/on-road/latest version.htm.

19. MOBILE6 model, "MOBILE6 Vehicle Ëmission Modeling Software," Aug. 2003, EPA, Aug. $4^{\text {th }} 2004$ http://www.epa.gov/otaq/m6.htm.

20. Pollack, A.K, Lindhjem, C., Stoeckenius, T.E., Tran, C., Mansell, G., Jimenez, M., Wilson, G. and Coulter-Burke, S., "Evaluation of the U.S. EPA MOBILE6 Highway Vehicle Emission Factor Model," Final Report, CRC Project E-64, http://www.epa.gov/otaq/models/mobile6/crce64.pdf, March 2004.

21. Tehranian, A. "Effects of Artificial Neural Networks Characterization on Prediction of Diesel Engine Emissions," Master's thesis at West Virginia University, Mechanical and Aerospace Engineering Department, WV, 2003.

22. Weinblatt, H., Dulla, R.G., and Clark, N.N., "Vehicle Activity-Based Procedure for Estimating Emissions of Heavy-Duty Vehicles," Transportation Research Record, Journal of the Transportation Research Board, No. 1842 Energy, Air Quality and Fuels pp. 64-72, 2003.

23. Clark, N.N., Azu, A., Jarrett, R., Balon, T., Moynihan, P., Lynch, S. and Webb, T., "Operating Envelopes of Hybrid Bus Engines," SAE Transactions, Journal of Engines Vol. 110, Section 3, pp. 2214-2225, 2002.

24. Gajendran, P. and Clark, N.N., "Effect of Truck Operating Weight on Heavy Duty Diesel Emissions," Environmental Science \& Technology, Vol. 37 No. 18, pp. 4309-4317, 2003

25. Gautam, M., Clark, N.N., Riddle, W., Nine, R., Wayne, W.S., Maldonado, H., Agrawal, A. and Carlock, M, "Development and Initial Use of a Heavy Duty Diesel Truck Test Schedule for Emissions Characterization", SAE Transactions, Journal of Fuels \& Lubricants, Vol. 111, 812-825, SAE 2002-01-1753, 2002.

26. Graboski, M.S., Yanowitz, J., McCormick, R.L., "In-Use Emissions From Heavy-Duty Vehicles Operating in the Colorado Northern Front Range Area," $8^{\text {th }}$ CRC On-Road Vehicle Emissions Workshop, San Diego, CA, 1998.

27. Code of Federal Regulations 40, Part 86, Subpart-N, Office of the Federal Register National Archives and Records Administration, Washington D.C., 1991.

28. Clark, N.N., Tehranian, A., Nine, R.D., and Jarrett, R., "Translation of Distance-Specific Emissions Rates between Different Chassis Test Cycles using Artificial Neural Networks," SAE Spring 2002 Fuels \& Lubricants Meeting, Reno, NV, SAE Paper 2002-01-1754, 2002.

29. EPA Document, "Draft Design and Implementation Plan for EPA's Multi-Scale Motor Vehicle and Equipment Emission System (MOVES),” EPA420-P-02-006, October 2002.

30. Clark, N.N., Gajendran, P. and Kern, J.M., "A Predictive Tool for Emissions from HeavyDuty Diesel Vehicles," Environmental Science \& Technology, Vol. 37, No. 1, pp. 7-15, 2003.

31. McCormick, R.L., Ryan, L.B.A., Daniels, T.L. and Graboski, M.S., "Comparison of Chassis Dynamometer In-Use Emissions With Engine Dynamometer Ftp Emissions for Three HeavyDuty Diesel Vehicles," SAE October 1998, International Fall Fuels and Lubricants Meeting and Exposition, SAE paper 982653.

32. Koskinen, O.H. and Sauna-aho, J.V., "Utilization of Ceasing Railroad Embarkments for Freight Transport from Environmental Viewpoint," $16^{\text {th }}$ CRC On-Road Vehicle Emissions Workshop, San Diego, CA, 2006.

33. Koskinen, O.H. and Sauna-aho, J.V., "Nordic VS. Central European Vehicle Configuration Fuel Economy, Emissions, Vehicle Operating Costs and Road Wear," $7^{\text {th }}$ International Symposium on Heavy Vehicle Weights \& Dimensions, Deft, Netherlands, Europe, 2002.

34. Brodrick, C., Laca, E.A., Burke, A.F., Farshchi, M., Lit, L., and Deaton, M., "Effect of vehicle operation, weight, and accessory use on emissions from a modern heavy-duty diesel truck," Transportation Research Record, Journal number 1880, pp 119-125, 2004.

35. Bishop, G.A., Morris, J.A., Stedman, D.H., Cohen, L.H., Countess, R.J., Countess, S.J., Maly, P. and Scherer, S., "The Effect of Altitude on Heavy-Duty Diesel Truck On-Road Emissions," Environmental Science \& Technology, Vol. 35, No. 8, pp. 1574-1578, 2001. 
36. Burgard, D.A., Gessener, V., Daeschlein, C., Bishop, G.A. and Stedman, D.H., "NO, $\mathrm{NO}_{2}$ and $\mathrm{SO}_{2}$ Remote Sensing Measurements from In-Use Heavy-Duty Diesel Vehicles at Sites in Golden and Dumont, Colorado," $16^{\text {th }}$ CRC On-Road Vehicle Emissions Workshop, San Diego, CA, 2006.

37. Clark, N.N., Gautam, M., Wayne, W.S., Nine, R.D., Thompson, G.J., Lyons, D.W., Maldonado, H., Carlock, M. \& Agrawal, A., "Creation and Evaluation of a Medium HeavyDuty Truck Test Cycle," SAE Powertrain Conf., Pittsburgh, Oct. 2003, SAE Paper 2003-013284.

38. Cadle, S.H., P.A. Mulawa, E.C. Hunsanger, K. Nelson, R. Ragazzi, R. Barrett, G.L. Gallagher, D.R. Lawson, K.T. Knapp, and R. Snow. "Light-Duty Vehicle Exhaust Particulate Matter Measurements in the Denver, Colorado Area," Journal of Air \& Waste Management, Vol. 49, pp. PM164-PM174, 1999.

39. Kean, A.J., Harley, R.A. and Kendall, G.R. "Effects of Vehicle Speed and Engine Load on Motor Vehicle Emissions," Environmental Science \& Technology, Vol. 37, No. 17, pp. 3739-3746, 2003.

40. Yanowitz, J., McCormick, R., and Graboski, M., "In-Use Emissions from Heavy Duty Diesel Vehicles," Environmental Science \& Technology, Vol. 34, No. 5, pp. 729-740, 2000. 


\section{Kuntal A. Vora}

Objective Obtain an entry level position as a Mechanical, Automotive, Aerospace, Aeronautical, Design, Aviation, Motor Vehicle or Systems Engineer

\begin{tabular}{|c|c|}
\hline Education & West Virginia University \\
\hline & 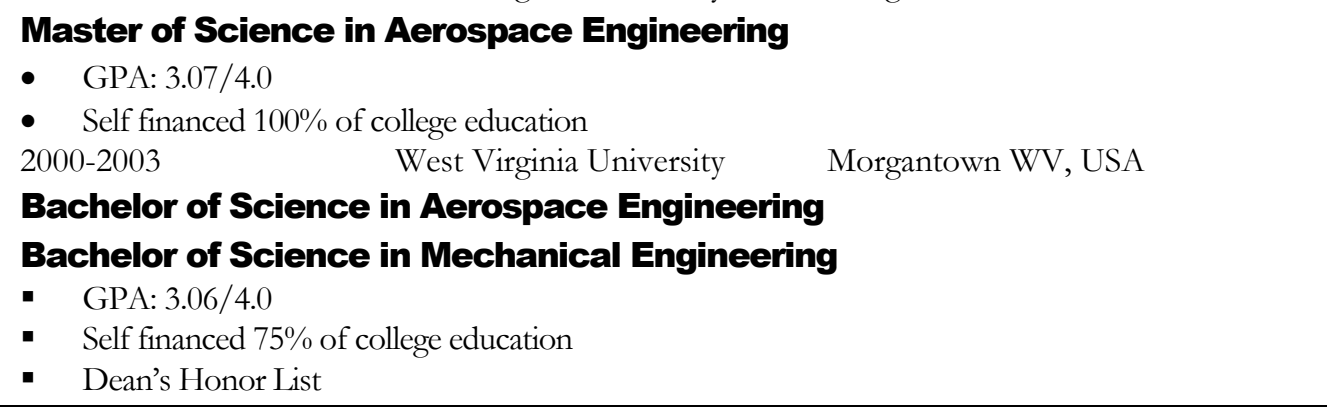 \\
\hline $\begin{array}{l}\text { Professional } \\
\text { Experience }\end{array}$ & $\begin{array}{l}\text { - Graduate Research Assistant under the WVU National Research Center for Alternative } \\
\text { Fuels, Engines and Emissions program } \\
\circ \quad \text { Performed emissions inventory analysis } \\
\circ \text { Conducted on-road emissions testing for commercial vehicles } \\
\circ \text { Developed predictive emissions models } \\
\text { - Mentor for the West Virginia University ChallengeX design competition } \\
\circ \quad \text { Strategy planning, component selection and PSAT modelling } \\
\text { - Participant in the FutureTruck } 2004 \text { design competition } \\
\circ \quad \text { Control System algorithm, GPS communications and ECU, electric motor controller, } \\
\text { battery management and user-interface integration and development } \\
\circ \quad \text { Monitored adherence to vehicle safety and integrity guidelines } \\
\text { - Participated in the AIAA Design/Build/Fly competition (April } 2002 \text { and April 2003) and } \\
\text { took third place in } 2002 \\
\circ \quad \text { Responsible for wing design, wing construction, body lay-up, avionics and power } \\
\text { management }\end{array}$ \\
\hline $\begin{array}{l}\text { Other } \\
\text { Experience }\end{array}$ & $\begin{array}{l}\text { - Residence Hall Assistant }(2001-2003) \text { in Braxton Towers at West Virginia University } \\
\circ \text { Supervise } 48 \text { freshman students living in the residence halls. } \\
\circ \text { Plan and organize educational and social programs. } \\
\circ \quad \text { Resolve conflicts and monitor community living conditions. } \\
\text { - Night Staff (Fall 2001) Residential Education at West Virginia University } \\
\circ \quad \text { Perform night security duties and provide assistance to the University Police }\end{array}$ \\
\hline Activities & $\begin{array}{l}\text { - Teaching Assistant for the West Virginia University's Orientation } 101 \text { Program } \\
\text { - Member of the Judicial Board in Braxton Tower (2000 Spring) and Brooke Tower (2000 } \\
\text { Fall) at West Virginia University. } \\
\text { - } \quad \text { Editor for the Braxton Tower Residence Hall News Letter } \\
\text { - } \quad \text { Member of the American Institute of Aeronautics and Astronautics } \\
\text { - } \quad \text { Represented the University as a member of the West Virginia University Cricket Club }\end{array}$ \\
\hline $\begin{array}{l}\text { Computer } \\
\text { Literacy }\end{array}$ & $\begin{array}{l}\text { - Software: Advanced Aircraft Analysis, Microsoft Office Suite, AutoCAD, MOBILE6, } \\
\text { PSAT, Matlab, LabView } \\
\text { - Operating System: DOS, Windows 95, 98, ME, 2000, NT and XP } \\
\text { - } \quad \text { Programming: Pascal, Basic, C, C++, HTML, Assembly language 8085A } \\
\text { - } \quad \text { Microsoft Certified Systems Engineer (Windows NT) Trained }\end{array}$ \\
\hline Other Skills & $\begin{array}{l}\text { Familiar with CNC equipment, Carbon, Fiberglas \& honeycomb composite lay-up, vehicle } \\
\text { systems integration and control philosophy, CFD and Fuel Cell technology }\end{array}$ \\
\hline Languages & English, Hindi, Marathi, Gujrati, French. \\
\hline
\end{tabular}

